\author{
UNIVERSIDADE DE SÃO PAULO \\ INSTITUTO DE QUÍMICA DE SÃO CARLOS
}

Suzi Oliveira Marques

Estudo químico da esponja Dysidea robusta

São Carlos

2009 
Suzi Oliveira Marques

\section{Estudo químico da esponja Dysidea robusta}

\section{Volume 1}

Dissertação apresentada ao Instituto
de Química de São Carlos, da
Universidade de São Paulo para
obtenção do título de Mestre em
Ciências (Físico-Química)

Orientador: Prof. Dr. Roberto Gomes de Souza Berlinck

São Carlos 


\title{
DEDICATÓRIA
}

AOS MEUS PAIS, Sílvio e Neuza, meu maior tesouro, combustível e razão da minha luta! Pelo amor incondicional, carinho, confiança, apoio e compreensão em todos os momentos de minha vida.

\author{
À minha irmã Carla, pelo amor \\ e cuidado, cada vez mais \\ maduros, que cultivamos!
}

Ao meu querido Wladimir, meu amor e companheiro durante toda minha trajetória. Pela cumplicidade e amor!

\section{Amo vocês!}

\author{
À Santa Rita de Cássia, \\ minha Santa Amada e Protetora!
}

Ao meu avô Bento, pela força incessante de sua presença na minha vida e no meu coração! 



\section{AGRADECIMENTOS}

Ao Prof. Dr. Roberto Berlinck, pela confiança, ensinamentos, amizade e compreensão durante a realização deste trabalho.

Ao CNPq e FAPESP, pelo apoio financeiro para a realização deste trabalho.

A minha grande amiga Naiara, pelo amor, cumplicidade e apoio durante os seis anos de convivência compartilhados e eterna amizade!

Aos meus amigos do Laboratório de Produtos Naturais, Simone, Fábio, Miriam, Eli, Marília, Raquel, Michelli, Renata, Stela, Richele, Carolina, Juliana, Marina, Camila e Milene pela alegria e amizade.

Ao Prof. Dr. Antônio Gilberto Ferreira e Katyuscya Veloso (DQ- UFSCAR) pela colaboração na obtenção de espectros de RMN.

Ao Prof. Eduardo Hajdu, colaborador do projeto, pelo maravilhoso trabalho de identificação das esponjas.

A equipe do Prof. Dr. Andersen, da Universidade de Cambridge, Canadá, pela colaboração.

Aos colaboradores da Biblioteca da Química e da Seção de PósGraduação, em especial à Sílvia e Andréia.

$\mathrm{E}$ a todos aqueles que me incentivaram e estiveram ao meu lado durante a realização deste trabalho. 


\title{
SUMÁRIO
}

\author{
Lista de Figuras \\ Lista de Tabelas \\ Lista de Símbolos e Abreviaturas
}

\section{Resumo}

\section{Abstract}

1. INTRODUÇÃO.

1.1. Esponjas Marinhas ................................................................ 13

1.2. Produtos Naturais de Esponjas Marinhas .................................... 13

1.3. Esponjas do gênero Dysidea..................................... 14

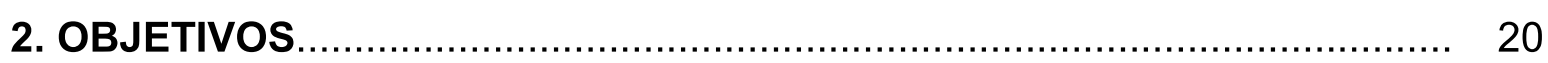

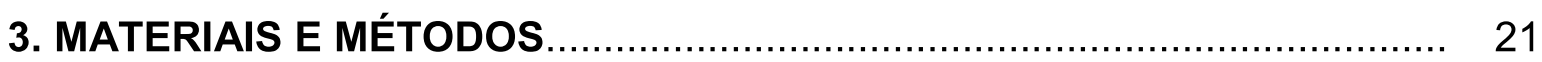

3.1. Técnicas Cromatográficas................................................... 21

3.1.1. Cromatografia em camada delgada (CCD) ............................ 21

3.1.2. Cromatografia em coluna pré empacotada Sep-Pak®................ 21

3.1.3. Cromatografia em coluna.................................................... 21

3.1.4. Cromatografia Líquida de Alta Eficiência .................................. 22

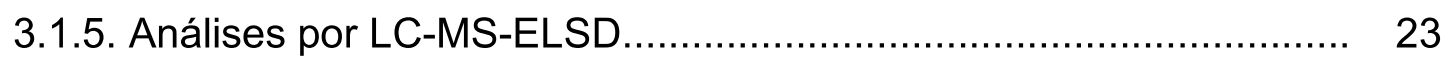

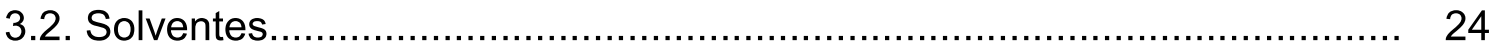

3.3. Técnicas espectrométricas................................................... 24

3.3.1. Ressonância Magnética Nuclear (RMN) ............................... 24

3.3.2. Infravermelho (IV) ......................................................... 25

3.3.3. Espectrometria de Massa Atômica (EM)................................ 25

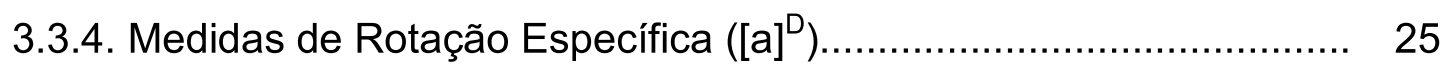

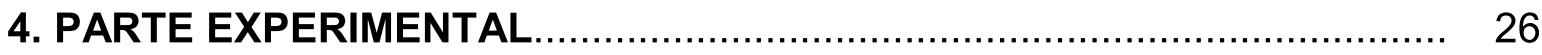

4.1. ESTUDO DE INVERTEBRADOS MARINHOS ................................. 26

4.1.1. Avaliação biológica de alíquotas dos extratos selecionados........... 26

4.1.2. Extração e fracionamento dos extratos ..................................... 28

4.1.2.1. Esponja Dysidea robusta (BA99ES-111)........................... 28

4.1.2.2. Esponja Dysidea robusta (BA99ES-108)......................... 35 
5.1. Isolamento e identificação dos compostos isolados da amostra 2 de Dysidea robusta - DR2..

5.1.1. Fracionamento do extrato $D R 2-A Q-6$.

5.1.1.1. Fracionamento de $D R 2-A Q-6 D$ e isolamento dos compostos: ácido pirodisinóico B (20), ácido pirodisinóico (18) e ácido isopirodisinóico (19)

5.1.1.1.1. Determinação estrutural do ácido pirodisinóico (18)...... 47

5.1.1.1.2. Determinação estrutural do ácido isopirodisinóico (19)... 51

5.1.1.1.3. Determinação estrutural do ácido pirodisinóico B (20)... 56

5.1.1.1.4. Determinação estrutural do ácido 13-hidróxiisopirodisinóico (21)

5.2. Isolamento e identificação dos compostos isolados da amostra de Dysidea robusta - DR1

5.2.1. Determinação estrutural das ceramidas 22 - 24 a partir de dados espectrocópicos de seus produtos de transesterificação $25-27$. 61

6. CONCLUSÃO 70

7. REFERÊNCIAS BIBLIOGRÁFICAS 


\section{Lista de Figuras}

Figura 1. Estruturas: furodisina e da lactona da O-etil-9-hidróxi.................. 15

Figura 2. Estruturas de um esterol poliidroxilado e haterumadisina A......... 15

Figura 3. Estruturas de linshuiperóxido (7) e spirolingsuiolídeo (8)............ 16

Figura 4. Estruturas de hidroquinona sesquiterpenóidica e halissulfato 3... 16

Figura 5. Estruturas da classe das azirinas........................................... 17

Figura 6. Éteres difenílicos bromados..................................................... 18

Figura 7. Estruturas do ácido herbácico e da barbamida.............................. 18

Figura 8. Estrutura da disidenina.................................................... 19

Figura 9. Compostos puros isolados de Dysidea rbosuta (DR2)................. 28

Figura 10. Fluxograma de obtenção dos extratos de Dysidea robusta......... 29

Figura 11. Fracionamento do extrato aquoso DR2-AQ ............................ 31

Figura 12. Fracionamento por HPLC dos extratos DR2-AQ-4 e DR2-AQ-6. 32

Figura 13. Análise da fração DR-2-Aq-6 por LC-PDA-MS-ELSD. Condições: coluna Phenyl- Inertsil -Phenomenex; grad. $\mathrm{H}_{3} \mathrm{O}^{+}$(ácido fórmico) : $\mathrm{MeOH}$; fluxo $=1 \mathrm{~mL} / \mathrm{min} ; \lambda=254$ e $280 \mathrm{~nm}$.

Figura 14. Análise da fração DR-2-Aq-6 por LC-DA em $254 \mathrm{~nm}$ Condições: coluna Phenyl- Inertsil -Phenomenex; grad. $\mathrm{H}_{3} \mathrm{O}^{+}$(ácido fórmico) : $\mathrm{MeOH}$; fluxo $=1 \mathrm{~mL} / \mathrm{min} ; \lambda=254$ e $280 \mathrm{~nm}$.............................. 34

Figura 15. Mistura de ceramidas da esponja Dysidea robusta (DR1)......... $\quad 35$

Figura 16. Fluxograma de extração e fracionamento da esponja $D$.

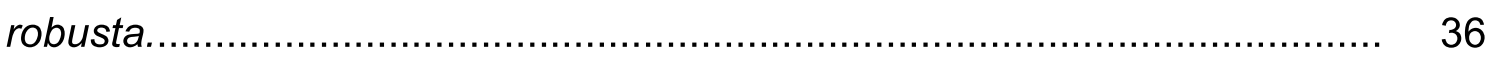

Figura 17. Fluxograma de obtenção dos extratos DR1-Aq e DR1-Ac.......... 37

Figura 18. Fracionamento do extrato DR1-Ac por cromatografia em gel Sephadex LH-20 ................................................................. 39

Figura 19. Fracionamento do extrato de éter de petróleo da esponja $D$. robusta.

Figura 20. Separação das frações DR1-EP-5A e -5B, por solubilidade.

Figura 21. Reação de acetilação da fração DR1-EP-5A, em piridina e anidrido acético.

Figura 22. Isolamento do composto acetilado, DR1-EP-5A-4, por Sep Pak. 
Figura 23. Mecanismo da reação de metanólise de DR1-EP-5A, gerando a fração esfingosínica DR1-EP-A-4-TD................................................... 44

Figura 24. Esquema de purificação e obtenção de 18, 19 e 20.................. 46

Figura 25. Estrutura dos compostos: ácido pirodisinóico (18), ácido isopirodisinóico (19) e ácido pirodisinóico $B(20)$

Figura 26. Acoplamentos observados no espectro de RMN - COSY da fração DR2-AQ-6D-1-2 .............................................................. 48

Figura 27. Estrutura do ácido pirodisinóico (18)..................................... 49

Figura 28. Correlações do ácido pirodisinóico (DR2-AQ-6D-1-2) observadas no espectro tROESY.

Figura 29. Correlações do ácido isopirodisinóico (DR2-AQ-6D-1-1) observadas no espectro HSQC

Figura 30. Acoplamentos ${ }^{1} \mathrm{H}-{ }^{1} \mathrm{H}$ do ácido isopirodisinóico (DR2-AQ-6D-11) observadas no espectro COSY

Figura 31. Correlações do ácido isopirodisinóico (19) observadas no espectro RMN tipo HMBC

Figura 32. Correlações do ácido isopirodisinóico (19) observadas no espectro tROESY.

Figura 33. Correlações do ácido pirodisinóico B (20) observadas no espectro tROESY.

Figura 34. Estrutura do ácido 13-hidróxi-isopirodisinóico (21).

Figura 35. Correlações do ácido 13-hidróxi-isopirodisinóico (21) observadas no espectro tROESY.

Figura 36. Correlações observadas no espectro de RMN tipo $\mathrm{COSY}^{-}{ }^{1} \mathrm{H}-$

${ }^{1} \mathrm{H}$, da porção esfingosínica das ceramidas tetracetiladas 25-27.

Figura 37. Correlações observadas no espectro de RMN tipo COSY- ${ }^{1} \mathrm{H}-$ ${ }^{1} \mathrm{H}$, da porção do ácido graxo $\alpha$-hidroxilado das ceramidas tetracetiladas 25-27.

Figura 38. Correlações observadas no espectro de RMN tipo HMBC ${ }^{1} \mathrm{H}$ ${ }^{13} \mathrm{C}$ das ceramidas tetracetiladas 25-27.

Figura 39. Porção esfingosínica das estruturas básicas de 22-24.

Figura 40. Estruturas das ceramidas isoladas e seus respectivos derivados acetilados.

Figura 41. Estruturas das ceramidas similares a mistura 22-24. 


\section{Lista de Tabelas}

Tabela 1. Atividades biológicas apresentadas pelos extratos brutos das duas amostras de esponjas Dysidea robusta a serem estudadas.

Tabela 2. Condições de análise por CCD dos extratos DR2-EP e DR2-AQ 30

Tabela 3. Extratos brutos da amostra DR1: Composições eluentes e padrões de comparação utilizados.

Tabela 4. Dados da análise por LC-MS da fração DR1-EP-5A-4.

Tabela 5. Dados comparativos de $\mathrm{RMN}^{-1} \mathrm{H}$ para o ácido pirodisinóico, segundo Goetz, et al, 2001

Tabela 6. Dados comparativos de $\mathrm{RMN}-{ }^{13} \mathrm{C}$ para o ácido pirodisinóico, segundo Goetz, et al, 2001.

Tabela 7. Dados espectroscópicos de RMN- ${ }^{1} \mathrm{H},{ }^{13} \mathrm{C}$ e HSQC para o ácido isopirodisinóico (19)

Tabela 8. Dados comparativos de $\mathrm{RMN}^{-1} \mathrm{H}, \mathrm{COSY}{ }^{1} \mathrm{H}-{ }^{1} \mathrm{H}$ e ${ }^{13} \mathrm{C}$ entre o ácido pirodisinóico (18) e o ácido pirodisinóico B (20).

Tabela 9. Dados espectroscópicos comparativos entre o ácido isopirodisinóico (19) e o ácido 13-hidróxi-isopirodisinóico (21).

Tabela 10. Dados de RMN- ${ }^{1} \mathrm{H}$ dos compostos 18, 19, 20 e 21 em DMSO$d_{6}(600 \mathrm{MHz})[\delta$, multiplicidade $(\mathrm{J}$ em Hz) $]$

Tabela 11. Dados de RMN $-{ }^{13} \mathrm{C}$ e $-{ }^{15} \mathrm{~N}$ dos compostos, 18, 19, 20 e 21 em DMSO-d $(150 \mathrm{MHz})$.

Tabela 12. Dados comparativos de $\mathrm{RMN}^{-}{ }^{1} \mathrm{H}$ entre as ceramidas 25-27, $\left(\mathrm{CDCl}_{3}, 400 \mathrm{MHz}\right)$ e a mistura de ptiloceramidas isoladas da esponja Ptilocaulis spiculifer. 


\section{Lista de Símbolos e Abreviaturas}

$I_{50}$ - Concentração que promove $50 \%$ de inibição da população testada

MS - Mass Espectrometry

UV - Ultravioleta

HPLC - High Performance Liquid Chromatography

PDA - Photodiode Array Detector

ELSD - Evaporative Light Scattering Detector

RMN- ${ }^{1} \mathrm{H}$ - Ressonância Magnética Nuclear de Hidrogênio

ESI-MS - Espectrometria de Massa Atômica por ionização de spray de elétrons

COSY - Correlation Spectroscopy

HSQC - Heteronuclear Single Quantum Coherence

HMBC - Heteronuclear Multiple Bond Coherence

HRESIMS - High Resolution Electrospray lonization Mass Spectrometry

tROESY - Transverse Rotating Frame Overhauser Enhancement Spectroscopy

$s$ - singleto

$d$ - dubleto

$\mathrm{t}$ - tripleto

$q$ - quarteto

$\mathrm{m}$ - multipleto 


\section{RESUMO}

SUZI, O. M. Estudo químico da esponja Dysidea robusta. 2009. Dissertação (Mestrado) - Instituto de Química de São Carlos, Universidade de São Paulo, São Carlos, 2009.

Esponjas do gênero Dysidea (Ordem: Dictyoceratida) caracterizam-se por apresentarem grande diversidade de metabólitos secundários, muitos dos quais apresentam potentes atividades biológicas. Este trabalho descreve o estudo de duas amostras de esponjas da espécie Dysidea robusta, DR1 e DR2, coletadas no litoral da Bahia em 1999. Tal estudo consistiu no fracionamento das amostras, nas análises de seus extratos brutos por LC-MS e técnicas de RMN- mono e bidimensionais. Dentre os extratos de DR1, a fração DR1-EP-5A obtida do extrato éter de petróleo apresentou uma mistura de três ceramidas saturadas $(\mathbf{2 2}, 23 \mathrm{e}$ 24). Já da amostra $D R 2$, as frações do extrato aquoso $D R 2-A Q-6 B$ e DR2-AQ-6D mostraram ser constituídas por derivados do ácido pirodisinóico (18, 19, 20 e 21). Com exceção do ácido pirodisinóico (18), os demais compostos isolados ainda não foram relatados na literatura.

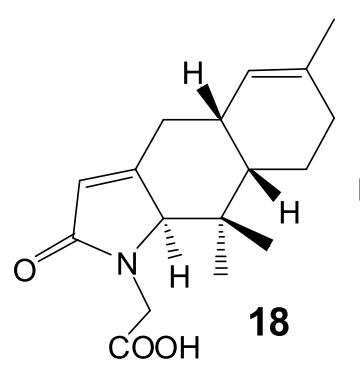

18

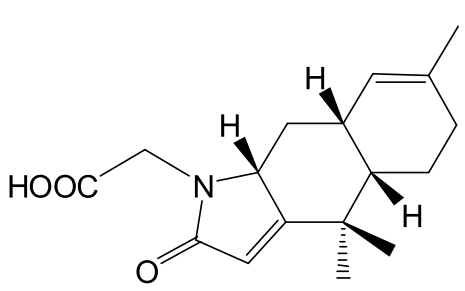

19

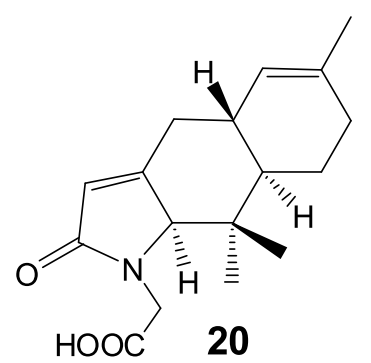

HOOC 20

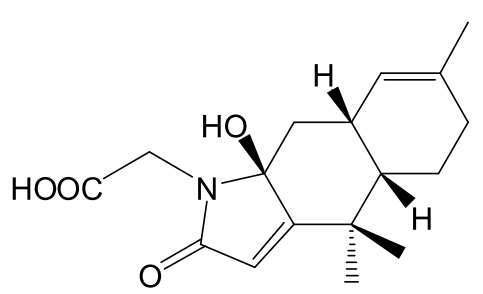

21

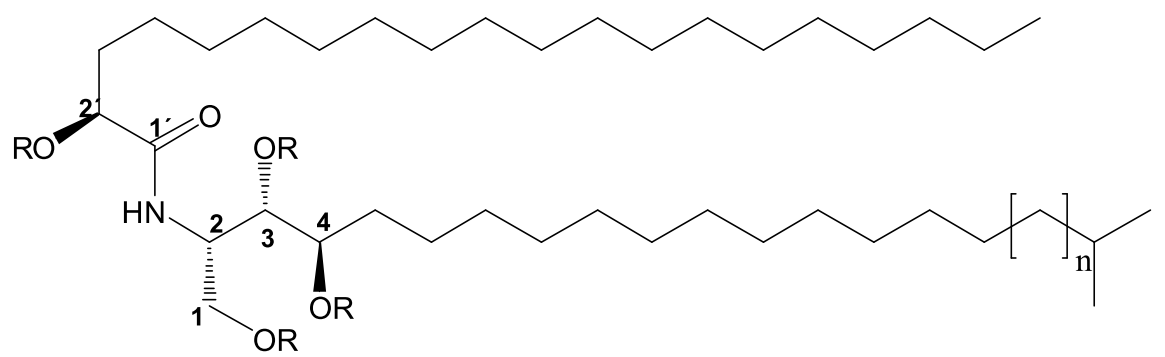

$22 \mathrm{R}=\mathrm{H}, \mathrm{n}=1$

$23 \mathrm{R}=\mathrm{H}, \mathrm{n}=2$

$24 \mathrm{R}=\mathrm{H}, \mathrm{n}=3$

Palavras-chave: Dysidea, metabólito secundário, ceramidas, derivados do ácido pirodisinóico; HPLC-PDA-MS. 


\section{ABSTRACT}

SUZI, O. M. Chemical study of the brazilian sponge Dysidea robusta. 2009.

Dissertation (Masters) - Instituto de Química de São Carlos, Universidade de São Paulo, São Carlos, 2009.

Sponges of the genus Dysidea (Order: Dyctioceratida) are characterized as sources of several biologically active secondary metabolites. This work describes the study of two samples of D.robusta, DR1 and DR2, both collected at the Bahia state coastline, in 1999. The investigation aimed the crude extract fractionation and analysis by LC-MS and by 1D and 2D NMR techniques. Among the extracts DR1, the fraction DR1-EP-5A obtained from the petroleum ether extract showed a mixture of three saturated ceramides, represented by 22, 23 and 24. From the DR2 sample, the fractions obtained from the aqueous extract DR2-AQ-6B and -6D presented pirodisinoic acid derivatives 18, 19, 20 and 21. Except for pyrodisinoic acid (18), all other isolated compounds haven't been reported in the literature yet.

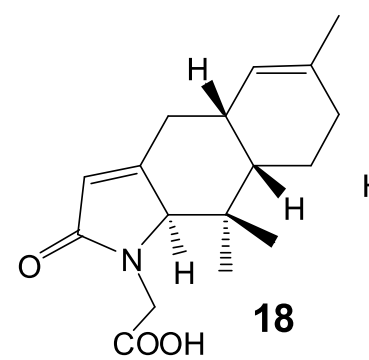

18

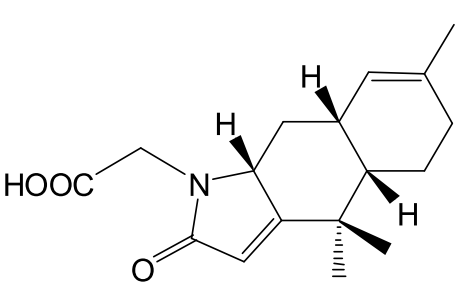

19

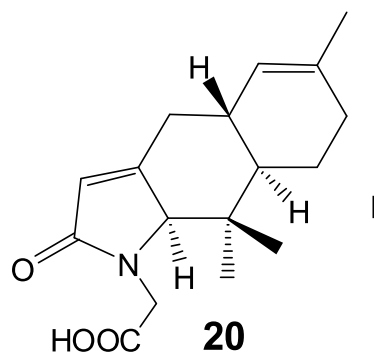

20

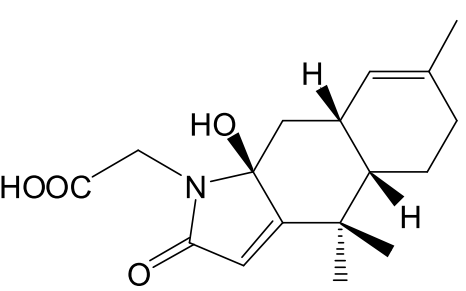

21

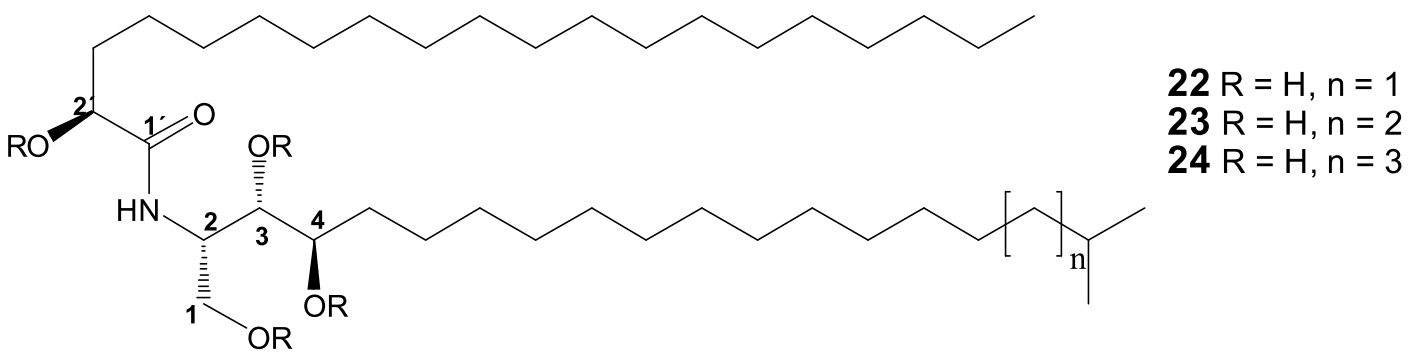

Keywords: Dysidea, secondary metabolite, ceramides, pyrodysinoic acid derivatives, HPLC-PDA-MS. 


\section{INTRODUÇÃO}

\subsection{Esponjas marinhas}

Pertencentes ao filo Porifera, as esponjas são os animais multicelulares mais primitivos. Não possuem órgãos, porém suas funções são desempenhadas por células do tecido conjuntivo, que é bem desenvolvido (Rupert, Barnes, 1996).

O nome Porifera origina-se do latim (porus = poro; ferre = portar). São animais aquáticos, predominantemente marinhos. Apresentam uma corrente unidirecional de água através de seu corpo, da qual se nutrem e também se utilizam para fins reprodutivos. O plano de construção dos poríferos é bem simples e apresenta uma constante reorganização do sistema aqüífero (Kelly-Borges, 1995). As esponjas apresentam uma ampla distribuição geográfica, sendo abundantemente encontradas em todo o oceano, desde mares tropicais até glaciais.

\subsection{Produtos Naturais Marinhos}

Nos últimos 50 anos quase 20.000 produtos naturais marinhos foram descobertos, muitos com atividade farmacológica, incluindo acetogeninas, policetídeos, terpenos, alcalóides, peptídeos e metabólitos de origem biossintética mista (Faulkner, 2002).

$\mathrm{Na}$ década de 60 deram-se início as pesquisas com Produtos Naturais marinhos no Brasil. No entanto, ainda são poucas as informações sobre as 
substâncias isoladas e a atividade biológica de produtos naturais de organismos marinhos coletados ao longo do litoral brasileiro (Berlinck et al, 2004).

O estudo químico de invertebrados marinhos, em especial com cnidários, teve grande impulso durante a década de 60 com o descobrimento das prostaglandinas em varias espécies de corais moles do Caribe (em especial a gorgónia Plexaura homomalla) (Weinnheimer, Spraggins, 1969). Desde então, ficou evidenciado o potencial destes organismos como produtores de compostos de interesse biológico e farmacológico.

As esponjas são os invertebrados marinhos que apresentam a maior diversidade de metabólitos secundários bioativos. Desde então, as esponjas do gênero Dysidea merecem destaque.

\subsection{Esponjas do gênero Dysidea}

Esponjas marinhas pertencentes ao gênero Dysidea (Ordem Dictyoceratida) vêm sendo investigadas por mais de 40 anos em função da grande diversidade de produtos naturais que este gênero apresenta. Alguns metabólitos da família Dysideidae incluem éteres difenílicos polibromados (Zhang et al., 2008) terpenos (Ueda et al., 2007), peptídeos modificados (Matsunaga; Fusetani, 2003), derivados atípicos de ácidos graxos (Skepper; Molinski, 2008), neurotoxinas funcionalizadas altamente polares (Sakai, et al., 1997), um meroterpenonucleosídeo conjugado (Sakai, et al. 1999), aminoácidos modificados (MacMillan; Molinski, 2000) e também um alcalóide peptídico ligado a um grupo guanidina (Caroll, et al. 2002). Uma vez que vários compostos de Dysidea spp. foram também isolados de cianobactérias, (Usher, et al., 2008; Sakai, et al., 2008; Flatt et al., 2005; Flowers et al., 1998) as quais também são uma importante fonte de 
produtos naturais (Goetz, et al., 2001), o fato dessas esponjas terem estabelecido uma associação íntima com tais simbiontes durante a evolução faz desse grupo de esponjas marinhas uma notável fonte de metabólitos secundários bioativos e estruturalmente variados.

Dentre os compostos isolados de Dysidea spp. destacam-se os derivados sesquiterpênicos furodisina (1), a lactona da o-etil-9-hidróxi (2) e um esterol poliidroxilado (3) (Piggott; Karuso, 2005), isolados de Dysidea arenaria, bem como a haterumadisina A (4), isolada de Dysidea chlorea (Ueda et al., 2006).<smiles>CC1=C[C@H]2Cc3occc3C(C)(C)[C@H]2CC1</smiles>

1<smiles>CCO[C@]12C[C@H]3C=C(C)[C@@H](O)C[C@H]3C(C)(C)C1=CC(=O)O2</smiles>

2

Figura 1. Estruturas: furodisina e a lactona da o-etil-9-hidróxi.
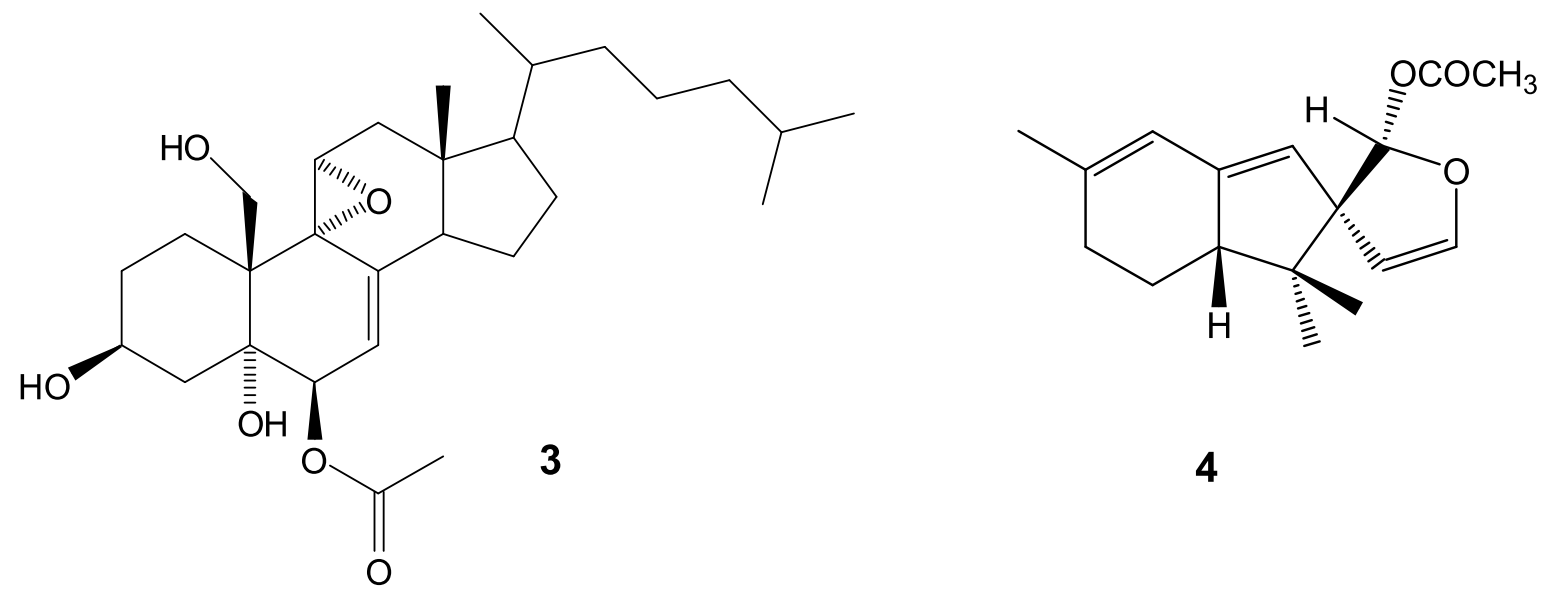

4

Figura 2. Estruturas de um esterol poliidroxilado e haterumadisina $A$.

Também na classe dos sesquiterpenos incluem-se linshuiperóxido (5) e spirolingsuiolídeo (6), ambos isolados de Dysidea septosa (Huang et al., 2008). 
Uma nova hidroquinona sesquiterpenóidica, (7), isolada de Dysidea arenaria (Qiu; Wang, 2008) e o halissulfato 3 (8), um sulfato de sesterterpeno, com atividade antifúngica contra Candida albicans $\left(\mathrm{IC}_{50}=18.2 \mu \mathrm{g} / \mathrm{ml}\right)$ (Lee, et al., 2008).
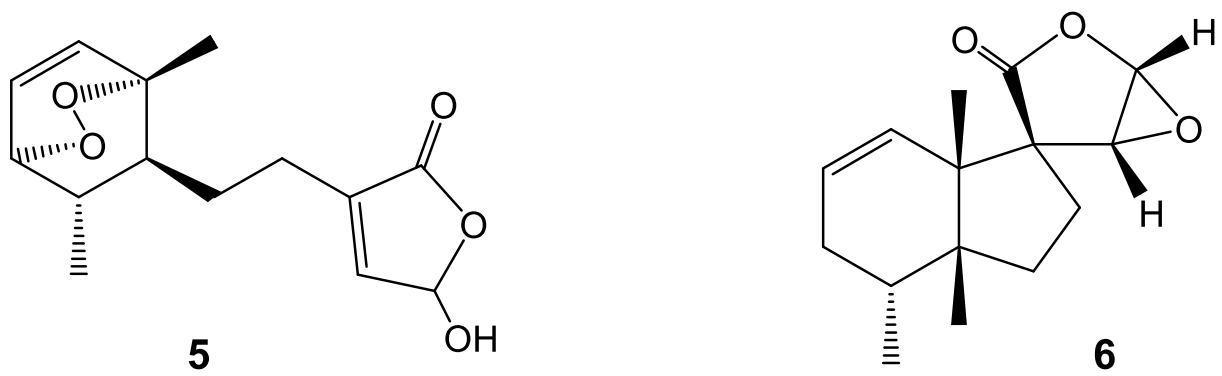

Figura 3. Estruturas de linshuiperóxido (5) e spirolingsuiolídeo (6).

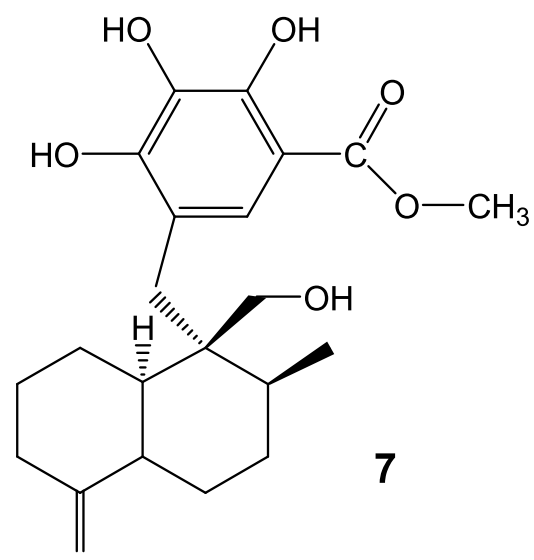<smiles>C[C@@H]1CCC2=C(CCCC2(C)C)[C@]1(C)CC[C@H](CCCc1ccoc1)CO[Se]([O-])([O-])O[Na]</smiles>

Figura 4. Estruturas de hidroquinona sesquiterpenóidica e halissulfato 3.

Exemplos da grande diversidade química do gênero Dysidea são as azirinas, i.e., ácidos graxos modificados com um grupo azaciclopropeno, como o derivado 9 (Skepper, Molinski, 2008) e a disidazirina (10) (Molinski, Ireland, 1988). Este último apresentou atividade citotóxica contra células $\mathrm{L} 1210$ com $\mathrm{IC}_{50}$ de 0.27 $\mu \mathrm{g} / \mathrm{mL}$. Tais compostos foram isolados da esponja $D$. fragilis. 

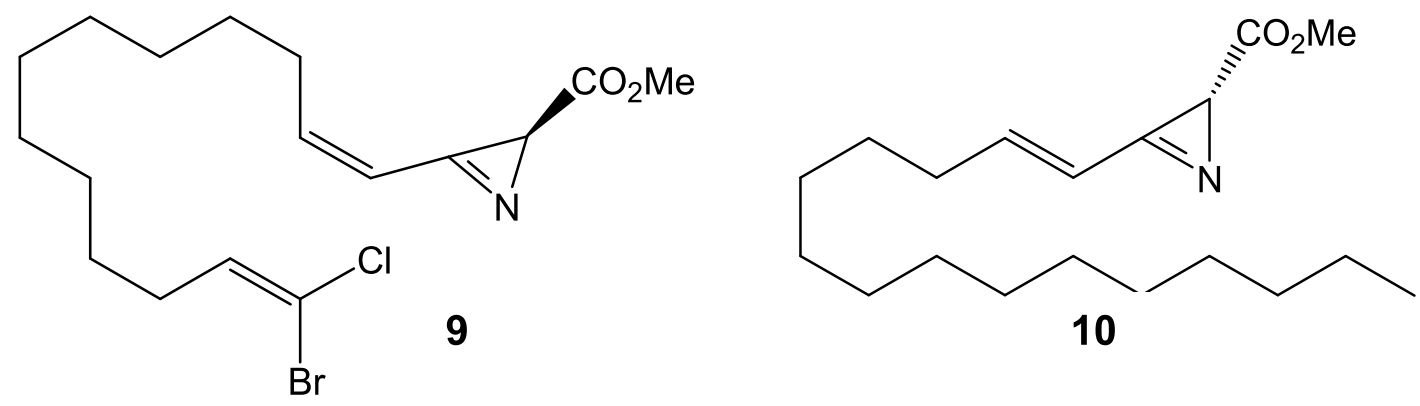

10

Figura 5. Estruturas da classe das azirinas.

Uma outra classe biologicamente importante de compostos precedentes de espécies do gênero Dysideidade é a dos éteres difenílicos bromados. Vários destes compostos apresentaram atividades biológicas e farmacológicas. Dentre elas antiinflamatória e antitumoral, através do mecanismo de inibição da 15lipoxigenase em mamíferos. Os compostos 11 e 12 foram isolados de Dysidea sp. (Zhang et al., 2008) e apresentaram atividade antitumoral. Tal classe de compostos caracteriza-se, além das diversas modalidades de atividades biológicas, pela ampla variação nos graus de hidroxilação, metoxilação e bromação, como se pode observar na figura 6. 
<smiles>Oc1cc(Br)cc(Br)c1Oc1ccc(Br)cc1Br</smiles>

11<smiles>Oc1cc(Br)cc(Br)c1Oc1cc(Br)cc(Br)c1O</smiles>

13<smiles>COc1c(O)c(Oc2ccc(Br)cc2Br)c(Br)c(Br)c1Br</smiles>

12<smiles>COc1c(Br)cc(Br)cc1Oc1c(Br)c(Br)c(Br)c(Br)c1OC</smiles>

Figura 6. Éteres difenílicos bromados.

Dentre as esponjas do gênero Dysidea, uma das espécies que mais se destacam é Dysidea herbacea. Dentre os metabólitos secundários já registrados pela literatura, incluem-se os compostos 13 e 14 (Utkina; Denisenko, 2006) da classe dos éteres difenílicos e peptídeos modificados derivados da leucina [ácido herbácico (15) e barbamida (16)] (MacMillan; Molinski, 2000).<smiles>C[C@@H](C[C@@H](C(=O)O)N(C)C(=O)/C=C/C[C@@H](C)C(Cl)(Cl)Cl)C(Cl)(Cl)Cl</smiles>

15<smiles>CO/C(=C/C(=O)N(C)C(Cc1ccccc1)c1nccs1)C[C@@H](C)C(F)(Cl)Cl</smiles>

16

Figura 7. Estruturas do ácido herbácico e da barbamida. 
Juntamente com 15 e 16, destaca-se ainda a disidenina (Kazlauskas, et al., 1977) (17), produzida por uma relação simbiótica entre $D$. herbacea e a cianobacteria Oscillatoria spongeliae (Hinde, et al., 1994).<smiles>C[C@@H](NC(=O)[C@@H](C[C@@H](C)C(F)(F)Cl)N(C)C(=O)C[C@@H](C)C(C)(C)C)c1nccs1</smiles>

Figura 8. Estrutura da disidenina.

Neste trabalho foi feito um estudo de duas amostras de de Dysidea robusta (Vilanova e Muricy, 2001; Muricy e Hajdu, 2006), com o intuito de se observar a diversidade química de seus metabólitos secundários e possíveis atividades biológicas.

A esponja Dysidea robusta é endêmica do Brasil e não há relatos na literatura sobre investigações químicas desta espécie. 


\section{OBJETIVOS}

Este trabalho tem como principais objetivos avaliar a diversidade do metabolismo secundário de duas amostras da espécie Dysidea robusta, realizando-se as seguintes etapas:

- Obtenção dos extratos brutos e fracionamento dos extratos por diversas modalidades cromatográficas, visando o isolamento de metabólitos puros;

- Determinação estrutural dos compostos puros isolados e;

- Se isolados em quantidades suficientes, realizar a avaliação biológica das substâncias puras. 


\section{MATERIAIS E MÉTODOS}

\subsection{Técnicas Cromatográficas}

\subsubsection{Cromatografia em camada delgada (CCD)}

Foram utilizadas cromatofolhas de silica-gel 60 sobre poliéster, com indicador ultravioleta F254, de dimensões $20 \times 20 \mathrm{~cm}$ (Aldrich). As manchas nas cromatofolhas foram observadas sob luz ultrvioleta (UV) Spectroline Model ENF240 C/FE, no comprimento de onda de 254 nm e 365 nm, após eluição.

\subsubsection{Cromatografia em coluna pré empacotada Sep-Pak®}

Para cromatografias realizadas em colunas pré-empacotadas foram utilizadas as seguintes colunas: a) Waters Sep-Pak® vac $35 \mathrm{cc}$ com as seguintes fases estacionárias: sílica-gel, $\mathrm{C}_{18}$ e cianopropila; b) Strata sílica-gel e $\mathrm{C}_{18} . \mathrm{O}$ tipo de coluna e a massa de fase estacionária utilizados na coluna foram escolhidos, respectivamente, de acordo com a natureza da amostra a ser fracionada e de sua quantidade.

\subsubsection{Cromatografia em coluna}

Para a cromatografia em coluna foi utilizada a técnica de permeação em gel Sephadex LH-20. Utilizou-se uma coluna de vidro com $170 \mathrm{~cm}$ de altura e $2 \mathrm{~cm}$ de diâmetro interno e MeOH grau analítico como eluente. 


\subsubsection{Cromatografia Líquida de Alta Eficiência}

Para as análises por HPLC foram utilizados dois equipamentos da marca Waters: um sistema com duas bombas Pump 600, um detector espectrofotométrico UV-Visível modelo 2487 com leitura em dois comprimentos de onda, um registrador modelo 746 e um sistema de controle Controller 600; o outro sistema utilizado é idêntico ao primeiro, porém com detector de arranjo de fotodiodos (PDA), e monitoramento pelo Software Millenium, versão 4.00. Em ambos os sistemas, foi utilizado fluxo de gás hélio para degaseificação dos eluentes.

Nas análises e separações por HPLC, foram utilizadas as seguintes colunas cromatográficas: a) de fase normal: coluna semi-preparativa Waters $\mu$-porasil sílica gel $125 \AA, 10 \mu \mathrm{m}$, de dimensões $7,8 \times 300 \mathrm{~mm}$; b) fase reversa: coluna analítica $\mathrm{C}_{18}$ Phenomenex, $5 \mu \mathrm{m}$, de dimensões $4,6 \times 250 \mathrm{~mm}$; coluna analítica GL Sciences Inc., $\mathrm{C}_{18}$ Inertsil, $5 \mu \mathrm{m}$, de dimensões 4,6 x 250 mm; coluna analítica GL Sciences Inc., Phenyl Inertsil, $5 \mu \mathrm{m}$, de dimensões 4,6 x $250 \mathrm{~mm}$; coluna semipreparativa CSC-Inertsil, ODS-2, $150 \AA$, $5 \mu \mathrm{m}$, de dimensões $0,94 \times 25 \mathrm{~cm}$; coluna semipreparativa Waters $\mu$-Bondapak Phenyl, $125 \AA$, $10 \mu \mathrm{m}$, dimensões 7,8 x 300 mm; coluna preparativa Whatman Partisil ODS-3, de dimensões 9,5 x 500

mm; e coluna preparativa Waters $C_{18}$ Deltapak, $100 \AA, 15 \mu \mathrm{m}$, de dimensões $19 \mathrm{x}$ $300 \mathrm{~mm}$. 


\subsubsection{Análises por LC-MS-ELSD}

Nas análises por LC-MS-ELSD foram utilizados os seguintes equipamentos: um cromatógrafo Waters Alliance Series - Column Heater and Column Heater/Cooler, modelo 2695; um detector ultravioleta com arranjo de fotodiodos Waters 2996; um espectrômetro ESCi Multi-mode lonization Source; e um detector de espalhamento de luz Waters 2424 Evaporative Light Scattering Detector. Tais análises foram monitoradas pelos softwares Empower 2 e ZQ V4.1/ ZQ Mass Detector Software.

Após os fracionamentos de todos os extratos das esponjas estudadas, foram selecionadas frações para análises por LC-MS-ELSD. Por ser uma técnica com sensibilidade suficiente para detectar pequenas quantidades em massa, foram selecionadas aquelas frações de maior interesse para o estudo, que compreendiam misturas complexas de substâncias. Alem do mais, a técnica de espalhamento de luz permite verificar se há compostos que não possuem cromóforos, ou seja, que não absorvem na região do ultravioleta. Outra vantagem da utilização deste tipo de detector é que as análises permitem verificar se existem, em frações de pouca massa, compostos majoritários, uma vez que o sinal obtido em ELSD é proporcional à concentração de cada composto presente na mistura.

Das diversas frações analisadas, somente de algumas delas foi possível realizar $\mathrm{o}$ isolamento de compostos puros. Nas análises de espectrometria de massas, foi utilizado um espectrômetro operando em dois diferentes modos, APCi e ESI, dependendo da natureza da fração, de sua polaridade, solubilidade e afinidade com diversas fases estacionárias. Nas análises por HPLC foram 
utilizados tanto fase reversa quanto normal, prevalecendo o uso das fases estacionárias $\mathrm{C}_{18}$ ou fenila; e sílica gel, respectivamente.

\subsection{Solventes}

Para cromatografias em camada delgada e de coluna em geral, foram utilizados solventes de pureza analítica das marcas Sinth e Quimex. Para cromatografia líquida de alta eficiência foram utilizados solventes grau HPLC das marcas J. T. Baker e Mallinckrodt. A água utilizada em todos os processos cromatográficos foi fornecida por um sistema Milli-Q Millipore equipado com resina de troca iônica e filtro biológico.

As frações aquosas resultantes das cromatografias em fase reversa foram evaporadas utilizando um sistema de centrífuga a vácuo da marca Savant, modelo SpeedVac®Plus SC 210.

\subsection{TÉCNICAS ESPECTROMÉTRICAS}

\subsubsection{Ressonância Magnética Nuclear (RMN)}

Os espectros de RMN foram obtidos nos seguintes aparelhos:

- Bruker DRX (9,4 Tesla), operando a 400,35 MHz na freqüência do hidrogênio $\left({ }^{1} \mathrm{H}\right)$ e a $100,1 \mathrm{MHz}$ na freqüência do carbono $\left({ }^{13} \mathrm{C}\right)$, pertencente ao $\mathrm{DQ}$ UFSCar;

- Bruker AV-600, operando a $600 \mathrm{MHz}$ na freqüência do hidrogênio $\left({ }^{1} \mathrm{H}\right)$ e a 150 $\mathrm{MHz}$ na freqüência do carbono $\left({ }^{13} \mathrm{C}\right)$.

As amostras foram preparadas com os seguintes solventes deuterados: clorofórmio deuterado $\left(\mathrm{CDCl}_{3}\right)$, acetonitrila deuterada $\left(\mathrm{CD}_{3} \mathrm{CN}\right)$, metanol 
deuterado, $\left(\mathrm{CD}_{3} \mathrm{OD}\right)$, dimetilsulfóxido deuterado (DMSO- $\left.d_{6}\right)$ e piridina deuterada (py- $\left.d_{5}\right)$, todos da marca Cambridge Isotopes. O padrão de referência interna utilizado foi o tetrametilsilano (TMS), da Cambridge Isotopes.

\subsubsection{Infravermelho (IV)}

Os espectros na região do infravermelho foram obtidos em um espectrofotômetro FTIR Bomem, modelo MB-102, pertencente ao IQSC - USP. As amostras foram dissolvidas em um solvente volátil e aplicadas sob forma de filme em disco de silício. Posteriormente, o disco de silício foi colocado em um dessecador para evaporação completa do solvente.

\subsubsection{Espectrometria de Massa (EM)}

Os espectros de massas foram obtidos utilizando-se um espectrômetro Bkuker-Hewlett-Pachard 1100.

As análises por espectrometria de massas foram realizadas com ionização do tipo ESI (Electro-Spray) e APCi (Atmospheric Pressure Chemical lonization)).

\subsubsection{Medidas de Rotação Específica $\left([\alpha]^{\mathrm{D}}\right)$}

Os experimentos de rotação específica foram realizados em um polarímetro Jasco P-1010, a 589 nm. 


\section{PARTE EXPERIMENTAL}

\subsection{ESTUDO DE INVERTEBRADOS MARINHOS}

\subsubsection{Avaliação biológica de alíquotas dos extratos selecionados}

Alíquotas dos extratos de todas as amostras de esponjas marinhas foram avaliadas quanto à sua bioatividade, em vários ensaios biológicos. A escolha dos invertebrados para estudo foi feita em função dos resultados obtidos pelos bioensaios.

Os extratos brutos das duas amostras de Dysidea robusta apresentaram-se ativos contra S. aureus, E. coli, S. aureus resistente a oxicilina, M. tuberculosis H37R, também atividade citotóxica contra linhagens de células tumorais dos pulmões MCF-7 e do cólon, HCT-8 (Seleghim et al, 2007).

O motivo pelo qual foram selecionadas duas amostras da mesma espécie, DR1 e DR2, foi verificar a existência ou não de diferentes classes de metabólitos entre amostras coletadas em uma mesma área geográfica. 
Tabela 1. Atividades biológicas apresentadas pelos extratos brutos das duas amostras de esponjas Dysidea robusta a serem estudadas (Seleghim et al, 2007)

\begin{tabular}{|c|c|c|}
\hline Atividade & BA99-ES-108 (DR1) & BA99ES-111 (DR2) \\
\hline $\begin{array}{c}\text { Staphylococcus aureus } \\
\text { ATCC } 6538\end{array}$ & + & \\
\hline Escherichia coli ATCC 25922 & + & + \\
\hline $\begin{array}{c}\text { Pseudomonas aeruginosa (linhagem } \\
\text { resistente \# 6.4) }\end{array}$ & + & + \\
\hline S. aureus resistente a oxicilina & + & + \\
\hline $\begin{array}{l}\text { S. aureus resistente a oxacilina } \\
\text { (linhagem \# 35); }\end{array}$ & & + \\
\hline $\begin{array}{l}\text { S. aureus resistente a oxacilina } \\
\text { (linhagem \# 36); }\end{array}$ & & + \\
\hline $\begin{array}{l}\text { S. aureus resistente a oxacilina } \\
\text { (linhagem \# 61); }\end{array}$ & + & \\
\hline $\begin{array}{l}\text { S. aureus resistente a oxacilina } \\
\text { (linhagem \# 63); }\end{array}$ & + & + \\
\hline $\begin{array}{l}\text { S. aureus resistente a oxacilina } \\
\text { (linhagem \# 68); }\end{array}$ & + & + \\
\hline $\begin{array}{l}\text { S. aureus resistente a oxacilina } \\
\text { (linhagem \# 108); }\end{array}$ & & + \\
\hline $\begin{array}{l}\text { S. aureus resistente a oxacilina } \\
\text { (linhagem \# 115); }\end{array}$ & + & + \\
\hline $\begin{array}{c}\text { S. aureus resistente a oxacilina } \\
\text { (linhagem \# 135); nível de atividade } \\
\text { antibacteriana: }+ \text { inhibition hallii }>5 \\
\mathrm{~mm} \text { and }<10 \mathrm{~mm} \text {; }\end{array}$ & + & + \\
\hline MCF-7 Células do cancer de pulmão & + & +++ \\
\hline HCT-8 Células do cancer do colon & +++ & \\
\hline $\begin{array}{l}\text { Células de melanoma murino B16; } \\
\text { Nivel de atividade citotóxica: + } \\
\text { inibição de até } 50 \% \text { do crescimento } \\
\text { das células cancerígenas;++++ } \\
\text { inibição maior que } 75 \% \text { do } \\
\text { crescimento da célula }\end{array}$ & + & +++ \\
\hline
\end{tabular}




\subsubsection{Extração e fracionamento dos extratos}

\subsubsection{Esponja Dysidea robusta (BA99ES-111)}

A esponja foi coletada no litoral baiano em 1999. A amostra (BA99ES-111) da esponja Dysidea robusta foi identificada pela equipe do Prof. Eduardo Hajdu, do Museu Nacional da Universidade Federal do Rio de Janeiro. Após liofilização da esponja congelada, a amostra foi armazenada em MeOH:EtOH 1:1 a $0^{\circ} \mathrm{C}$.

O fracionamento do extrato polar desta esponja levou ao isolamento do ácido pirodisinóico (18), do ácido isopirodisinóico (19), do ácido pirodisinóico B (20) e do ácido 13-hidróxi-isopirodisinóico (21).

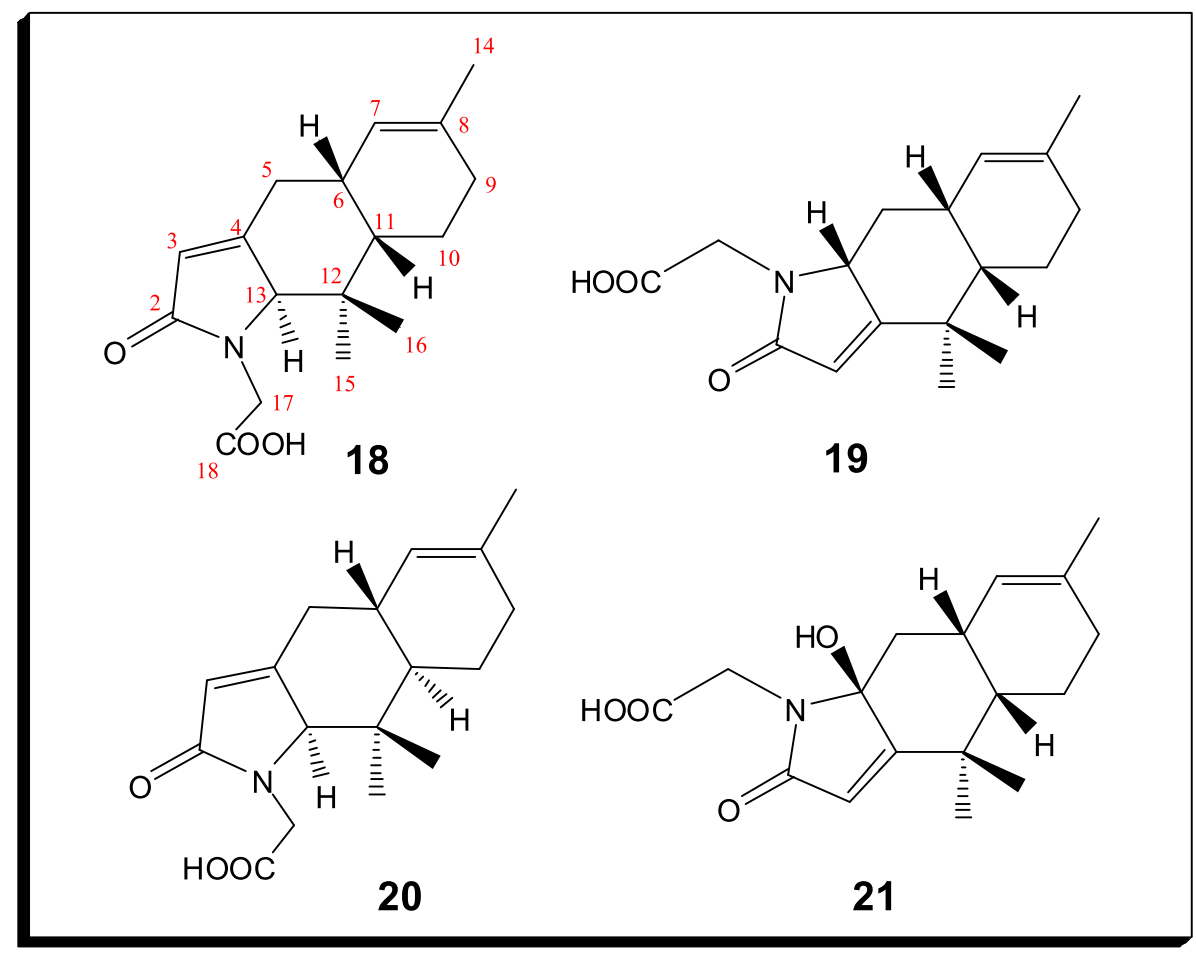

Figura 9. Compostos puros isolados de Dysidea rbosuta (DR2).

A amostra selecionada para estudo foi codificada como "DR2" (=Dysidea robusta; amostra 2) e pesada, obtendo-se uma massa úmida de aproximadamente 
100g. Em seguida, esta foi triturada com MeOH:EtOH 1:1 e filtrada a vácuo através de Celite. O material sólido foi submetido a mais uma extração com 300 $\mathrm{mL}$ de $\mathrm{MeOH}$, a temperatura ambiente, sob agitação, por doze horas. O resíduo sólido foi separado do filtrado por filtração através de Celite em papel de filtro e o líquido foi parcialmente evaporado, obtendo-se desta forma o extrato bruto.

Ao extrato bruto dissolvido em $\mathrm{MeOH}$ e $\mathrm{EtOH}(\mathrm{V} \sim 300 \mathrm{~mL}$ ) foram adicionados $10 \%$ vol. de $\mathrm{H}_{2} \mathrm{O}$ e em seguida realizaram-se três partições líquidolíquido com éter de petróleo, utilizando-se $300 \mathrm{~mL}$ de éter de petróleo por cada extração. Das partições realizadas obtiveram-se dois extratos, éter de petróleo (DR2-EP) e metanólico/aquoso (DR2-AQ), que após evaporação total dos solventes, a massa obtida foi de, respectivamente, 146 e $907 \mathrm{mg}$. Todo o procedimento é sumarizado e ilustrado no fluxograma a seguir:

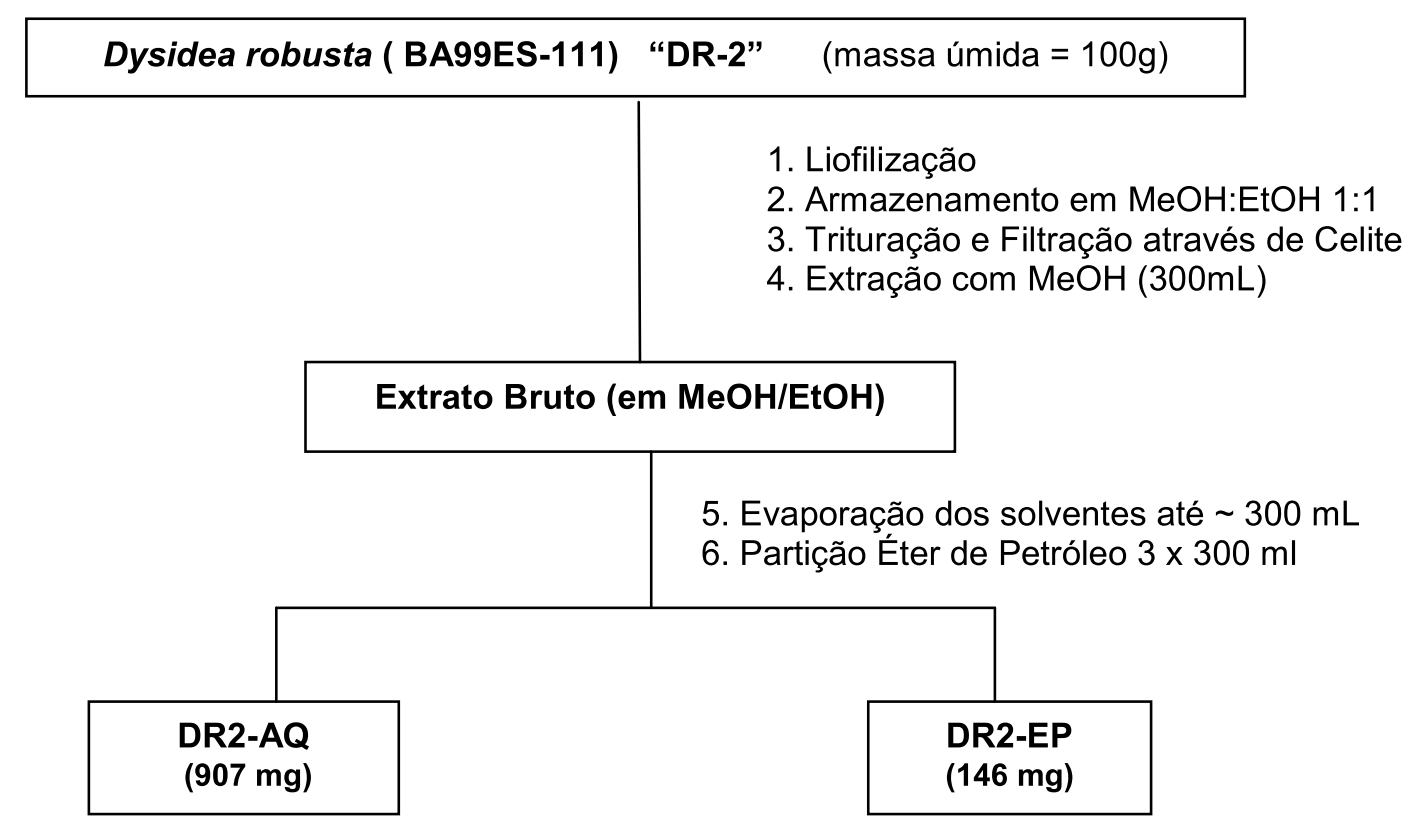

Figura 10. Fluxograma de obtenção dos extratos de Dysidea robusta 
Os dois extratos foram detalhadamente analisados por cromatografia em camada delgada em placas de sílica gel com dimensões de $20 \times 20 \mathrm{~cm}$, com indicador UV e comparados com padrões de metabólitos primários (colesterol e timidina). Os extratos foram eluídos com diversas composições eluentes, afim de se observar todas as manchas possíveis em seus variados tempos de retenção. Todas as placas foram observadas à luz UV em $254 \mathrm{~nm}$ e $365 \mathrm{~nm}$ e reveladas com: a) solução de ninidrina $0,1 \%$ em $\mathrm{EtOH}$, que revela aminas primárias e secundárias; b) reagente de Dragendorff, que detecta a presença de alcalóides; e c) solução de ácido fosfomolíbdico $5 \%$ em EtOH, agente oxidante de compostos que contêm ligações $\pi$. Uma relação completa da análise por CCD está descrita na tabela 2.

Tabela 2 : Condições de análise por CCD dos extratos DR2-EP e DR2-AQ:

\begin{tabular}{c|c|c} 
Extrato & Composições eluentes & Padrão / composição eluente \\
\hline \multirow{2}{*}{ DR2-EP } & éter de petróleo/ EtOAc: & Colesterol/ \\
& $9: 1,7: 3$ e $1: 1$ & éter de petróleo/EtOAc/MeOH \\
\hline \multirow{2}{*}{ DR2-AQ } & $\mathrm{CH}_{2} \mathrm{Cl}_{2} / \mathrm{MeOH}$ & $50: 48: 2$ \\
& $9: 1$ e $7: 3$ & $7: 3$
\end{tabular}

O extrato DR2-EP apresentou grande quantidade de compostos com absorção em $254 \mathrm{~nm}$ e que migraram abaixo do colesterol, indicando a possível presença de compostos contendo grupos polares. Sendo assim, o extrato DR2-EP foi submetido a um pré-fracionamento em coluna Sep Pak $(10,0 \mathrm{~g})$ de sílica gel, objetivando-se desengordurar o extrato. As frações obtidas foram analisadas por LC-MS. Tendo-se obtido um grande número de frações em quantidades muito pequenas (poucos miligramas de cada fração), descartou-se o prosseguimento do estudo da fração DR2-EP. 
O extrato DR2-AQ apresentou várias substâncias com tempo de retenção menor que o do padrão timidina e alto grau de polaridade. Geralmente, compostos que apresentam este comportamento em relação à timidina, constituem metabólitos primários sem interesse (aminoácidos essenciais e nucleosídeos). Entretanto, em função de uma pequena quantidade de manchas de polaridade menor que a do padrão, considerou-se viável o estudo deste extrato.

Desta forma, depois de estabelecidas as condições de fracionamento de ambos extratos, tal procedimento foi realizado de acordo com o fluxograma da figura 11:

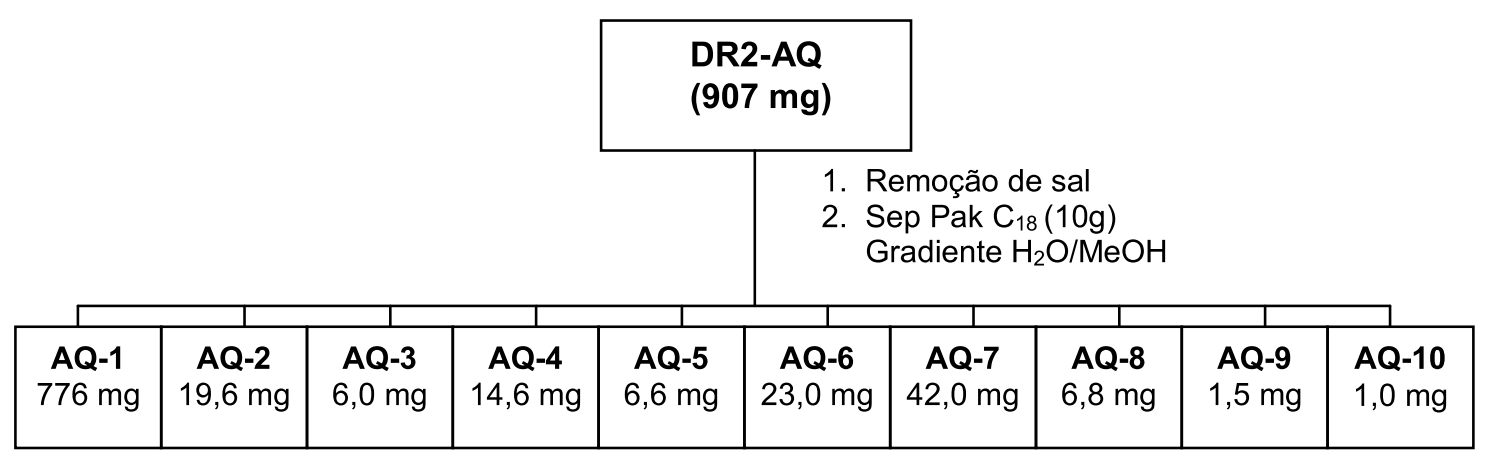

Figura 11. Fracionamento do extrato aquoso DR2-AQ.

Neste processo, o extrato DR2-AQ foi eluído a um gradiente crescente de $\mathrm{MeOH}$ em $\mathrm{H}_{2} \mathrm{O}$, iniciando-se com $100 \%$ de água $(50 \mathrm{~mL}$ ) e aumentando-se gradativamente em proporções de $5 \%$ de $\mathrm{MeOH}$ a composição da mistura, até $100 \%$ de metanol. Foram obtidos 124 tubos de ensaio, com aproximadamente 7 $\mathrm{mL}$ cada. As frações foram analisadas por $\mathrm{CCD}$, eluídas em $\mathrm{CH}_{2} \mathrm{Cl}_{2} / \mathrm{MeOH} 8: 2$, observadas sob UV em $\lambda=254 \mathrm{~nm}$ e reunidas conforme semelhanças nos tempos de retenção das manchas. 
Após reunião, as frações obtidas foram novamente analisadas por CCD e em função dos resultados (complexidade química, quantidade em massa) e algumas delas foram submetidas a separações por HPLC.

As frações DR2-AQ-4 e DR2-AQ-6 (figura 12) foram analisadas por LC-PDAMS-ELSD. Para ambas, foi utilizado um sistema gradiente de eluição, constituído por $\mathrm{MeOH}$ e $\mathrm{H}_{2} \mathrm{O}+0,1 \%$ de ácido fórmico.

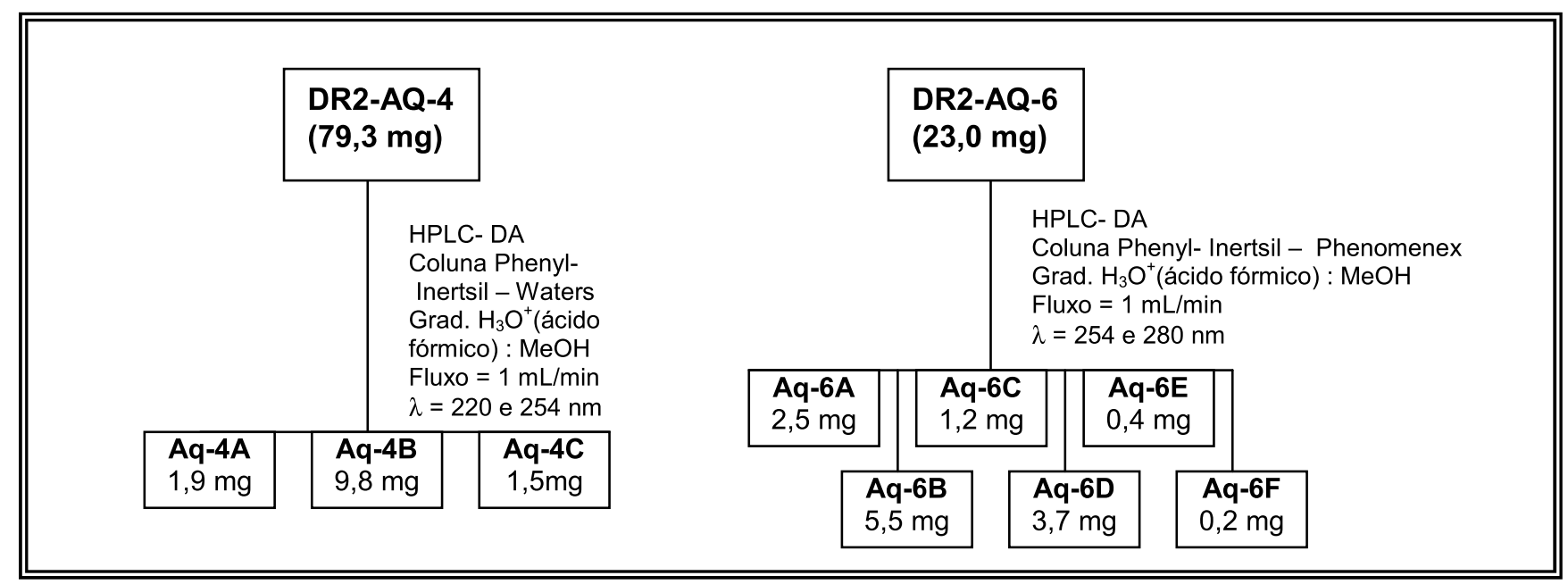

Figura 12. Fracionamento por HPLC dos extratos DR2-AQ-4 e DR2-AQ-6

Após tal análise, a fração DR2-AQ-4 foi purificada por HPLC. Utilizou-se como fase estacionária uma coluna Phenyl - Inertsil e como fase móvel um gradiente de $\mathrm{MeOH}$ em $\mathrm{H}_{2} \mathrm{O}+0,1 \%$ de ácido fórmico, a uma taxa de $1 \mathrm{~mL}$ por minuto, com detecção UV em dois comprimentos de onda, 220 e $254 \mathrm{~nm}$. Coletaram-se três frações, sendo que a fração DR2-AQ-4B apresentou vários compostos. Análises por $\mathrm{RMN}^{-1} \mathrm{H}$ das frações $\mathrm{DR} 2-\mathrm{AQ}-4 \mathrm{~A}$ e $-4 \mathrm{C}$ indicaram misturas razoavelmente complexas. Portanto, em função da quantidade escassa de massa e da complexidade das frações, o estudo destas foi interrompido. 
A fração DR2-Aq-6 foi analisada por LC-MS-ELSD com MS no modo eletrospray positivo (figura 13) e estabeleceu-se uma condição favorável de separação dos picos da fração.

Em seguida, esta foi purificada em HPLC (figura 14) com detector UV em 254 e $280 \mathrm{~nm}$, em uma coluna Phenyl Inertsil semipreparativa, utilizando gradiente de $\mathrm{H}_{2} \mathrm{O}+0,1 \%$ de ácido fórmico em $\mathrm{MeOH}$, em um fluxo de $1 \mathrm{~mL}$ por minuto. Foi possível coletar quatro picos bem definidos (DR2-Aq-6B, -6C, -6D e -6F) e outras duas misturas de picos superpostos (frações DR2-Aq-6A e -6E).
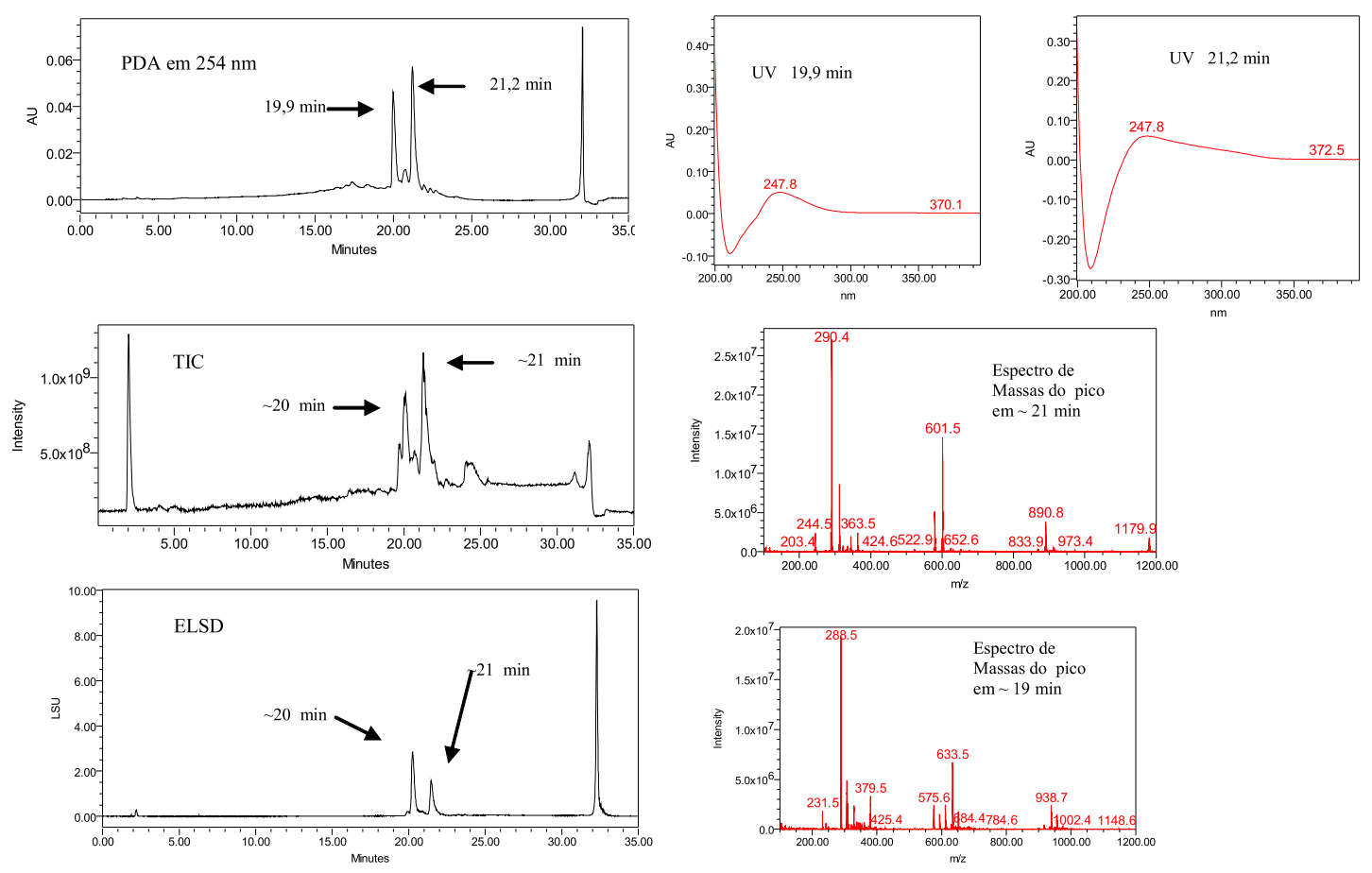

Figura 13. Análise da fração DR-2-Aq-6 $(23,0 \mathrm{mg})$ por LC-PDA-MS-ELSD (condições: Coluna Phenyl- Inertsil - Phenomenex; grad. $\mathrm{H}_{2} \mathrm{O}+0,1 \%$ de ácido fórmico : $\mathrm{MeOH}$; fluxo $1 \mathrm{~mL} / \mathrm{min}$; ĺon mode $\mathrm{ESi}^{+}$). 


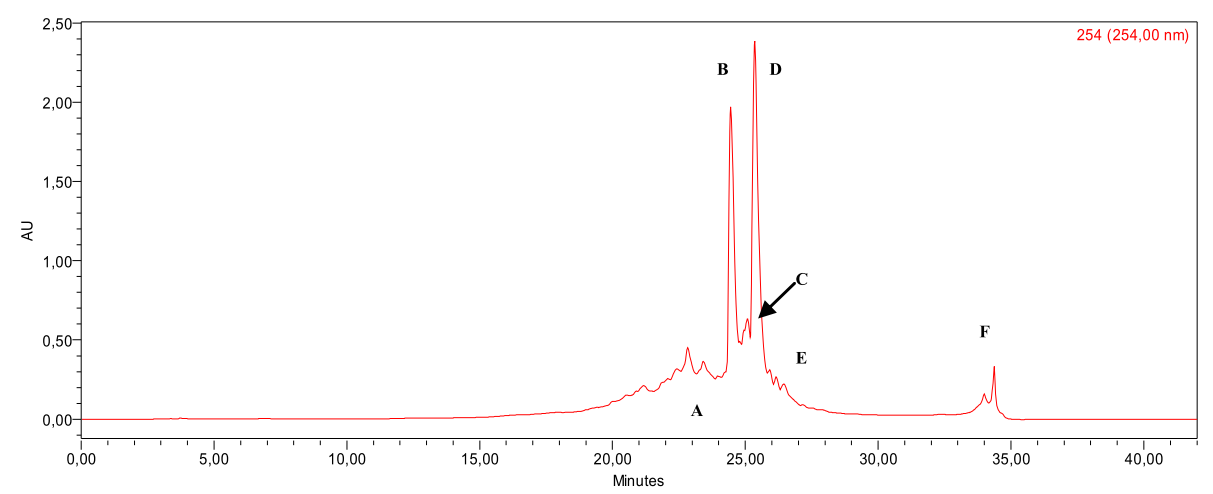

Figura 14. Cromatograma da separação semipreparativa da fração DR-2-Aq-6 por LC-DA em 254 nm. Condições: coluna Phenyl- Inertsil -Phenomenex; grad. $\mathrm{H}_{3} \mathrm{O}^{+}$(ácido fórmico) : $\mathrm{MeOH}$; fluxo $=1 \mathrm{~mL} / \mathrm{min} ; \lambda=254$ e $280 \mathrm{~nm}$.

Foram obtidos espectros de RMN- ${ }^{1} \mathrm{H}$ das frações DR2-Aq-6B, $-6 \mathrm{C},-6 \mathrm{D}$ e6F. As análises indicaram que as frações $-6 \mathrm{C},-6 \mathrm{D}$ e $-6 \mathrm{~F}$ eram misturas de dois ou mais compostos e que a fração DR2-Aq-6B de massa igual a 5,5 mg continha um composto majoritário, juntamente com impurezas. Desta forma, a fração DR2Aq-6B foi repurificada por cromatografia líquida de alta eficiência em fase reversa. Foi utilizada em tal processo uma coluna CSC-Inertsil 150A/ODS2, $5 \mu \mathrm{m}, 25 \mathrm{X}$ $0.94 \mathrm{~cm}$, com eluição de $\left(0.05 \% \mathrm{TFA} / \mathrm{H}_{2} \mathrm{O}\right) / \mathrm{MeCN}$, resultando no isolamento do ácido 13-hidróxi-isopirodisinóico (21) (1,3 mg).

Utilizando-se as mesmas condições, a purificação da fração DR2-AQ-6D (3,7 mg) forneceu o ácido pirodisinóico $B(20)(0,2 \mathrm{mg})$ e uma mistura de ácido pirodisinóico (18) e do ácido isopirodisinóico (19). A mistura de 18 e 19 foi fracionada por HPLC em fase reversa $\left(\mathrm{C}_{18}\right)$, usando a mesma coluna em uma mistura 3:2 $\mathrm{MeOH} /\left(0,05 \% \mathrm{TFA} / \mathrm{H}_{2} \mathrm{O}\right)$ como eluentes, obtendo-se o ácido pirodisinóico (18) (0,2 mg) e o ácido isopirodisinóico (19) (0,5 mg). 
Os compostos obtidos foram analisados por técnicas de RMN bidimensionais, tendo por fim suas estruturas determinadas. Todo o processo de determinação estrutural dos compostos está descrito no item Resultados e Discussão, página 45.

\subsubsection{Esponja Dysidea robusta (BA99ES-108)}

A esponja de código BA99ES-108 também foi coletada no litoral baiano em 1999. A amostra foi liofilizada e armazenada em $\mathrm{MeOH} / \mathrm{EtOH} \mathrm{1:1} \mathrm{a} \mathrm{0C.}$

O fracionamento do extrato hexânico desta esponja levou ao isolamento da mistura de ceramidas 22, 23 e 24 .

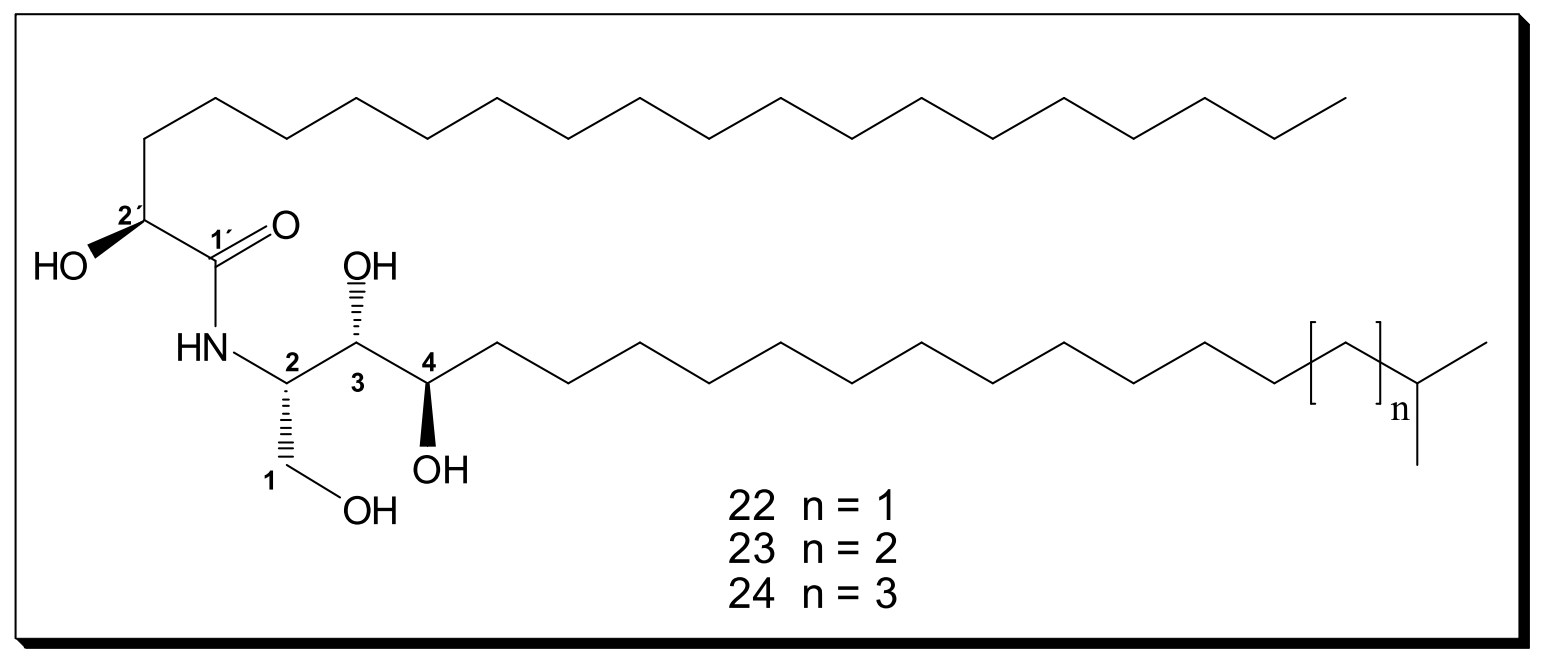

Figura 15. Mistura de ceramidas da esponja Dysidea robusta (DR1).

A amostra de Dysidea robusta foi codificada como "DR1" (=Dysidea robusta; amostra 1) e sua massa úmida (300 g) foi triturada com MeOH:EtOH 1:1 e filtrada a vácuo através de Celite. Foram realizadas mais duas extrações com $300 \mathrm{~mL}$ de $\mathrm{MeOH}$, a temperatura ambiente, sob agitação, por vinte horas. O resíduo sólido foi separado do filtrado por filtração através de Celite em papel de filtro e o extrato 
bruto em solução foi obtido através de evaporação parcial (até $~ 300 \mathrm{~mL}$ ) da mistura de solventes.

Ao extrato bruto foram adicionados aproximadamente $150 \mathrm{~mL}$ de água milli-Q e $300 \mathrm{~mL}$ de hexano. Todo o volume $(750 \mathrm{~mL})$ foi conduzido a um funil de separação e submetido a uma partição líquido-líquido da mistura. Esta partição foi realizada três vezes, tendo-se utilizado $300 \mathrm{~mL}$ de hexano a cada partição. Após evaporação da fração hexânica, foram obtidos 668,4 mg de extrato hexânico seco. Este procedimento está ilustrado no fluxograma seguinte.

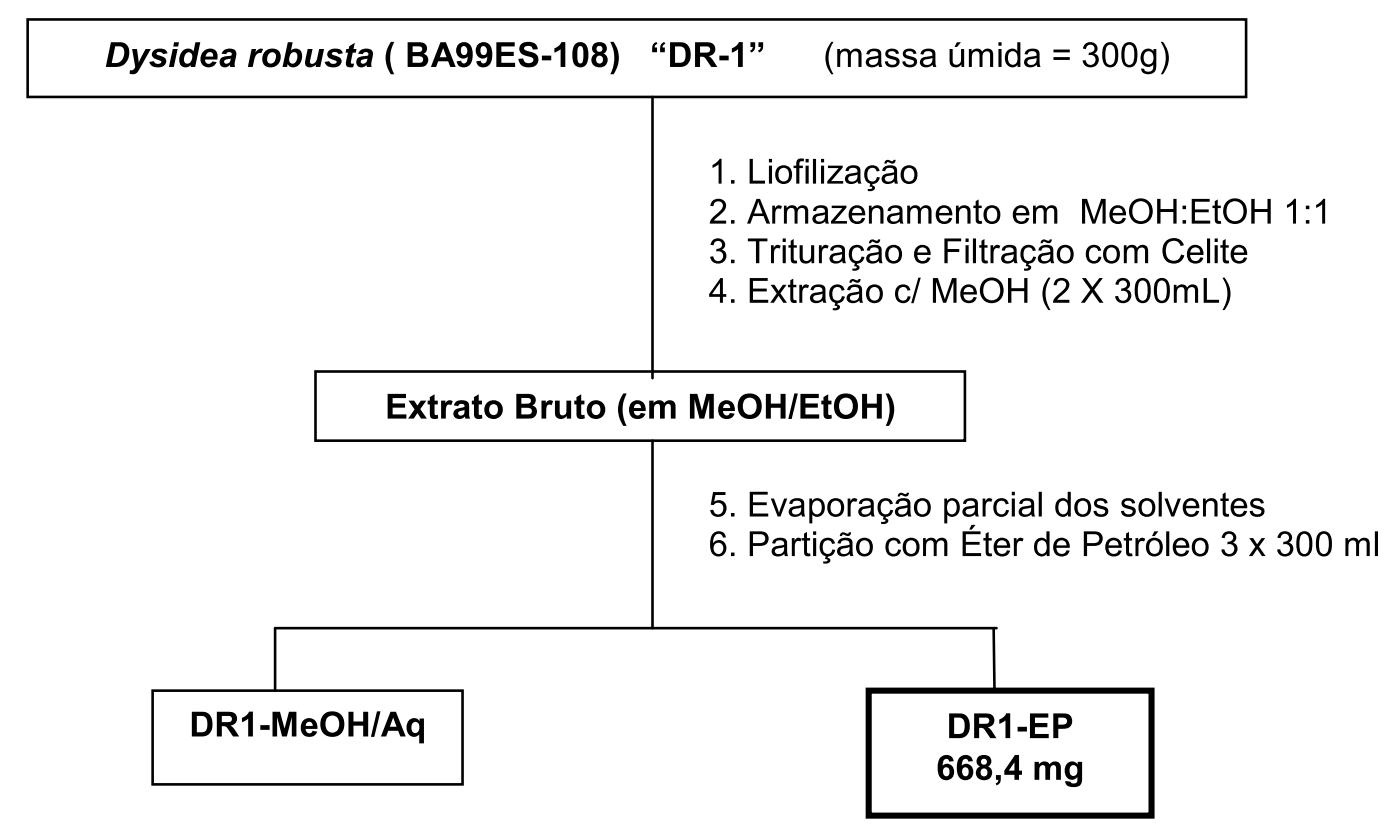

Figura 16. Fluxograma de extração e fracionamento da esponja $D$. robusta.

Quanto à mistura remanescente - DR1-MeOH/Aq - todo o solvente orgânico (metanol e pequena quantidade de etanol) foi evaporado, de maneira que só restasse água. Foram adicionados a este volume mais $100 \mathrm{~mL}$ de água Milli-Q e $250 \mathrm{~mL}$ de acetato de etila. Todo o volume foi submetido a uma partição líquidolíquido com água e acetato de etila, por três vezes, adicionando-se $250 \mathrm{~mL}$ de 
acetato de etila por vez. Desta maneira, a etapa de partição líquido-líquido foi finalizada, obtendo-se os dois últimos extratos, o aquoso (DR1-Aq) e o extrato acetato de etila (DR1-Ac). O procedimento está descrito conforme a figura a seguir:

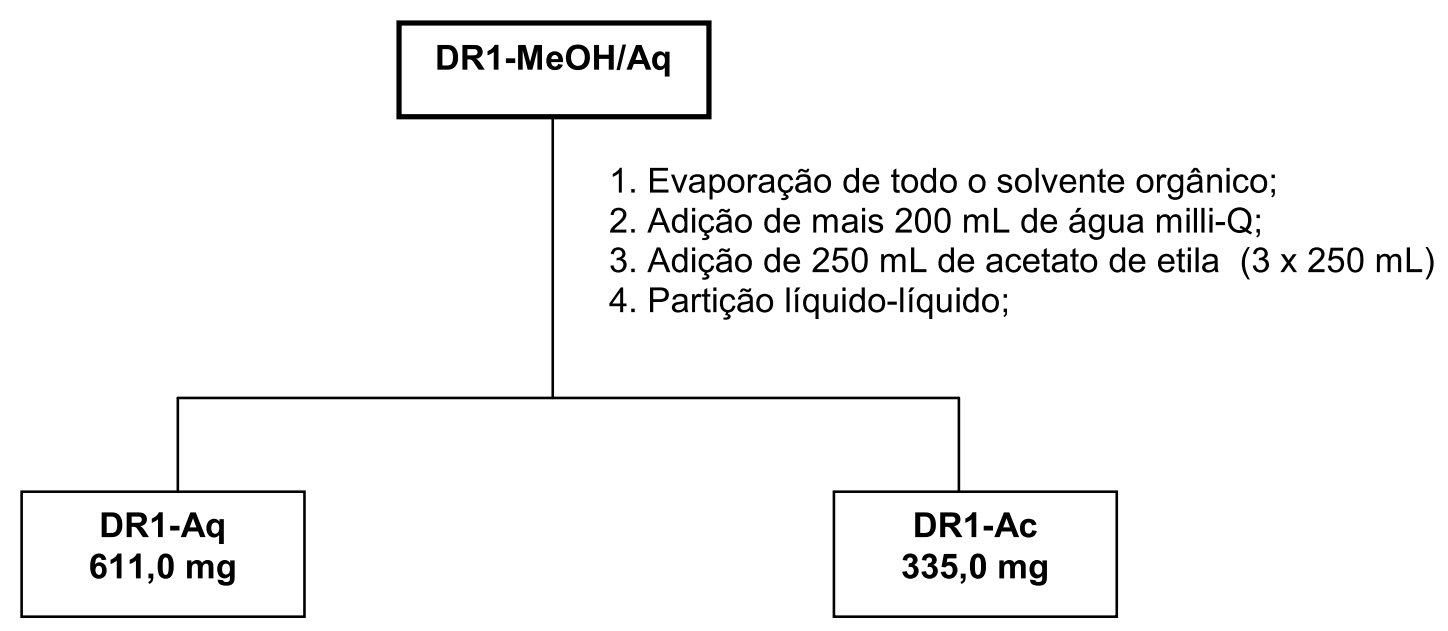

Figura 17. Fluxograma de obtenção dos extratos DR1-Aq e DR1-Ac.

Após todo o processo de obtenção dos extratos, estes foram cuidadosamente analisados por CCD e comparados com padrões de aminoácidos e esteróis. As análises foram feitas em placas de sílica gel de dimensões 20 × 20 $\mathrm{cm}$ com indicador ultravioleta na região de $254 \mathrm{~nm}$. Foi utilizado o colesterol como padrão de comparação na análise do extrato éter de petróleo. Já para o extrato aquoso foi utilizada a timidina como padrão. $O$ extrato acetato de etila, por apresentar um caráter de polaridade médio entre os extratos éter de petróleo e aquoso, foi analisado com ambos os padrões. As placas foram eluídas com diferentes composições de misturas eluentes e todas elas, após eluição, foram observadas a luz UV em $254 \mathrm{~nm}$ e $365 \mathrm{~nm}$ e reveladas com diferentes reagentes específicos. Todo o processo está descrito na tabela 3: 
Tabela 3: Extratos brutos da amostra DR1: Composições eluentes e padrões de comparação utilizados

\begin{tabular}{c|c|c} 
Extrato & Composições eluentes & Padrão; composição eluente \\
\hline DR1-EP & éter de petróleo/ EtOAc: $90: 10,70: 30$ e & $\begin{array}{c}\text { Colesterol; } \\
\text { E.P/EtOAc/MeOH } 50: 45: 5\end{array}$ \\
\hline DR1-Ac & éter de petróleo/ EtOAc, $70: 30$ e 50:50 & $\begin{array}{c}\text { Timidina; } \mathrm{E} . \mathrm{P}^{\prime} \mathrm{CH}_{2} \mathrm{Cl}_{2} / \mathrm{EtOAc}, 25: 25: 50 ; \\
\text { Colesterol; } \mathrm{E} . \mathrm{P}_{\mathrm{CH}} \mathrm{Cl}_{2} / \mathrm{EtOAc}, 40: 30: 30\end{array}$ \\
\hline DR1-Aq & $\mathrm{CH}_{2} \mathrm{Cl}_{2} / \mathrm{MeOH}, 90: 10$ e $70: 30$ & Timidina; $\mathrm{CH}_{2} \mathrm{Cl}_{2} / \mathrm{MeOH}, 70: 30$
\end{tabular}

Dos três extratos analisados, apenas o extrato aquoso apresentou um perfil cromatográfico de pouco interesse para o estudo, uma vez que foram observadas somente manchas com tempo de retenção menor que a da timidina, indicando provavelmente a presença de metabólitos primários ligados a açúcares, que são classes de compostos comuns. Além do mais, grande parte da massa do extrato aquoso mostrou ser constituída de sais. Os extratos éter de petróleo e acetato de etila (DR1-EP e DR1-Ac, respectivamente) apresentaram perfis químicos interessantes frente aos padrões. Em função destes resultados, o extrato EtOAc foi selecionado para ser fracionado.

O extrato DR1-Ac, contendo $335,0 \mathrm{mg}$ de massa, foi submetido a cromatografia em coluna de gel Sephadex LH-20, com eluição isocrática de $\mathrm{MeOH}$. Com o auxilio de um coletor automático, as frações de 500 gotas foram coletadas, por ação da gravidade, gerando 95 tubos de ensaio. O solvente de eluição foi evaporado em um sistema SpeedVac®. As frações foram analisadas por CCD em sílica gel com indicador UV. A análise compreendeu eluição com 
$\mathrm{CH}_{2} \mathrm{Cl}_{2} / \mathrm{MeOH}$ 90:10, observação a luz UV em 254 e $365 \mathrm{~nm}$ e revelação com ninidrina. As frações foram reunidas de acordo com suas características químicas, gerando onze frações finais, denominadas de DR1-Ac-1 a DR1-Ac-11. Estas frações resultantes do processo foram transferidas para frascos, foram evaporadas, secas em um dessecador a vácuo e tiveram suas massas determinadas. Por fim, foram novamente analisadas por CCD e reveladas com ninidrina e ácido fosfomolíbdico. O processo está ilustrado na figura 18.

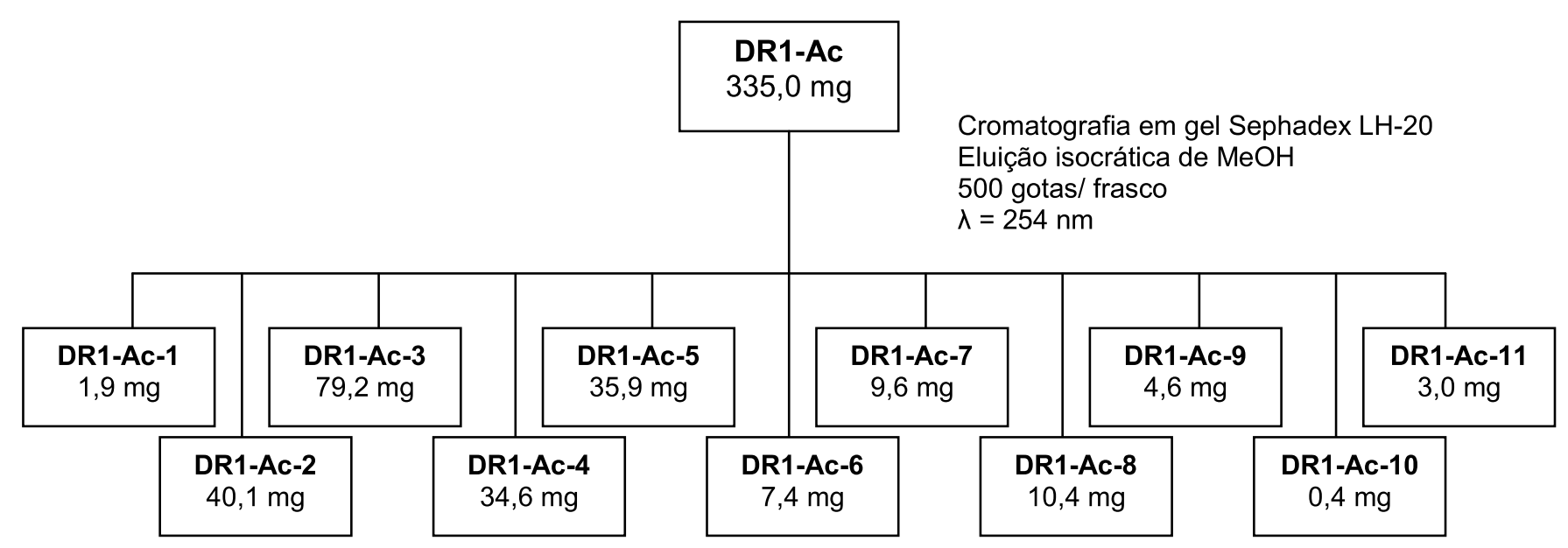

Figura 18. Fracionamento do extrato DR1-Ac por cromatografia em gel Sephadex LH-20.

A análise por CCD de cada fração final indicou manchas avermelhadas intensas provenientes da revelação com ninidrina, significando a predominância de metabólitos primários (aminoácidos e nucleosídeos) cuja natureza não é interessante ao estudo. Em função destes indicadores, descartou-se o estudo dessas frações.

A fração DR1-EP foi submetida a uma separação por cromatografia em coluna Sep Pak® de sílica gel (figura 19). No processo foi utilizado um gradiente de "P" (EtOAc/MeOH 9:1) em "A" (éter de petróleo/ $\mathrm{CH}_{2} \mathrm{Cl}_{2}$ ). Foram obtidas 96 
frações, contendo $8 \mathrm{~mL}$ cada. As frações foram analisadas por CCD sob eluição de uma mistura de éter de petróleo, $\mathrm{CH}_{2} \mathrm{Cl}_{2}$, EtOAc e $\mathrm{MeOH}$, em composições variadas. As frações foram aplicadas sobre cromatofolhas de Si com indicador ultravioleta, as quais foram observadas sob luz UV em $254 \mathrm{~nm}$. Desta maneira, as frações foram reunidas conforme seus padrões de absorção e tempos de retenção semelhantes. Foram obtidas nove frações, de DR1-EP-1 a DR1-EP-9. Estas frações apresentaram um perfil bastante complexo, contendo variações de polaridades consideráveis em uma mesma fração, de acordo com interações com a sílica gel.

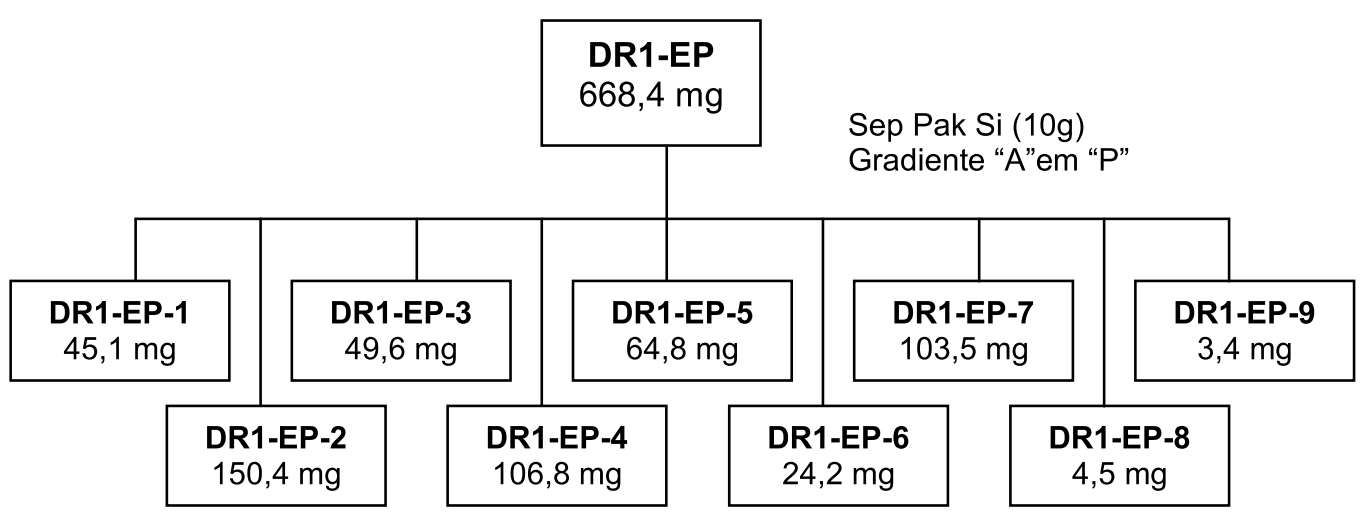

Figura 19. Fracionamento do extrato de éter de petróleo da esponja $D$. robusta.

A fração DR1-EP-5 resultou da reunião de frações semelhantes eluídas em uma proporção de polaridade média (gradiente de hexano, $\mathrm{CH}_{2} \mathrm{Cl}_{2}$, EtOAc e $\mathrm{MeOH}$ ). Com o intuito de se purificar esta fração, foram realizados vários testes de solubilidade em hexano, $\mathrm{CH}_{2} \mathrm{Cl}_{2}, \mathrm{CHCl}_{3}$, EtOAc, $\mathrm{ACN}$, acetona, $\mathrm{MeOH}, \mathrm{EtOH}$, DMSO e $\mathrm{H}_{2} \mathrm{O}$, tanto puros quanto em misturas destes solventes. A fração mostrou-se insolúvel em todos os testes, sendo parcialmente solúvel em $\mathrm{MeOH}$, resultando em uma solução límpida amarelada com partículas brancas sólidas suspensas. Desta forma, o frasco contendo a mistura foi submetido à 
centrifugação e separou-se a parte insolúvel (DR1-EP-5A) da parte solúvel em MeOH (DR1-EP-5B). A fração DR1-EP-5A demonstrou ser solúvel somente em piridina (figura 20).

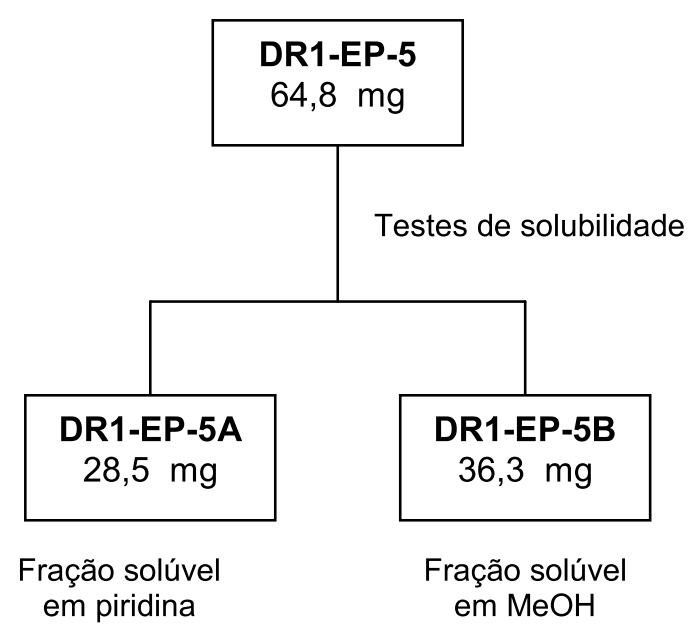

Figura 20. Separação das frações DR1-EP-5A e -5B, por solubilidade.

A fração DR1-EP-5A demonstrou caráter anfifílico através da análise por CCD. Foi então dissolvida em piridina e enviada para análise por $R M N-{ }^{1} H$, que demonstrou sinais intensos na região de $\delta 1.26$ indicando metilenos em uma cadeia longa, e um sinal em $\delta 8.57$ correpondente a um grupo $\mathrm{N}-\mathrm{H}$, para o composto majoritário (Figura 1, p. 6 - 11, Volume 2). Tal análise permitiu-nos identificar parcialmente a substância da fração DR1-EP-5A-4 como sendo uma mistura de ceramidas. (ver determinação estrutural na página 62).

Desta forma, realizou-se uma reação de esterificação dos grupos hidroxila (figura 21), para tornar a fração solúvel em solventes orgânicos apolares, com o intuito de viabilizar a separação por HPLC. Foram utilizados $15,0 \mathrm{mg}$ dos cristais dissolvidos em 1,5 mL de piridina e 1,5 mL de anidrido acético, sob agitação em temperatura ambiente, por 24 horas. 


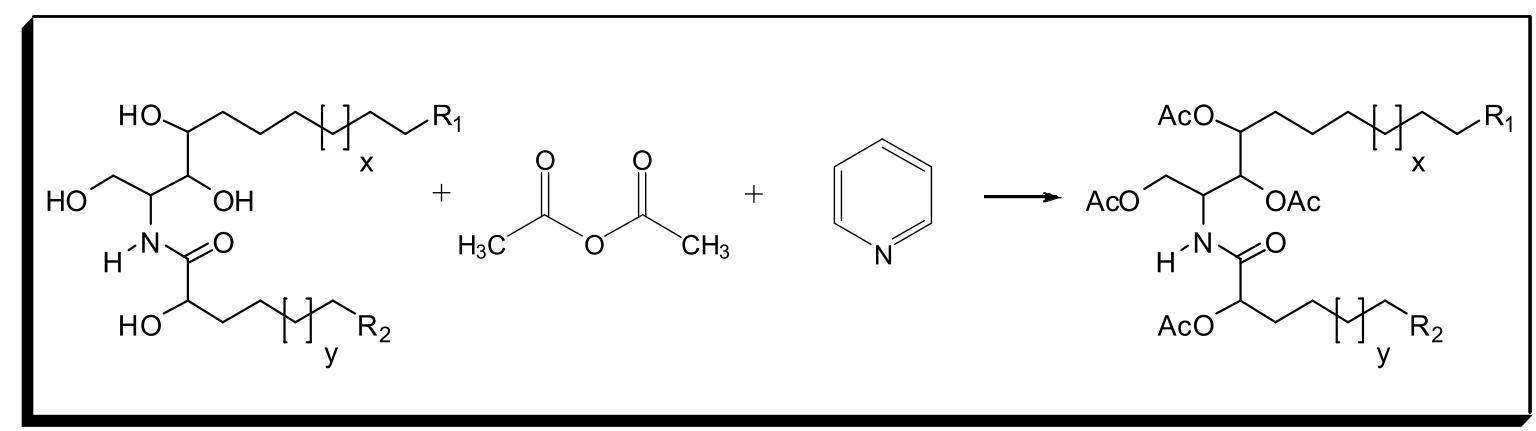

Figura 21. Reação de acetilação da fração DR1-EP-5A, em piridina e anidrido acético.

Com o objetivo de pré-purificar a amostra, a mistura foi submetida à cromatografia em coluna Sep Pak sílica gel (1g), através de um gradiente de $\mathrm{MeOH}, \mathrm{CH}_{2} \mathrm{Cl}_{2}$ e éter de petróleo. Foram coletadas 105 frações, sendo uma a uma analisada por CCD (eluição: hexano/EtOAc 9:1). As frações foram devidamente reunidas em seis finais, DR1-EP-5A-1 a DR1-EP-5A-6 (figura 22). Através de análises das frações por $\mathrm{RMN}^{-1} \mathrm{H}$, foi possível identificar o composto acetilado na fração DR1-EP-5A-4.

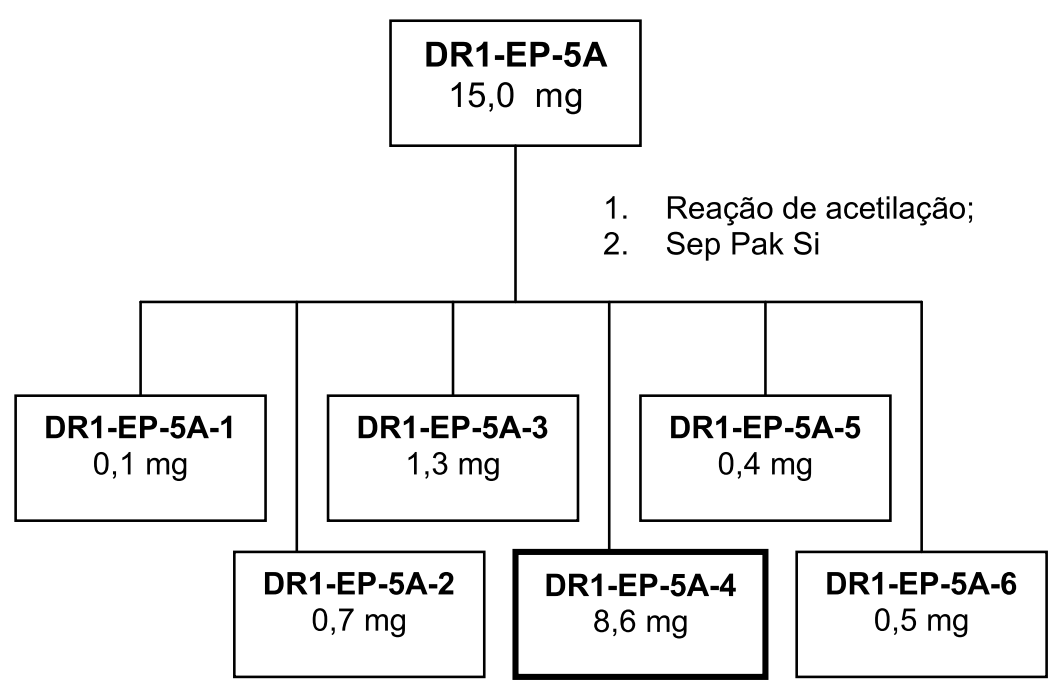

Figura 22. Isolamento do composto acetilado, DR1-EP-5A-4, por Sep Pak. 
A fração DR1-EP-5A-4 foi submetida a análise por LC-MS (tabela 4), utilizando-se um fluxo de $1,0 \mathrm{~mL} / \mathrm{min}$ do eluente em coluna de fase normal (sílica gel) e no modo $\mathrm{APCi}^{+}$para a análise de massa atômica.

Tabela 4: Dados da análise por LC-MS da fração DR1-EP-5A-4.

\begin{tabular}{|c|l|l|}
\hline Condições de análise & LC & MS \\
\hline & Coluna: Waters Sílica $\mu-$ & Modo: APCi ${ }^{+}$contínuo \\
& Corona: 3,0 \\
DR1-EP-5A-4 & Eluição Isocrática: & Cones: 25 e $50 \mathrm{~V}$ \\
& Hexano/EtOAc/MeOH & Extractor: 3.0 \\
& $70: 27: 3$ & Source Temp: $100 .{ }^{\circ} \mathrm{C}$ \\
& Fluxo: $1 \mathrm{~mL} / \mathrm{min}$ & APCi Probe Temp: $200^{\circ} \mathrm{C}$ \\
& Scan Time: $1 \mathrm{~s}$ \\
\hline
\end{tabular}

Com o intuito de facilitar o processo de determinação estrutural da ceramida isolada, foi realizada, com uma alíquota do composto original (DR1-EP-5A), uma reação de metanólise (Ahmed et al., 2008). Tomou-se 3,0 mg da fração original (não acetilada), a qual foi submetida a refluxo com $10,0 \mathrm{~mL}$ de $\mathrm{MeOH}$ e uma solução $1 \mathrm{~N}$ de $\mathrm{HCl}$, por quatro horas. Em seguida, a mistura foi extraída três vezes com hexano e evaporada, gerando a fração hexânica, DR1-EP-5A-Hex, de massa igual a 1,2 mg. À parte aquosa remanescente foi adicionado um excesso de solução de $\mathrm{NaOH} 10 \%$, até atingir $\mathrm{pH}-12,0$. A fase aquosa alcalinizada foi extraída com $\mathrm{CH}_{2} \mathrm{Cl}_{2}$ por três vezes. Após o solvente ter sido evaporado, obtevese a fração DR1-EP-5A-TD, de massa igual a 1,4 mg, segundo a ilustração a seguir: 


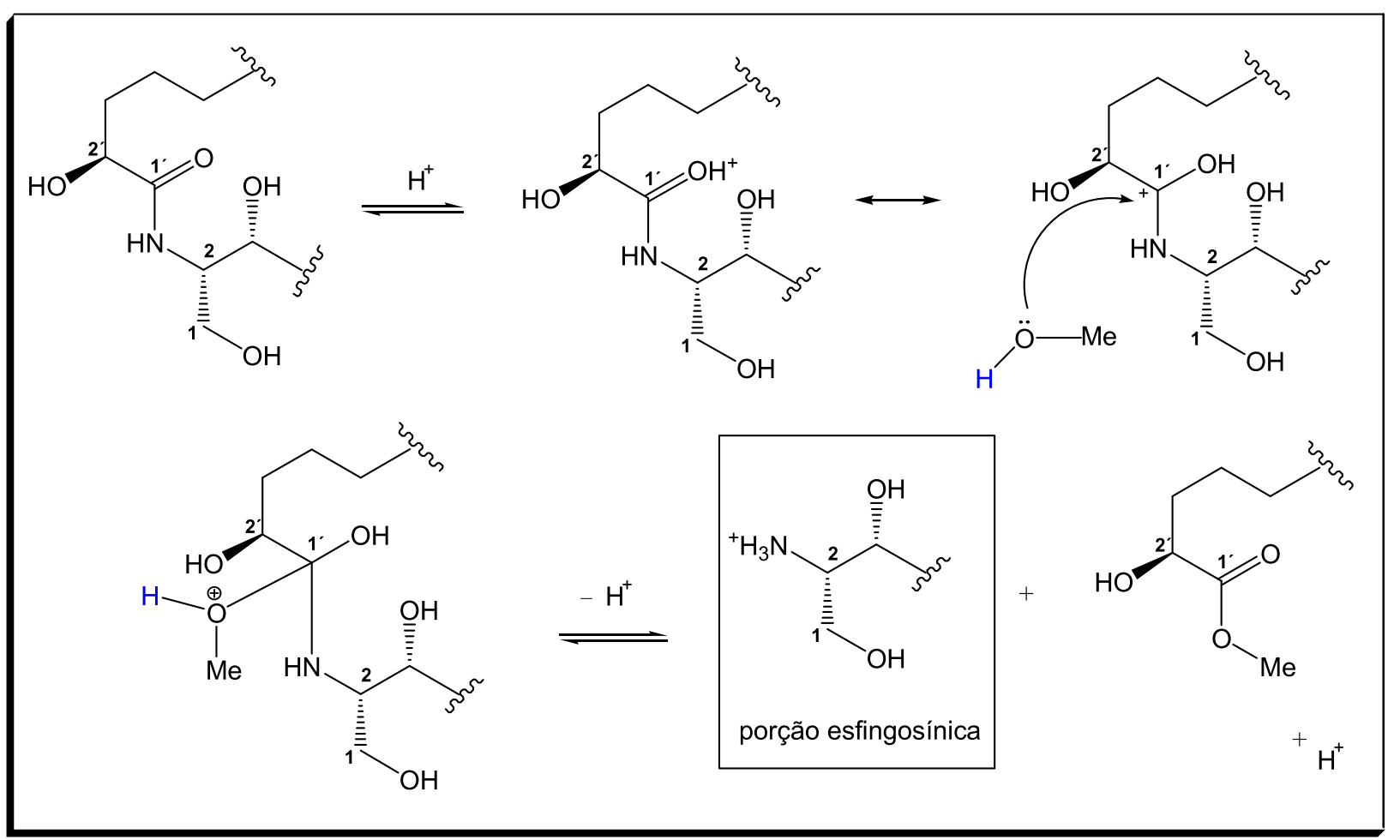

Figura 23. Mecanismo da reação de metanólise de DR1-EP-5A, gerando a fração esfingosínica DR1-EP-A-4-TD.

A porção esfingosínica foi então submetida a análises bidimensionais de RMN $-{ }^{1} \mathrm{H},-{ }^{13} \mathrm{C}$ e espectrometria de massas (Figuras 9 e 10, pp. $25-29$, Volume 2), podendo ter desta forma sua estrutura determinada. 


\section{RESULTADOS E DISCUSSÃO}

5.1. Isolamento e identificação dos compostos isolados da amostra 2 de Dysidea robusta - DR2.

\subsubsection{Fracionamento do extrato DR2-AQ-6}

A fração aquosa DR2-AQ-6 foi submetida a análise por HPLC-DA (condições : coluna Phenyl- Inertsil - Phenomenex; gradiente de $\mathrm{H}_{3} \mathrm{O}^{+}$(ácido fórmico) : MeOH; fluxo = $1 \mathrm{~mL} / \mathrm{min} ; \lambda=254$ e $280 \mathrm{~nm}$ ). Foram obtidas as frações DR2-AQ-6A a DR2-AQ-6F, cujos picos majoritários corresponderam às frações DR2-AQ-6B e DR2-AQ-6D. A fração DR2-AQ-6A apresentou-se como uma mistura muito complexa, cuja separação não foi possível. E as frações DR2-AQ$6 \mathrm{C}$ e -6F apresentaram-se com quantidades em massa muito pequenas. Assim sendo, as frações DR2-AQ-6B e DR2-AQ-6D foram analisadas por RMN, a primeira apresentando-se como uma fração quase pura e a segunda, como uma mistura de vários compostos.

5.1.1.1. Fracionamento de DR2-AQ-6D e isolamento dos compostos: ácido pirodisinóico B (20), ácido pirodisinóico (18) e ácido isopirodisinóico (19).

A fração DR2-AQ-6D (3,7 mg) foi repurificada (condições: coluna CSCInertsil 150A/ODS2, $5 \mu \mathrm{m}, \quad 25 \times 0.94 \mathrm{~cm}$, com eluição de $(0.05 \%$ $\mathrm{TFA} / \mathrm{H}_{2} \mathrm{O}$ )/MeCN, $\lambda=254 \mathrm{~nm}$ ) fornecendo uma mistura de ácido pirodisinóico (18) e do ácido isopirodisinóico (19) e o ácido pirodisinóico B (20) (0,2mg) . 


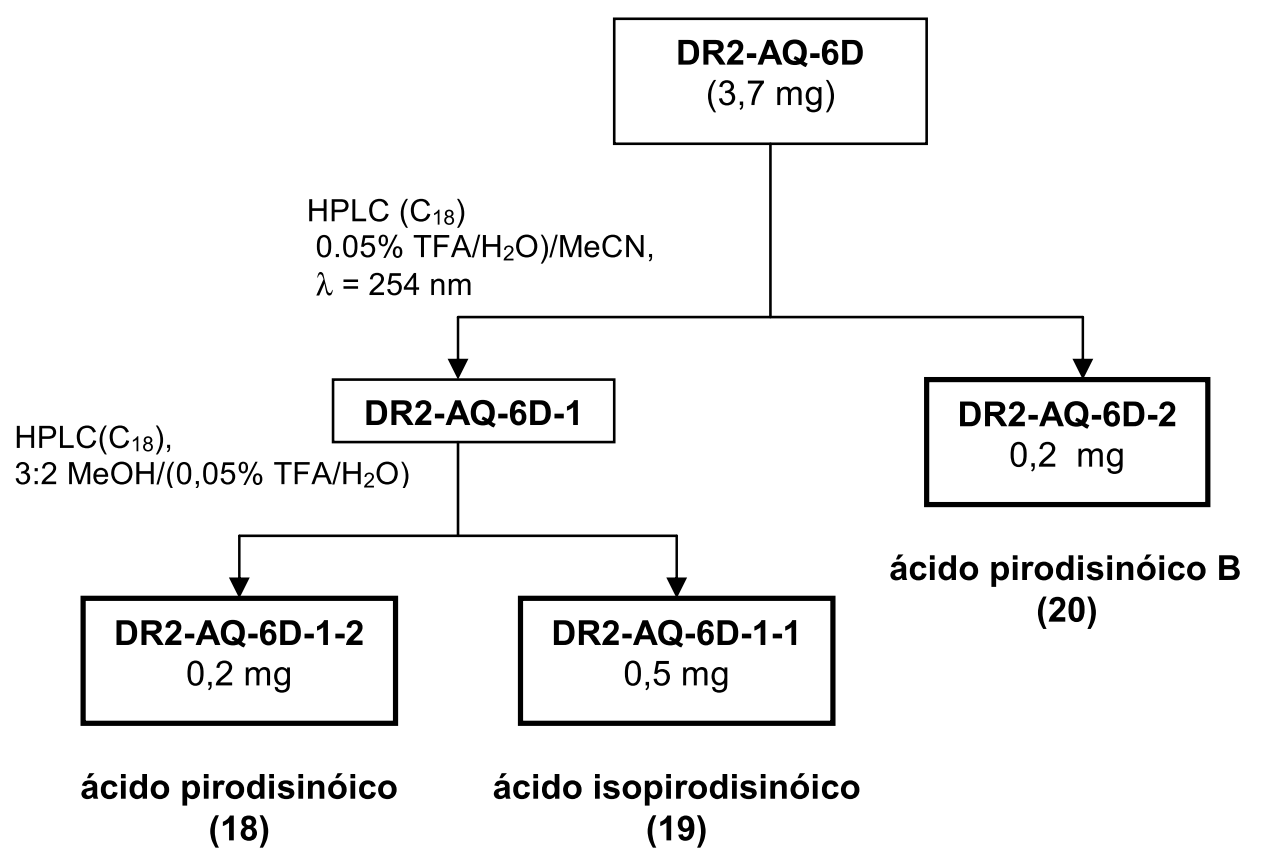

Figura 24. Esquema de purificação e obtenção de 18, 19 e 20.

A mistura de 18 e 19 foi fracionada por HPLC em fase reversa $\left(C_{18}\right)$, usando a mesma coluna em uma mistura $3: 2 \mathrm{MeOH} /\left(0,05 \% \mathrm{TFA} / \mathrm{H}_{2} \mathrm{O}\right)$ como eluentes, obtendo-se o ácido pirodisinóico (18) (0,2 mg) e o ácido isopirodisinóico (19) (0,5

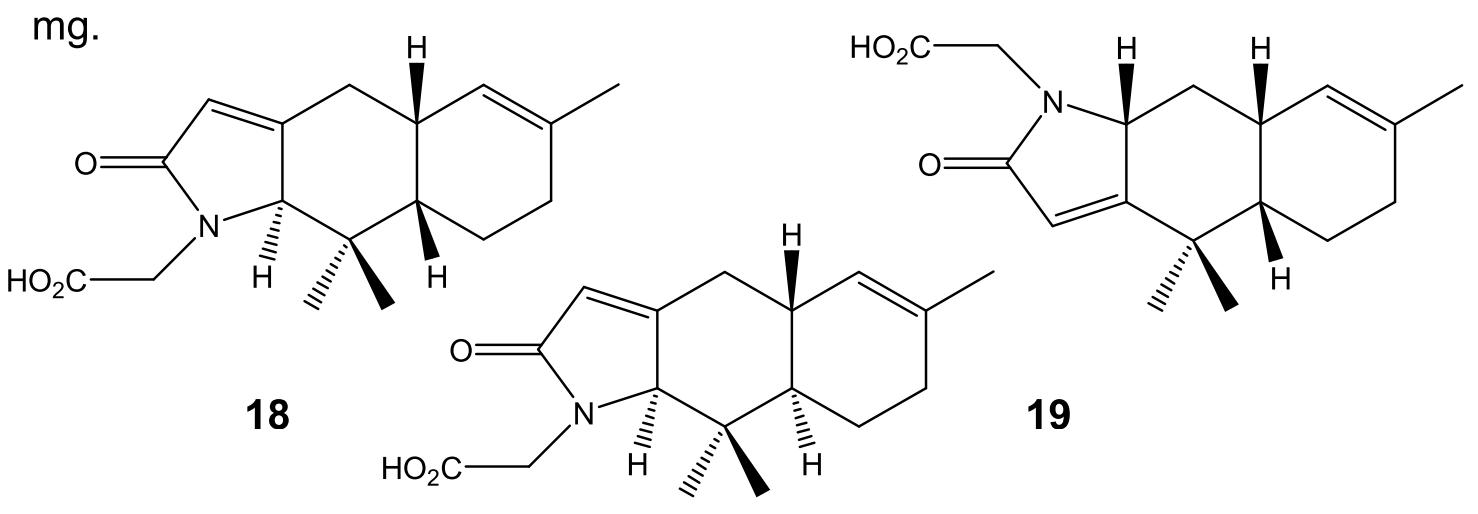
20

Figura 25. Estrutura dos compostos: ácido pirodisinóico (18), ácido isopirodisinóico (19) e ácido pirodisinóico B (20). 


\subsection{Determinação estrutural do ácido pirodisinóico (18)}

O espectro de massas da fração DR2-AQ-6D-1-2 (ácido pirodisinóico) apresentou o íon negativo [M-H] em $\mathrm{m} / \mathrm{z} 288.1598$ (Figura 18, p.48, Volume 2). A análise dos espectros de $\mathrm{RMN}^{-1} \mathrm{H}\left(\mathrm{DMSO}^{-} d_{6}, 600 \mathrm{MHz}\right.$ - Figura 21, pp. 54 - 58, Volume 2) e HSQC (Figura 14, pp. 41 - 42, Volume 2) forneceu os seguintes sinais:

-um singlete em $\delta 5.78$ referente a um hidrogênio ligado a um carbono $\mathrm{sp}^{2}$;

- um duplo dubleto em $\delta 2.71(J=4.9,13.8 \mathrm{~Hz})$ e um tripleto em $\delta 2.14(\mathrm{~J}=$ 13.8 Hz) referentes a dois hidrogênios ligados ao mesmo carbono ( $\delta 31.3)$;

- um multipleto em $\delta 2.36$ referente a um hidrogênio ligado a um carbono $\mathrm{sp}^{3}$ $(\delta 32.9)$;

- um dubleto em $\delta 5.41(J=4.3 \mathrm{~Hz})$ referente a um hidrogênio ligado a um carbono $\mathrm{sp}^{2}(\delta 125.1)$

- um multipleto em $\delta 1.98$ referente a dois hidrogênios ligados ao mesmo carbono ( $\delta 31.5)$;

- um dubleto em $\delta 1.76(\mathrm{~J}=11.5 \mathrm{~Hz})$ e um multipleto em $\delta 1.58$, referentes a dois hidrogênios distintos ligados ao mesmo átomo de carbono ( $\delta$ 18.0);

- um dubleto em $\delta 1.38(\mathrm{~J}=11.0 \mathrm{~Hz})$ ligado a um carbono em $\delta 46.1$;

- dois singletes, sendo um em $\delta 3.97$ referente a um hidrogênio ligado ao carbono em $\delta 67.2$ e outro em $\delta 1.61$, referente a três hidrogênios de um grupo metil $(\delta 23.0)$

- dois singletes, um em $\delta 0.70$ e outro em $\delta$ 1.18, referentes a três hidrogênios cada (grupo metil); ligados ao carbono em $\delta 20.6$ e $\delta$ 27.0, respectivamente. 
- dois dubletes, um em $\delta 4.27(J=8.0 \mathrm{~Hz})$ e outro em $\delta 3.81(\mathrm{~J}=8.0 \mathrm{~Hz})$ referentes a dois hidrogênios ligados ao mesmo carbono ( $\delta 44.2)$;

- um singlete em $\delta 12.72$ referente a um hidrogênio ligado a oxigênio (hidroxila de um grupo carboxila).

O espectro de $\mathrm{RMN}-{ }^{13} \mathrm{C}$ (DMSO- $d_{6}, 150 \mathrm{MHz}$ - Figura 12, pp. 36-39, Volume 2) forneceu os seguintes sinais: em $\delta 172.6$ e 170.8, referentes a carbonos carbonílicos e sinais em $\delta 67.2$ e 44.2 de carbonos ligados a nitrogênio. Os sinais em $\delta 20.6,23.0$ e 27.0 referem-se a carbonos $\mathrm{sp}^{3}$ de grupos metila e os sinais em $\delta 31.5,18.0,31.3$ representam carbonos metilênicos. Os carbonos metínicos referem-se aos sinais em $\delta 32.9$ e 46.1. Sinais em $\delta 117.8,125.1,133.4$ e 161.9 referem-se a carbonos $\mathrm{sp}^{2}$ e o sinal em $\delta 40.0$ corresponde a um carbono tetrassubstituído.

O espectro de RMN do tipo COSY ${ }^{1} \mathrm{H}-{ }^{1} \mathrm{H}$ (DMSO-d $6,600 \mathrm{MHz}-$ Figura 13, p. 40, Volume 2) forneceu as seguintes acoplamentos:

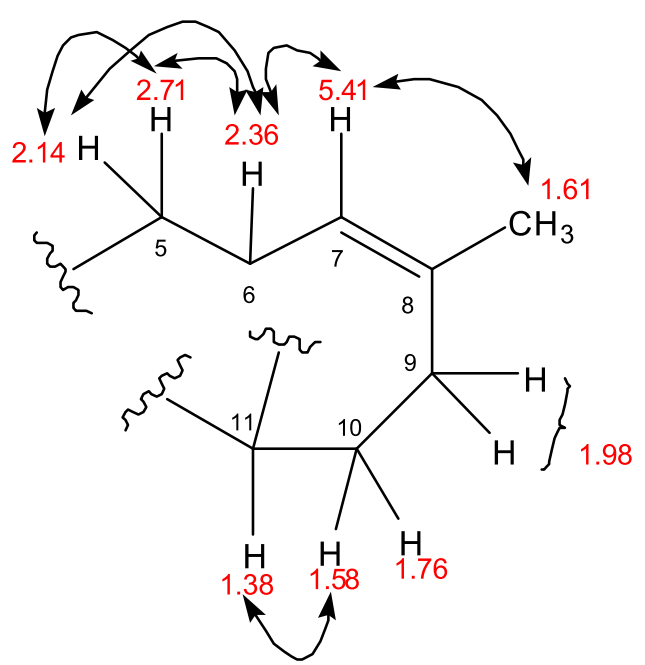

Figura 26. Acoplamentos observados no espectro de RMN - COSY da fração DR2-AQ-6D-1-2.

Uma busca no banco de dados Marinlit, utilizando o fragmento estrutural determinado pela análise do espectro COSY levou-nos a encontrar a estrutura do 
ácido pirodisinóico (18) como uma potencial estrutura relacionada ao composto DR2-AQ-6D-1-2.

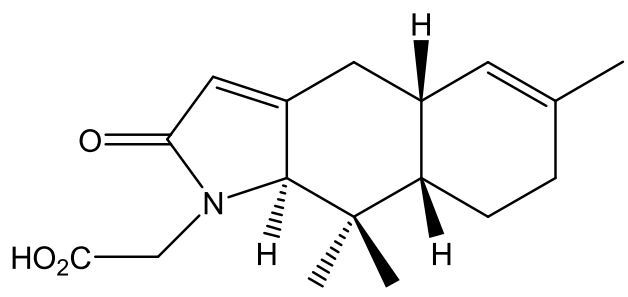

Figura 27. Estrutura do ácido pirodisinóico (18)

Através de comparação com dados da literatura, foi possível identificar a estrutura do composto DR2-AQ-6D-1-2 como sendo o ácido pirodisinóico. Através de comparação entre os dados espectroscópicos (Tabelas 5 e 6), verificou-se que a estrutura planar de DR2-AQ-6D-1-2 era idêntica àquela previamente registrada para o ácido pirodisinóico (18) isolado de uma esponja Dysidea sp. coletada nas Filipinas. Entretanto, na publicação original os autores não haviam determinado a estereoquímica relativa de 18 (Goetz, et al., 2001).

Tabela 5. Dados comparativos de $\mathrm{RMN}^{1} \mathrm{H}$ para o ácido pirodisinóico, segundo Goetz, et al, 2001.

\begin{tabular}{lll}
\hline \multicolumn{1}{c}{ Átomo } & \multicolumn{1}{c}{ DR2-AQ-6D-1-2 } & \multicolumn{1}{c}{18} \\
\hline $\mathrm{H}-3$ & $5.78(\mathrm{~s})$ & $5.77(\mathrm{~m})$ \\
$\mathrm{H}-4$ & & \\
$\mathrm{H}-5 \mathrm{eq}$ & $2.71 \mathrm{~m}(\mathrm{dd}, 4.9,13.8)$ & $2.70(\mathrm{dd}, 4.9,14.1)$ \\
$\mathrm{H}-5 \mathrm{ax}$ & $2.14(\mathrm{t}, 13.8)$ & $2.13(\mathrm{ddd}, 14.1,2.2,0.5)$ \\
$\mathrm{H}-6$ & $2.36(\mathrm{~m})$ & $2.35, \mathrm{~m}$ \\
$\mathrm{H}-7$ & $5.41(\mathrm{~d}, 4.3)$ & $5.40, \mathrm{dd}(1.6,5.4$ \\
$\mathrm{H}-9_{\mathrm{eq}}$ & $1.98(\mathrm{~m})$ & $1.98, \mathrm{~m}(7.0)$ \\
$\mathrm{H}-9_{\mathrm{ax}}$ & $1.98(\mathrm{~m})$ & $1.98, \mathrm{~m}(7.0)$ \\
$\mathrm{H}-10_{\mathrm{eq}}$ & $1.76(\mathrm{bd}, 11.5)$ & $1.76, \mathrm{~m}$ \\
$\mathrm{H}-10_{\mathrm{ax}}$ & $1.58(\mathrm{~m})$ & $1.56, \mathrm{~m}$ \\
$\mathrm{H}-11$ & $1.38(\mathrm{~d}, 11.0)$ & $1.37, \mathrm{~m}$ \\
$\mathrm{H}-13$ & $3.97(\mathrm{~s})$ & $3.97, \mathrm{~s}$ \\
$\mathrm{H}-14$ & $1.61(\mathrm{~s})$ & $1.60, \mathrm{~s}$ \\
$\mathrm{Me} 15_{\mathrm{ax}}$ & $0.70(\mathrm{~s})$ & $0.70, \mathrm{~s}$ \\
$\mathrm{Me} 16_{\mathrm{eq}}$ & $1.18(\mathrm{~s})$ & $1.17, \mathrm{~s}$ \\
$\mathrm{H}-17 \mathrm{a}$ & $4.27(\mathrm{~d}, 18.0)$ & $4.27, \mathrm{~d}(18.0)$ \\
$\mathrm{H}-17 \mathrm{~b}$ & $3.81(\mathrm{~d}, 18.0)$ & $3.80, \mathrm{~d}(18.0)$ \\
$\mathrm{CO}{ }_{2} \mathrm{H}$ & $12.72(\mathrm{~s})$ &
\end{tabular}


Tabela 6. Dados comparativos de $\mathrm{RMN}-{ }^{13} \mathrm{C}$ para o ácido pirodisinóico, segundo Goetz, et al, 2001.

\begin{tabular}{crr}
\hline Átomo & DR2-AQ-6D-1-2 & $\mathbf{1 8}$ \\
\hline 2 & 172.6 & 172.5 \\
3 & 117.8 & 117.7 \\
4 & 161.9 & 161.7 \\
5 & 31.3 & 31.0 \\
6 & 32.9 & 32.6 \\
7 & 125.1 & 124.9 \\
8 & 133.4 & 133.3 \\
9 & 31.5 & 31.2 \\
10 & 18.0 & 17.6 \\
11 & 46.1 & 45.8 \\
12 & 40.0 & 39.7 \\
13 & 67.2 & 67.0 \\
14 & 23.0 & 22.7 \\
15 & 20.6 & 20.3 \\
16 & 27.0 & 26.7 \\
17 & 44.2 & 44.0 \\
18 & 170.8 & 170.8 \\
\hline
\end{tabular}

Estas atribuições foram confirmadas pelas análises dos espectros HSQC (Figura 14, pp. 41-42, Volume 2) e HMBC (Figura 15, pp. 43-44, Volume 2).

Análises do espectro tROESY do ácido pirodisinóico (18, Figura 16, pp. 4546, Volume 2), por nós isolado de D. robusta (DR2-AQ-6D-1-2), mostraram uma junção cis entre dois anéis de seis membros, tendo em vista o acoplamento dipolar entre H-6 ( $\delta$ 2.36) e H-11 ( $\delta$ 1.38). Também pôde-se observar no espectro tROESY correlações de $\mathrm{H}-13$ ( $\delta 3.97)$ com os hidrogênios $\mathrm{H}-5_{\mathrm{ax}}(\delta 2.14)$ e $\mathrm{H}-10_{\mathrm{ax}}$ $(\delta 1.58)$ e também com Me-16 eq $(\delta 1.18)$. A partir de tais observações estabeleceuse que a estereoquímica relativa de 18 requer que os dois anéis de seis membros estejam na conformação indicada, com uma junção cis dos anéis de 6 membros e que N-1 esteja em orientação equatorial (figura 28). 


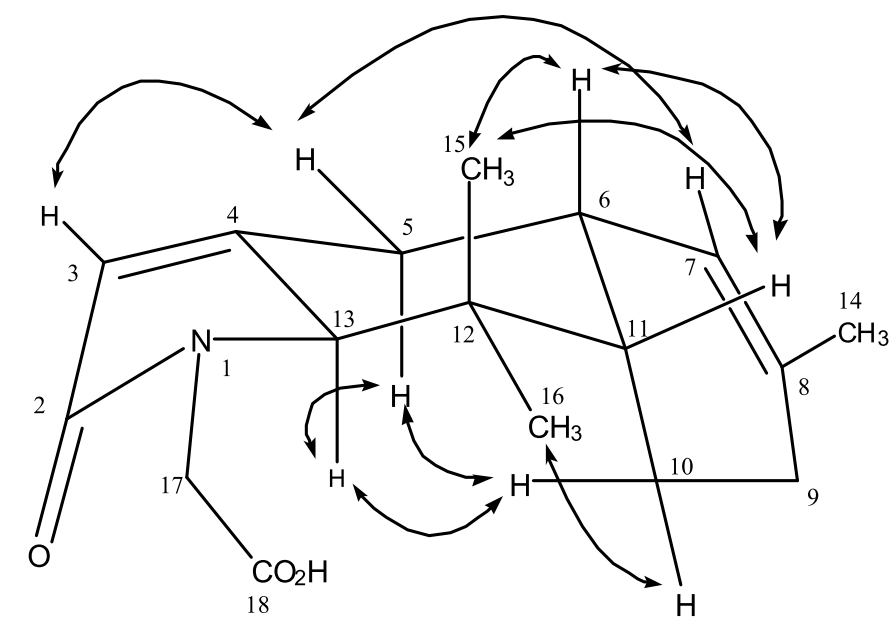

Figura 28. Correlações do ácido pirodisinóico (DR2-AQ-6D-1-2) observadas no espectro tROESY.

Uma vez que a medida de $[\alpha]^{25} \mathrm{D}+18.9^{\circ}(c \quad 0.13, \mathrm{MeOH})$ obtido para 18 confere favoravelmente com o valor $[\alpha]^{25} \mathrm{D}+9.1^{\circ}(c 0.666, \mathrm{MeOH})$ reportado para o ácido pirodisinóico isolado por Goetz et al (2001), ambas provavelmente apresentam a mesma estereoquímica absoluta, ainda indefinida.

\subsubsection{Determinação estrutural do ácido isopirodisinóico (19).}

O espectro de massas em modo negativo HRESIMS da fração DR2-AQ-6D1-1 originou o íon negativo $[\mathrm{M}-\mathrm{H}]^{-}$em $\mathrm{m} / \mathrm{z} 288.1598$, indicando que. a fórmula molecular para 19 era a mesma que aquela do ácido pirodisinóico (18). Além disso, os espectros de $\mathrm{RMN}-{ }^{1} \mathrm{H}$ e $-{ }^{13} \mathrm{C}$ de 18 e 19 mostraram ser bastante similares. 
Tabela 7. Dados espectroscópicos de $\mathrm{RMN}-{ }^{1} \mathrm{H}$ e ${ }^{13} \mathrm{C}$ para o ácido isopirodisinóico (19).

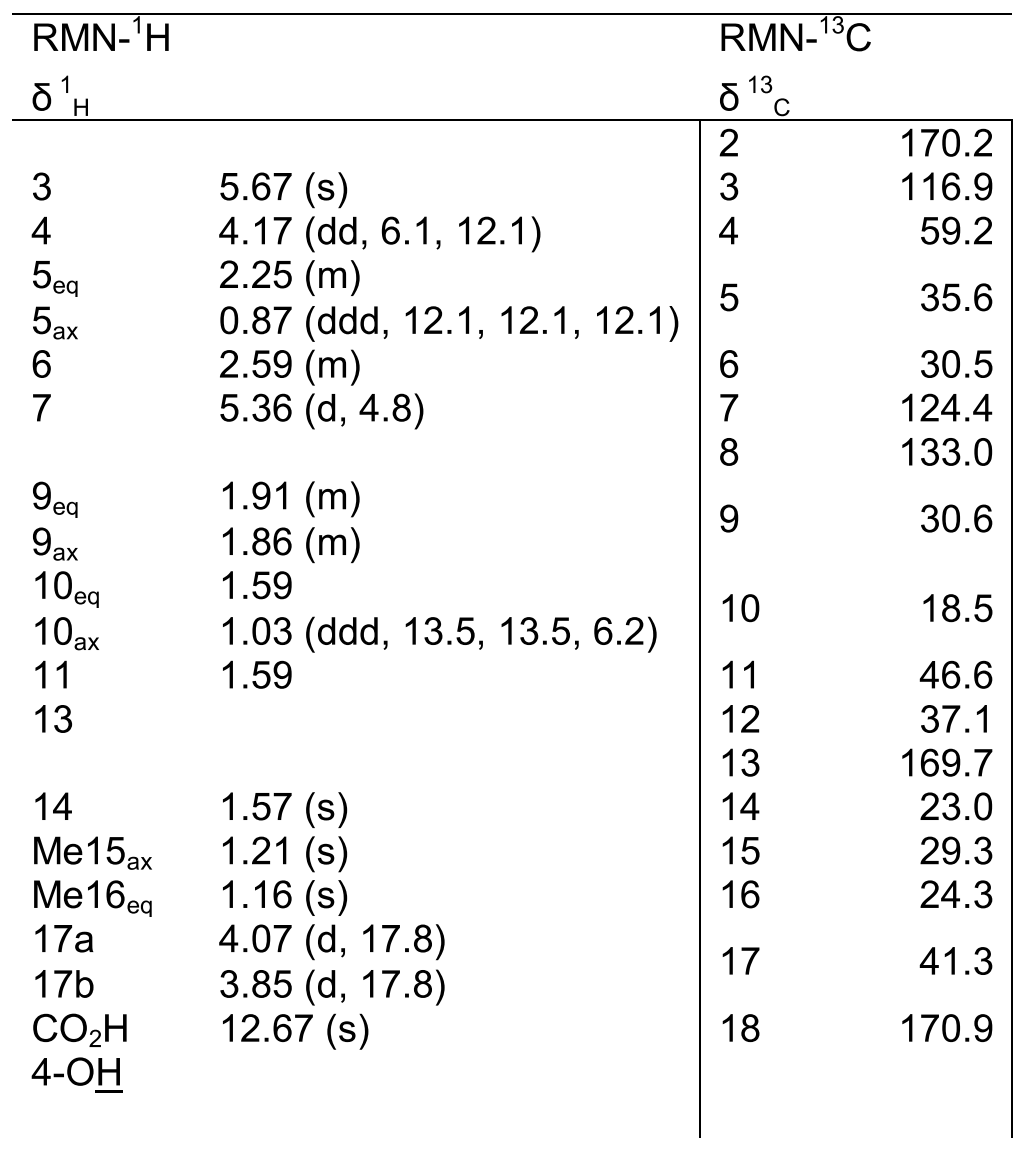

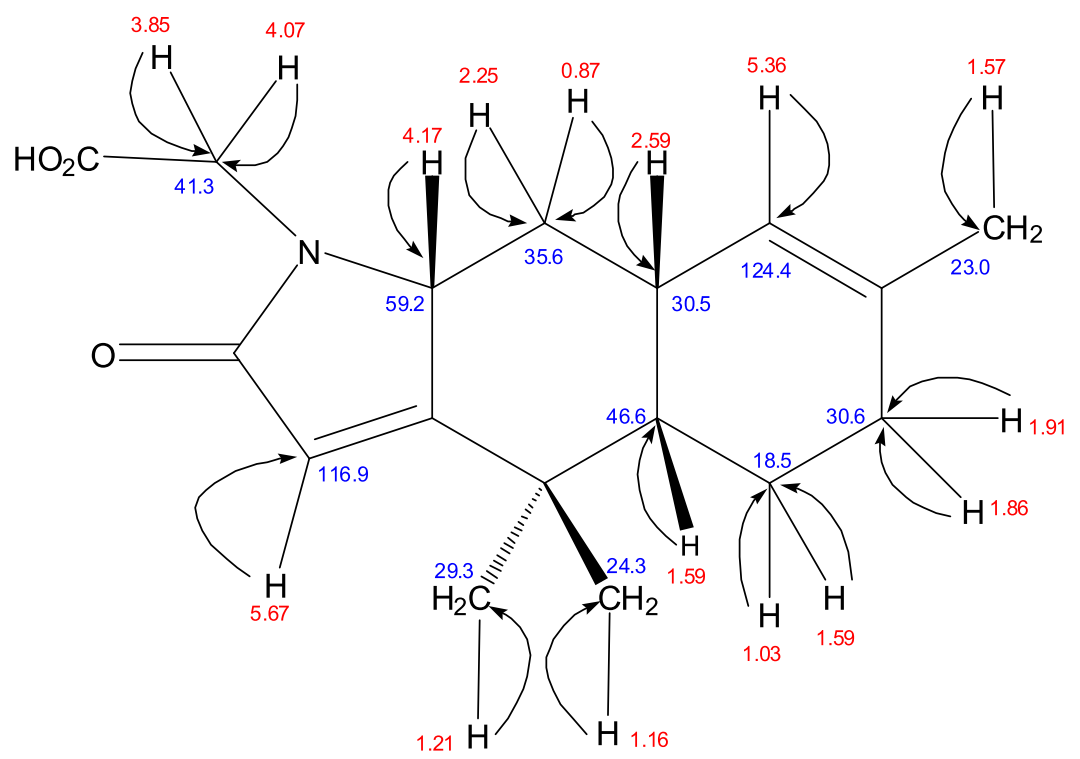

Figura 29. Correlações do ácido isopirodisinóico (DR2-AQ-6D-1-1) observadas no espectro HSQC (Figura 14, pp. 41-42, Volume 2). 
Através do espectro de RMN do tipo COSY (DMSO- $d_{6}, 600 \mathrm{MHz}-$ Figura 13, p. 40, Volume 2), observou-se os seguintes acoplamentos ${ }^{1} \mathrm{H}-{ }^{1} \mathrm{H}$ :

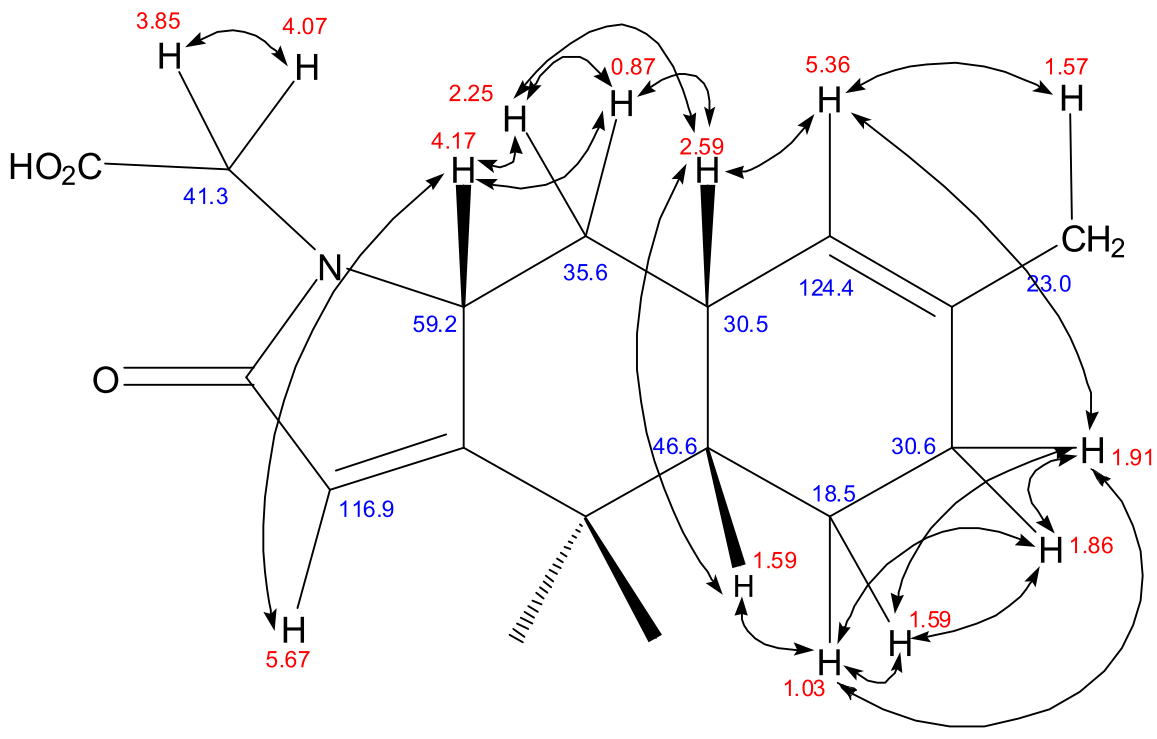

Figura 30. Acoplamentos ${ }^{1} \mathrm{H}-{ }^{1} \mathrm{H}$ do ácido isopirodisinóico (DR2-AQ-6D-1-1) observadas no espectro COSY.

Análises dos espectros de $\mathrm{RMN}-{ }^{1} \mathrm{H},{ }^{13} \mathrm{C}$ e HSQC (Tabelas 11 e 12, p. 61) indicaram que os compostos 18 e 19 apresentavam as mesmas caracteristicas estruturais de C-5 ao C-12. Havia entretanto, algumas diferenças significativas nos espectros de $\mathrm{RMN}^{-1} \mathrm{H}$ e ${ }^{13} \mathrm{C}$ observadas na região da junção dos anéis $6 / 5$. Por exemplo, em 19, os prótons metilênicos de $\mathrm{H}-5$ surgem em $\delta 0.87$ e $\delta 2.25$, enquanto que em 18 são observados em $\delta 2.14$ e $\delta 2.71$. Além disso, C-4 e C-13 apresentam deslocamentos químicos inversos para 18 e 19. Em 19 eles são vistos em $\delta 59.2$ e $169.7\left(\mathrm{RMN}^{13} \mathrm{C}-\right.$ Figura 12, pp. 36-39, Volume 2), enquanto em 18 estes são observados em $\delta 161.9$ e 67.2, respectivamente. Desta forma, pôde-se suspeitar que o ácido isopirodisinóico (19) representa um isômero de posição de 18 na junção 6/5 de anel. Esta hipótese foi confirmada através de análise de dados de RMN-2D de 19. No espectro COSY, os prótons metilênicos de H-5 
surgem não só correlacionados com H-6 ( $(2.59)$ mas, ao contrário de 18, também com H-4 (ס 4.17). Correlações à longa distância observadas no espectro HMBC ${ }^{1} \mathrm{H}-{ }^{13} \mathrm{C}$ estabeleceram que $\mathrm{N}-1$ está ligado a $\mathrm{C}-4, \mathrm{C}-3$ a $\mathrm{C}-13$ e que o $\mathrm{C}-2$ de carbonila está situado entre N-1 e C-3. Essas correlações foram observadas entre

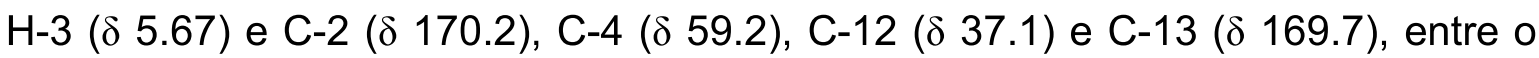
H-4 metínico com C-3 ( $\delta$ 116.9), C-5 ( $\delta$ 35.6) e C-13 e entre Me-15 ( $\delta 1.21)$, e Me$16(\delta 1.16)$ com $\Subset-11$ ( $\delta$ 46.6), C-12 e C-13.
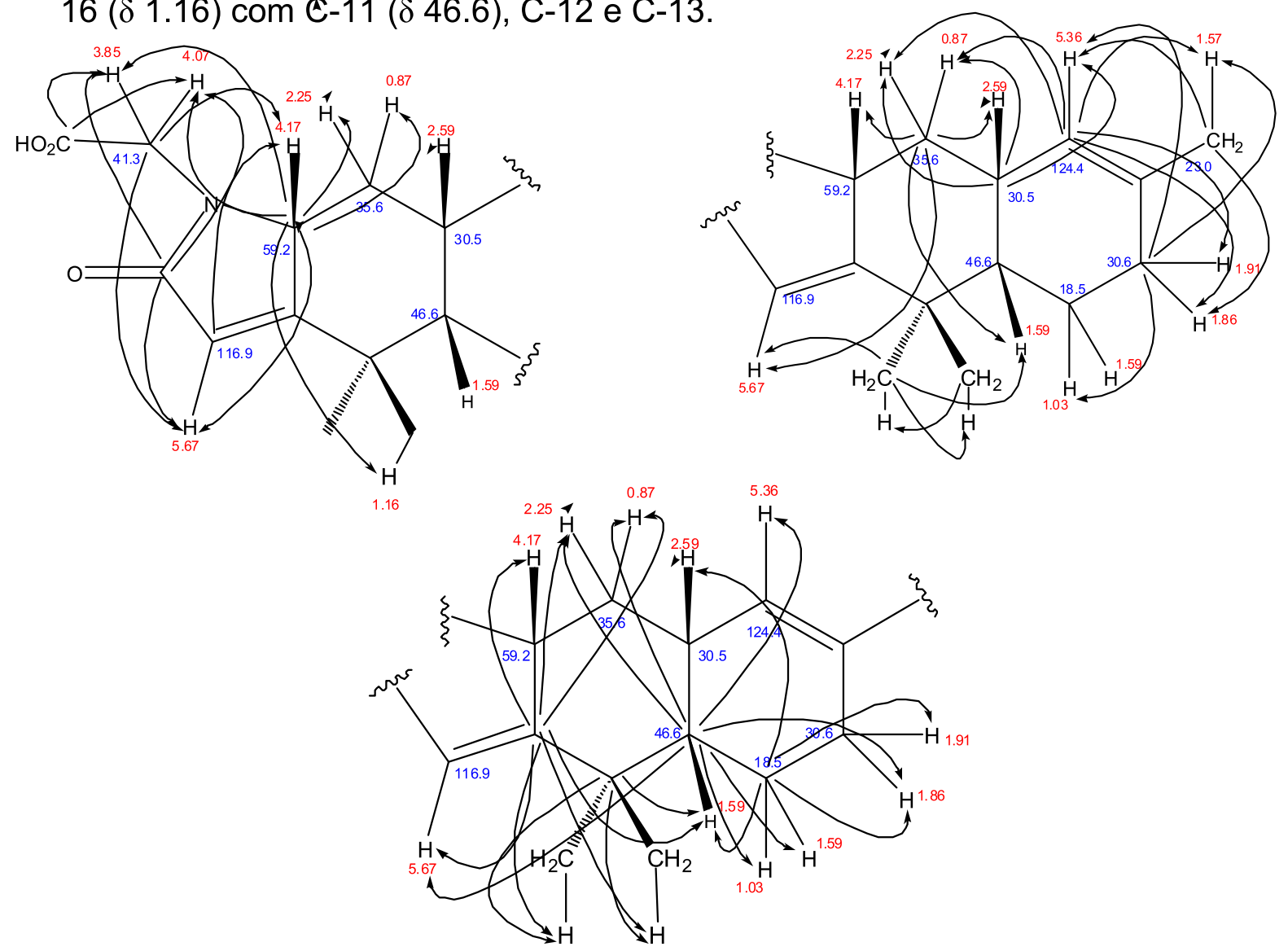

Figura 31. Correlações do ácido isopirodisinóico (19) observadas no espectro RMN tipo HMBC .

De acordo com o espectro HMBC (Figura 15, pp.43-44, Volume 2), as correlações entre os prótons metilênicos $\mathrm{CH}_{2}-17$ ( $\delta 3.85$ e 4.07 ) e $\mathrm{C}-2$, C-4 e C-18 ( $\delta$ 170.9), juntamente com uma correlação tROESY entre $\mathrm{H}-5_{\text {eq }}(\delta 2.25)$ e $\mathrm{H}-17 \mathrm{~b}(\delta$ 
3.85), estabeleceram a posição do grupamento glicina. Finalmente, as correlações entre $\mathrm{N}-1$ ( $\delta$-256.9) e $\mathrm{H}-3, \mathrm{H}-4$ e $\mathrm{H}-17 \mathrm{~b}$ no espectro HMBC- ${ }^{15} \mathrm{~N}-{ }^{1} \mathrm{H}$ confirmaram a estrutura planar do ácido isopirodisinóico (19).

Assim como o ácido pirodisinóico (18), a análise do espectro tROESY (DMSO-d $d_{6}, 600 \mathrm{MHz}$ - Figura 16, p. 45, Volume 2) do ácido isopirodisinóico (19) indicou uma junção cis 6/6, uma vez que foi observado um acoplamento dipolar entre $\mathrm{H}-6$ e $\mathrm{H}-11$. O hidrogênio $\mathrm{H}-4$ apareceu como um duplo dubleto com um acoplamento com H-5ax $\left(\begin{array}{ll}\delta & 0.87\end{array}\right)$ de aproximadamente $12 \mathrm{~Hz}$, indicando uma relação trans diaxial entre $\mathrm{H}-4$ e $\mathrm{H}-5 \mathrm{ax}$. No espectro tROESY $\mathrm{H}-4$ correlaciona-se com $\mathrm{H}-6$ e Me-15ax, enquanto $\mathrm{H}-5$ ax correlaciona-se com $\mathrm{H}-10 \mathrm{ax}$ ( $\delta 1.03)$. Tais observações indicaram que a estereoquímica relativa de 19 requer uma junção cis de anel, e que N-1 esteja em orientação equatorial. (figura 32).

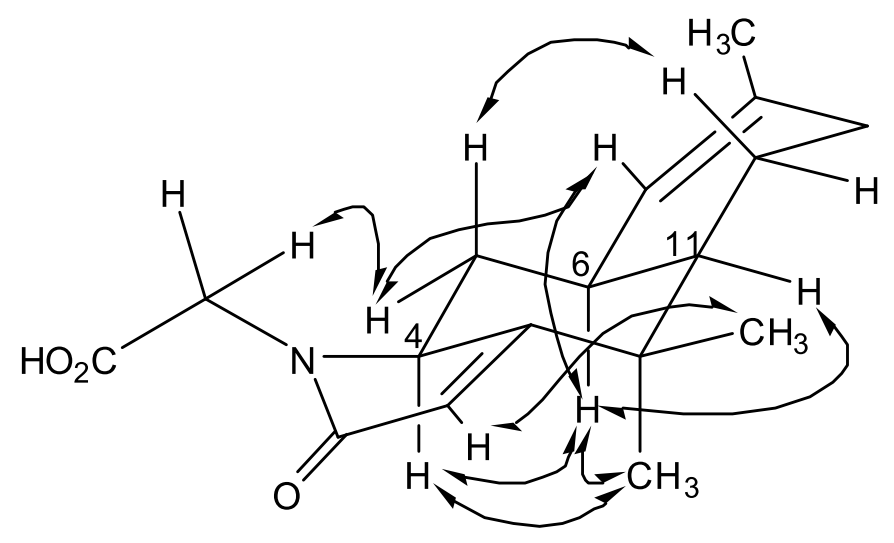

Figura 32. Correlações do ácido isopirodisinóico (19) observadas no espectro tROESY. 


\subsubsection{Determinação estrutural do ácido pirodisinóico $B(20)$}

Análises HRESIMS do ácido pirodisinóico B (20) indicaram que a fórmula molecular, $\mathrm{C}_{17} \mathrm{H}_{22} \mathrm{NO}_{3}$, era a mesma de 18 e 19.

A determinação estrutural do ácido pirodisinóico $B$ foi feita a partir de comparação com os dados espectroscópicos do ácido pirodisinóico (18), uma vez que os sinais observados no espectro de $\mathrm{RMN}-{ }^{1} \mathrm{H}$ e ${ }^{13} \mathrm{C}$ de 20 e 18 apresentam muitas semelhanças.

Dados espectroscópicos de RMN-1D e -2D prontamente estabeleceram que a estrutura planar de $\mathbf{2 0}$ era a mesma que de 18. Através de uma análise detalhada dos dados de RMN-2D e dos valores das constantes de acoplamento $J$ indicaram que a única diferença entre 20 e 18 era a configuração relativa na junção dos dois anéis de seis membros.

Tabela 8. Dados comparativos de $\mathrm{RMN}^{1} \mathrm{H}, \mathrm{COSY}{ }^{1} \mathrm{H}-{ }^{1} \mathrm{H}$ e ${ }^{13} \mathrm{C}$ entre o ácido pirodisinóico (18) e o ácido pirodisinóico B (20).

\begin{tabular}{|c|c|c|c|c|c|c|c|}
\hline & \multicolumn{2}{|c|}{$\delta_{H}^{1}$} & \multicolumn{2}{|c|}{${ }^{1} \mathrm{H}-{ }^{1} \mathrm{H}$} & & \multicolumn{2}{|c|}{$\delta^{13} c$} \\
\hline & 18 & 20 & 18 & 20 & & 18 & 20 \\
\hline & & & & & 2 & 172.6 & 172.6 \\
\hline 3 & $5.78(\mathrm{~s})$ & $5.82(\mathrm{~s})$ & $13,5_{\mathrm{ax}}$ & 13 & 3 & 117.8 & 118.0 \\
\hline 4 & & & & & 4 & 161.9 & 161.6 \\
\hline $5_{\text {eq }}$ & $2.71(\mathrm{dd}, 4.9,13.8)$ & $2.72(\mathrm{dd}, 1.7,11.9)$ & $5 \mathrm{ax}, 6$ & $5 \mathrm{ax}$ & 5 & 31.3 & 34.6 \\
\hline $5_{\mathrm{ax}}$ & $2.14(t, 13.8)$ & $1.94(t, 11.9)$ & $3,5_{\mathrm{eq}}, 6$ & $5_{\text {eq }}$ & 6 & 32.9 & 36.2 \\
\hline 6 & $2.36(\mathrm{~m})$ & 1.97 & $5_{\mathrm{ax}}, 5_{\mathrm{eq}}, 7,11$ & 7,11 & 7 & 125.1 & 125.0 \\
\hline 7 & $5.41(\mathrm{~d}, 4.3)$ & 5.17 (bs) & $6,9,14$ & 6,14 & 8 & 133.4 & 133.8 \\
\hline $9_{\text {eq }}$ & $1.98(\mathrm{~m})$ & 1.97 & $7,10_{\mathrm{eq}}, 10_{\mathrm{ax}}$ & $10_{\mathrm{ax}}$ & 9 & 31.5 & 31.0 \\
\hline $9_{\mathrm{ax}}$ & $1.98(\mathrm{~m})$ & 1.97 & $7,10_{\mathrm{eq}}, 10_{\mathrm{ax}}$ & $10_{\mathrm{ax}}$ & 10 & 18.0 & 21.7 \\
\hline $10_{\text {eq }}$ & $1.76(d, 11.5)$ & $1.86(\mathrm{~d}, 10.1)$ & $9,10_{\mathrm{ax}}, 11$ & $10_{\mathrm{ax}}, 11$ & 11 & 46.1 & 46.0 \\
\hline $10_{\mathrm{ax}}$ & $1.58(\mathrm{~m})$ & 1.15 & $9,10_{\mathrm{ax}}, 11$ & $9,10_{\text {eq }}$ & 12 & 40.0 & 40.7 \\
\hline 11 & $1.38(\mathrm{~d}, 11.0)$ & $1.18(t, 11.3)$ & $6,10_{\mathrm{eq}}, 10_{\mathrm{ax}}$ & $6,10_{\mathrm{eq}}$ & 13 & 67.2 & 71.2 \\
\hline 13 & 3.97 (s) & 3.88 (s) & 3 & 3 & 14 & 23.0 & 22.8 \\
\hline 14 & $1.61(\mathrm{~s})$ & $1.62(\mathrm{~s})$ & 7 & 7 & 15 & 20.6 & 26.0 \\
\hline Me15 & $0.70(\mathrm{~s})$ & $1.14(\mathrm{~s})$ & & & 16 & 27.0 & 13.5 \\
\hline Me15 & $1.18(\mathrm{~s})$ & $0.51(\mathrm{~s})$ & & & 17 & 44.2 & 44.2 \\
\hline $17 a$ & $4.27(\mathrm{~d}, 18.0)$ & $4.39(\mathrm{~d}, 18.0)$ & $17 b$ & $17 b$ & 18 & 170.8 & 170.9 \\
\hline $17 b$ & $3.81(\mathrm{~d}, 18.0)$ & $3.87(\mathrm{~d}, 18.0)$ & $17 a$ & $17 a$ & & & \\
\hline $\mathrm{CO}_{2} \mathrm{H}$ & $12.72(\mathrm{~s})$ & $12.78(\mathrm{~s})$ & & & & & \\
\hline
\end{tabular}


Considerando que no espectro de $\mathrm{RMN}^{-1} \mathrm{H}$ de 20 (Figura 22, pp. 60-65, Volume 2) o hidrogênio $\mathrm{H}-5_{\mathrm{ax}}(\delta$ 1.94) é um triplete com $J=11.9 \mathrm{~Hz}$, este apresenta uma relação trans pseudo-axial com H-6 ( $\delta$ 1.97). Uma vez que um acoplamento dipolar foi observado entre $\mathrm{H}-5_{\mathrm{ax}}$ e $\mathrm{H}-11(\delta 1.18)$ e $\mathrm{H}-13(\delta 3.88)$, a estereoquímica relativa de $\mathbf{2 0}$ requer que os dois anéis de seis membros estejam em conformação de pseudo-cadeira com uma junção de anel trans ao invés de uma junção cis, observada no ácido pirodisinóico (18), e que N-1 esteja em orientação equatorial. Correlações adicionais observadas no espectro tROESY (Figura 26, pp. 74-75, Volume 2) confirmaram a estereoquímica relativa do ácido pirodisinóico B (20) (figura 33).

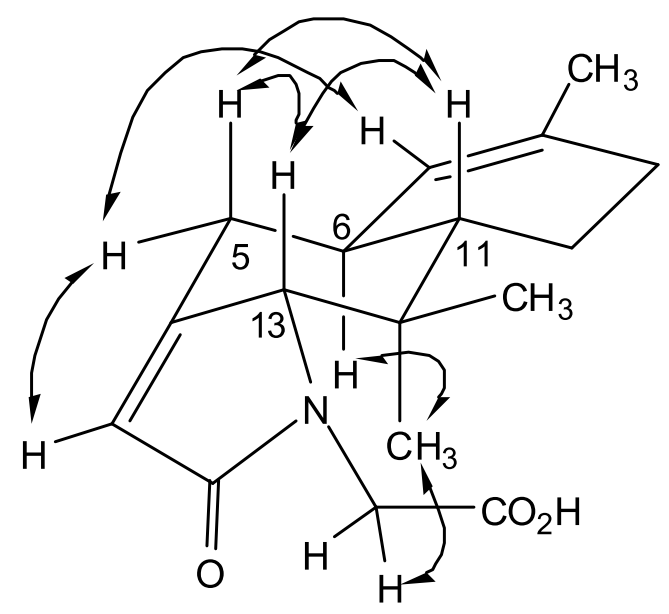

Figura 33. Correlações do ácido pirodisinóico B (20) observadas no espectro tROESY

\subsection{Determinação estrutural do ácido 13-hidróxi-isopirodisinóico (21)}

Após repurificação da fração DR2-AQ-6B por HPLC em fase reversa (condições: coluna CSC-Inertsil 150A/ODS2, $5 \mu \mathrm{m}, 25 \times 0.94 \mathrm{~cm}$, com eluição de $\left.\left(0.05 \% \mathrm{TFA} / \mathrm{H}_{2} \mathrm{O}\right) / \mathrm{MeCN}, \lambda=254 \mathrm{~nm}\right)$ obteve-se a fração DR2-AQ-6B-2D, que corresponde ao ácido 13-hidróxi-isopirodisinóico (21) (1,3mg). 


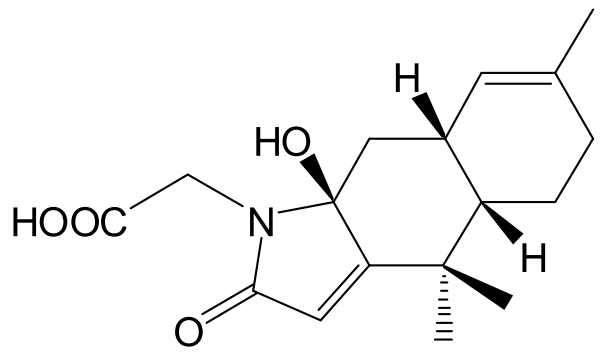

Figura 34. Estrutura do ácido 13-hidróxi-isopirodisinóico (21).

O sinal de um íon $[\mathrm{M}-\mathrm{H}]^{-}$em $\mathrm{m} / \mathrm{z} 304.1637$ (Figura 34, p. 90, Volume 2) no modo HRESIMS negativo de 21 estabeleceu a fórmula $\mathrm{C}_{17} \mathrm{H}_{23} \mathrm{NO}_{4}$ (calculado para $\mathrm{C}_{17} \mathrm{H}_{22} \mathrm{NO}_{4}$ 304.1637) que corresponde a um oxigênio adicional com relação ao ácido isopirodisinóico (19).

Os dados espectrais de RMN obtidos para o ácido 13-hidróxi-isopirodisinóico (21 - Figuras $28-33$, pp. $78-89$, Volume 2) foram muito similares àqueles obtidos para 19.

Tabela 9. Dados espectroscópicos comparativos entre o ácido isopirodisinóico (19) e o ácido 13-hidróxi-isopirodisinóico (21).

\begin{tabular}{|c|c|c|c|c|c|}
\hline \multicolumn{3}{|c|}{$\delta^{1}{ }_{H}$} & \multicolumn{3}{|c|}{$\delta^{13}{ }_{C}$} \\
\hline Átomo & 19 & 21 & Átomo & 19 & 21 \\
\hline 3 & $5.67(\mathrm{~s})$ & $5.66(\mathrm{~s})$ & 2 & 170.2 & 168.2 \\
\hline 4 & $4.17(\mathrm{dd}, 6.1,12.1)$ & & 3 & 116.9 & 118.2 \\
\hline $5_{\text {eq }}$ & $2.25(\mathrm{~m})$ & $1.93(\mathrm{dd}, 3.6,13.5)$ & 4 & 59.2 & 88.2 \\
\hline $5_{\mathrm{ax}}$ & $0.87(\mathrm{ddd}, 12.1,12.1,12.1)$ & $1.29(\mathrm{t}, 13.5)$ & 5 & 35.6 & 39.9 \\
\hline 6 & $2.59(\mathrm{~m})$ & $2.67(\mathrm{~m})$ & 6 & 30.5 & 29.5 \\
\hline 7 & $5.36(\mathrm{bd}, 4.8)$ & $5.34(d, 5.1)$ & 7 & 124.4 & 124.7 \\
\hline $9_{\mathrm{eq}}$ & $1.91(\mathrm{~m})$ & $1.90(\mathrm{~m})$ & 8 & 133.0 & 133.0 \\
\hline $9_{\mathrm{ax}}$ & $1.86(\mathrm{~m})$ & $1.90(\mathrm{~m})$ & 9 & 30.6 & 30.6 \\
\hline $10_{\text {eq }}$ & 1.59 & $1.58(\mathrm{~m})$ & 10 & 18.5 & 18.3 \\
\hline $10_{a x}$ & $1.03(\mathrm{ddd}, 13.5,13.5,6.2)$ & $1.02(\mathrm{~m})$ & 11 & 46.6 & 46.7 \\
\hline 11 & 1.59 & $1.55(\mathrm{~m})$ & 12 & 37.1 & 37.3 \\
\hline 13 & & & 13 & 169.7 & 167.9 \\
\hline 14 & 1.57 (bs) & $1.56(\mathrm{~s})$ & 14 & 23.0 & 23.0 \\
\hline Me15 $\mathrm{ax}$ & $1.21(\mathrm{~s})$ & $1.32(\mathrm{~s})$ & 15 & 29.3 & 27.3 \\
\hline Me15 & $1.16(\mathrm{~s})$ & $1.13(s)$ & 16 & 24.3 & 25.5 \\
\hline $17 a$ & $4.07(\mathrm{~d}, 17.8)$ & $3.89(17.8)$ & 17 & 41.3 & 38.9 \\
\hline $17 b$ & $3.85(d, 17.8)$ & $3.72(17.8)$ & 18 & 170.9 & 170.9 \\
\hline $\mathrm{CO}_{2} \mathrm{H}$ & $12.67(\mathrm{~s})$ & $12.54(\mathrm{~s})$ & & & \\
\hline $4-\mathrm{OH}$ & & $5.93(\mathrm{~s})$ & & & \\
\hline
\end{tabular}


A presença de um grupo hidroxila em C-4 em 21 foi evidente. Os sinais correspondentes a C-4 $\left(\delta_{\mathrm{H}} 4.17 ; \delta_{\mathrm{C}} 59.2\right)$ em 19 foram substituídos por ressonâncias a $\delta_{C} 88.2$ e um singlete largo a $\delta_{H} 5.93$ (4-OH). Correlações a longa distância observadas no espectro HMBC (DMSO-d6, 600 MHz - Figura 33, pp. 8789, Volume 2$)$ entre $\mathrm{C}-4(\delta 88.2)$ e $\mathrm{H}-3$ ( $\delta$ 5.66), o metileno $\mathrm{CH}_{2}-5(\delta 1.93$ e 1.29$)$ e os prótons $\mathrm{H}-17$ ( $\delta 3.89$ e 3.72 ) confirmaram a posição do grupo hidroxila em C-4. Correlações observadas no espectro tROESY entre $\mathrm{H}-5_{\text {eq }}(\delta 1.93)$ e os dois prótons metilênicos de $\mathrm{CH}_{2}-17$, tanto quanto entre o grupo metil equatorial Me-16 ( $\delta$ 1.13) e $\mathrm{H}-3$, estabeleceram que o grupo $-\mathrm{OH}$ em $\mathrm{C}-4$ encontrava-se em orientação axial. Este fato foi confirmado pela observação de uma correlação fraca entre $\mathrm{H}-6$ e o próton de 4-OH. Um análise detalhada dos dados de RMN bidimensionais tROESY e dos valores das constantes de acoplamento $J$ demonstraram que a configuração relativa da junção 6/6 do anel em 21 era cis, a mesma observada em 19. Todas as demais características de 19 e 21 eram as mesmas e a estrutura do ácido 13-hidróxi-isopirodisinóico foi determinada assim como a do ácido isopirodisinóico (19).

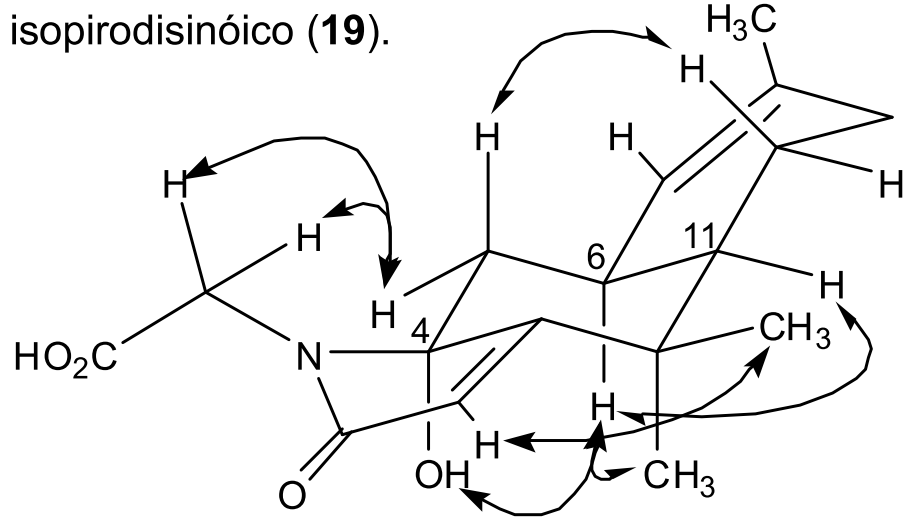

21

Figura 35. Correlações do ácido 13-hidróxi-isopirodisinóico (21) observadas no espectro tROESY.

A título de comparação, as tabelas 10 e 11 apresentam dados de $\mathrm{RMN}-{ }^{1} \mathrm{H}$ e de ${ }^{13} \mathrm{C}$ dos derivados do ácido pirodisinóico isolados de Dysidea robusta. 
Tabela 10. Dados de RMN- ${ }^{1} \mathrm{H}$ dos compostos 18, 19, 20 e 21 em DMSO- $d_{6}(600$

$\mathrm{MHz})[\delta$, multiplicidade $(\mathrm{J}$ em Hz$)]$

\begin{tabular}{|c|c|c|c|c|}
\hline Átomo & 18 & 19 & 20 & 21 \\
\hline 3 & $5.78(\mathrm{~s})$ & $5.67(\mathrm{~s})$ & $5.82(s)$ & $5.66(\mathrm{~s})$ \\
\hline 4 & & $4.17(\mathrm{dd}, 6.1,12.1)$ & & \\
\hline $5 e q$ & $2.71(\mathrm{dd}, 4.9,13.8)$ & $2.25(\mathrm{~m})$ & $2.72(\mathrm{dd}, 1.7,11.9)$ & $1.93(\mathrm{dd}, 3.6,13.5)$ \\
\hline $5_{\mathrm{ax}}$ & $2.14(\mathrm{t}, 13.8)$ & $0.87(\mathrm{ddd}, 12.1,12.1,12.1)$ & $1.94(t, 11.9)$ & $1.29(t, 13.5)$ \\
\hline 6 & $2.36(\mathrm{~m})$ & $2.59(\mathrm{~m})$ & 1.97 & $2.67(\mathrm{~m})$ \\
\hline 7 & $5.41(\mathrm{~d}, 4.3)$ & $5.36(\mathrm{bd}, 4.8)$ & $5.17(\mathrm{~s})$ & $5.34(d, 5.1)$ \\
\hline $9_{\text {eq }}$ & $1.98(\mathrm{~m})$ & $1.91(\mathrm{~m})$ & 1.97 & $1.90(\mathrm{~m})$ \\
\hline $9_{\mathrm{ax}}$ & $1.98(\mathrm{~m})$ & $1.86(\mathrm{~m})$ & 1.97 & $1.90(\mathrm{~m})$ \\
\hline $10_{\mathrm{eq}}$ & $1.76(d, 11.5)$ & 1.59 & $1.86(d, 10.1)$ & $1.58(\mathrm{~m})$ \\
\hline $10_{a x}$ & $1.58(\mathrm{~m})$ & $1.03(\mathrm{ddd}, 13.5,13.5,6.2)$ & 1.15 & $1.02(\mathrm{~m})$ \\
\hline 11 & $1.38(\mathrm{~d}, 11.0)$ & 1.59 & $1.18(\mathrm{t}, 11.3)$ & $1.55(\mathrm{~m})$ \\
\hline 13 & $3.97(\mathrm{~s})$ & & $3.88(\mathrm{~s})$ & \\
\hline 14 & $1.61(\mathrm{~s})$ & $1.57(\mathrm{~s})$ & $1.62(\mathrm{~s})$ & $1.56(\mathrm{~s})$ \\
\hline Me15 ax & $0.70(\mathrm{~s})$ & $1.21(\mathrm{~s})$ & $1.14(s)$ & $1.32(\mathrm{~s})$ \\
\hline Me16 eq & $1.18(\mathrm{~s})$ & $1.16(\mathrm{~s})$ & $0.51(\mathrm{~s})$ & $1.13(\mathrm{~s})$ \\
\hline $17 a$ & $4.27(\mathrm{~d}, 18.0)$ & $4.07(d, 17.8)$ & $4.39(\mathrm{~d}, 18.0)$ & $3.89(17.8)$ \\
\hline $17 \mathrm{~b}$ & $3.81(\mathrm{~d}, 18.0)$ & $3.85(\mathrm{~d}, 17.8)$ & $3.87(\mathrm{~d}, 18.0)$ & $3.72(17.8)$ \\
\hline $\mathrm{CO}_{2} \mathrm{H}$ & $12.72(\mathrm{~s})$ & $12.67(\mathrm{~s})$ & $12.78(\mathrm{~s})$ & $12.54(\mathrm{~s})$ \\
\hline $4-\mathrm{OH}$ & & & & $5.93(\mathrm{~s})$ \\
\hline
\end{tabular}

Tabela 11. Dados de RMN $-{ }^{13} \mathrm{C}$ e $-{ }^{-15} \mathrm{~N}$ dos compostos, 18, 19, 20 e 21 em DMSO$d_{6}(150 \mathrm{MHz})$.

\begin{tabular}{crrrr}
\hline Átomo & $\mathbf{1 8}$ & $\mathbf{1 9}$ & $\mathbf{2 0}$ & $\mathbf{2 1}$ \\
\hline 1 & -263.0 & -256.9 & - & -244.3 \\
\hline 2 & 172.6 & 170.2 & 172.6 & 168.2 \\
3 & 117.8 & 116.9 & 118.0 & 118.2 \\
4 & 161.9 & 59.2 & 161.6 & 88.2 \\
5 & 31.3 & 35.6 & 34.6 & 39.9 \\
6 & 32.9 & 30.5 & 36.2 & 29.5 \\
7 & 125.1 & 124.4 & 125.0 & 124.7 \\
8 & 133.4 & 133.0 & 133.8 & 133.0 \\
9 & 31.5 & 30.6 & 31.0 & 30.6 \\
10 & 18.0 & 18.5 & 21.7 & 18.3 \\
11 & 46.1 & 46.6 & 46.0 & 46.7 \\
12 & 40.0 & 37.1 & 40.7 & 37.3 \\
13 & 67.2 & 169.7 & 71.2 & 167.9 \\
14 & 23.0 & 23.0 & 22.8 & 23.0 \\
15 & 20.6 & 29.3 & 26.0 & 27.3 \\
16 & 27.0 & 24.3 & 13.5 & 25.5 \\
17 & 44.2 & 41.3 & 44.2 & 38.9 \\
18 & 170.8 & 170.9 & 170.9 & 170.9 \\
\hline
\end{tabular}


5.2. Isolamento e identificação dos compostos isolados da amostra de Dysidea robusta - DR1.

\subsubsection{Determinação estrutural das ceramidas 22 - 24 a partir de dados} espectrocópicos de seus produtos de transesterificação 25 - 27 .

A fração DR1-EP-5A, obtida após o fracionamento do extrato éter de petróleo, foi analisada por $\mathrm{RMN}-{ }^{1} \mathrm{H}$ em piridina- $d_{5}$ (Figura 1, pp. 6 - 11, Volume 2). Observou-se que a fração DR1-EP-5A era constituída de uma mistura de ceramidas. A presença de sinais de hidrogênios de uma cadeia alifática em $\delta 1.26$, e de uma série de duplos dubletos e outros sinais mais complexos de ${ }^{1} \mathrm{H}$ na região entre $\delta 4.0$ e 5.2, atribuídos a grupos metino e metileno funcionalizados com oxigênios e/ ou nitrogênios, são típicos sinais de ceramidas observadas em espectro de RMN- ${ }^{1} \mathrm{H}$ (Ahmed et al, 2008; Ibrahim et al, 2008; Krishna et al, 2004; Radhika et al, 2004; Asai et al, 2000; Loukaci et al, 2000; Inagaki et al, 1998; Hirsch, Kashman, 1989). Um outro indicativo foi a presença do grupo $\mathrm{N}-\mathrm{H}$, observado em $\delta 8.57$ (d, 8,9 Hz) de um grupo amida.

Os sinais de ${ }^{1} \mathrm{H}$ observados nesta fração foram bastante similares aos sinais das ptiloceramidas (Hirsch; Kashman, 1989) que também foram isoladas pelo Professor Roberto Berlinck a partir da esponja Crambe-crambe. (Berlinck, R.G.S., 1992 - Tabela 12, p.65).

Como a mistura de ceramidas isolada da esponja $D$. robusta mostrou ser solúvel apenas em piridina, optou-se pela acetilação da mistura para facilitar a obtenção de seus dados espectroscópicos. Após acetilada e purificada por cromatografia em sílica-gel, a mistura foi transformada nos derivados tetraacetilados 25 - 27. Estes apresentaram sinais no espectro ESI-MS de íons 
quase-moleculares $[\mathrm{M}+\mathrm{H}]^{+}$em $\mathrm{m} / \mathrm{z} 824.69$ (majoritário), 838.76 (intermediário) e 852.58 (minoritário). Tais sinais são idênticos aos sinais das ptiloceramidas $(\mathrm{m} / \mathrm{z}$ 852, 838, 824), também obtidos como uma mistura de homólogos peracetilados de uma fração isolada da esponja Ptilocaulis spiculifer (Hirsch; Kashman, 1989). Comparando-se os dados de 25 - 27 (RMN- $\left.{ }^{1} \mathrm{H}\right)$ com os dados das tetracetil ptiloceramidas, e de vários outros compostos simliares, foi possível observar que tais compostos são bastante parecidos e que correspondem a ceramidas saturadas (Tabela 12, p.65).

A análise dos espectros de RMN bidimensionais das ceramidas acetiladas 25 - 27 (fração DR1-EP-5A-4-1, Figuras 6 - 8, pp. 22-24, Volume 2) possibilitou estabelecer suas estruturas planares.

O espectro de $\mathrm{RMN}^{-1} \mathrm{H}$ (Figura 3, pp. 13-17, Volume 2) contendo a mistura de ceramidas acetiladas, em $\mathrm{CDCl}_{3}(400 \mathrm{MHz})$, forneceu os seguintes sinais:

- dois duplos dubletos, sendo um em $\delta 4.34(J=6.4$ e $11.7 \mathrm{~Hz})$ e outro em $\delta 4.01$ $(J=3.1$ and $11.7 \mathrm{~Hz})$, referentes a hidrogênios metilênicos de C-1;

- um multipleto em $\delta$ 4.45, referente a um hidrogênio ligado ao carbono funcionalizado com nitrogênio e um dubleto em $\delta 6.66(J=8.9 \mathrm{~Hz})$, referente ao hidrogênio da ligação N-H;

- um multipleto em $\delta 5.09$ referente a um hidrogênio ligado a carbono funcionalizado com oxigênio;

- um duplo tripleto em $\delta 4.95(J=3.3$ e $9.8 \mathrm{~Hz})$, referente a um hidrogênio ligado a outro carbono funcionalizado com oxigênio;

- dois multipletos, sendo o primeiro em $\delta 1.68$ referente a dois hidrogênios ligados a C-5 e o segundo em $\delta 1.25$, referente a vários hidrogênios metilênicos. Estes sinais indicaram a presença de uma cadeia alquílica; 
- um septeto em $\delta 1.50(J=6.5 \mathrm{~Hz})$, referente a um hidrogênio pertencente a um grupo isopropil e um dubleto em $\delta 0.86(J=6.6 \mathrm{~Hz})$, referente a seis hidrogênios constituintes do grupo isopropil;

- dois multipletos, em $\delta 5.10$ e $\delta 1.82$, sendo que o primeiro refere-se a um hidrogênio ligado a carbono funcionalizado com oxigênio, e o segundo a dois hidrogênios metilênicos.

- dois multipletos, em $\delta 1.34$ e em $\delta 1.28$, referentes a quatro hidrogênios em dois diferentes metilenos;

- um tripleto em $\delta 0.88(J=6.8 \mathrm{~Hz})$, referente a três hidrogênios de um grupo metila de fim de cadeia alifática;

- vários singletos em $\delta 2.05, \delta 2.17, \delta 2.08$ e $\delta 2.03$, referentes a três hidrogênios cada um, atribuídos a quatro grupos acetila.

A análise do espectro de $\mathrm{RMN}^{13}{ }^{13} \mathrm{C}\left(100 \mathrm{MHz}, \mathrm{CDCl}_{3}\right)$ (Figuras 4 e 5, p.1821, Volume 2), indicou sinais em $\delta 170.9,170.1,170.0$ e 169.9 referentes a carbonos $\mathrm{sp}^{2}$, de grupos $\mathrm{C}=\mathrm{O}$. Sinais em $\delta 74.0,72.8,72.3$ e 62.4 indicaram a presença de carbonos ligados a oxigênio e um sinal em $\delta 47.9$ referente a carbono ligado a nitrogênio. Também foram observados os sinais em $\delta 36.7,34.4$, $31.9,31.8,29.9,29.7,29.6,29.5,29.4,29.3,29.2,28.6,24.9,22.7,22.6$ e 19.2 correspondendo a carbonos metilênicos. Os sinais em $\delta$ 21.0, 20.9, 20.8, 20.7, 14.1 e 11.0 referem-se a carbonos $\mathrm{sp}^{3}$ terminais, sendo que o último corresponde a um carbono do grupo isolpropil, juntamente com o sinal em $\delta 28.0$, referente ao carbono terciário do grupo isopropil. 
Tabela 12. Dados comparativos de $\mathrm{RMN}-{ }^{1} \mathrm{H}$ entre as ceramidas 25-27, $\left(\mathrm{CDCl}_{3}, 400 \mathrm{MHz}\right)$ e a mistura de ptiloceramidas isoladas da esponja Ptilocaulis spiculifer.

\begin{tabular}{|c|c|c|}
\hline Posição & $\begin{array}{c}\text { Ceramidas } \\
\text { Tetracetiladas 25-27 }\end{array}$ & $\begin{array}{c}\text { Ptiloceramidas } \\
\text { (Hirsch; Kashman, 1989) }\end{array}$ \\
\hline $\mathrm{H}-1 \mathrm{a}$ & $4.34,1 \mathrm{H}, \mathrm{dd},(\mathrm{J}=6.4$ e $11.7 \mathrm{~Hz})$ & $4.35, \mathrm{dd},(\mathrm{J}=6.4 \mathrm{e} 11.7 \mathrm{~Hz})$ \\
\hline $\mathrm{H}-1 \mathrm{~b}$ & $4.01,1 \mathrm{H}, \mathrm{dd},(J=3.1 \mathrm{e} 11.7 \mathrm{~Hz})$ & $4.02, \mathrm{dd},(J=11.7 \mathrm{~Hz})$ \\
\hline $\mathrm{H}-2$ & $4.45,1 \mathrm{H}, \mathrm{m}$ & $4.44, \mathrm{~m}$ \\
\hline $\mathrm{H}-3$ & $5.09,1 \mathrm{H}, \mathrm{m}$ & $5.11, \mathrm{~m}$ \\
\hline $\mathrm{H}-4$ & $4.95,1 \mathrm{H}, \mathrm{dt},(J=3.3$ e $9.8 \mathrm{~Hz})$ & 4.95, dt, $(J=3.2$ e $9.8 \mathrm{~Hz})$ \\
\hline $\mathrm{H}-5$ & $1.68,2 \mathrm{H}, \mathrm{m}$ & $1.65, \mathrm{~m}$ \\
\hline $\mathrm{CH}_{2}-6$ ao $\mathrm{CH}_{2}-15$ & $1.25 \mathrm{~m}$ & $1.29, \mathrm{~m}$ \\
\hline $\mathrm{CH}$ (isopropil) & $1.50,1 \mathrm{H}$, sept, $(J=6.5 \mathrm{~Hz})$ & $1.50, \mathrm{~m}$ \\
\hline $\mathrm{CH}_{3}$ (isopropil) & $0.86,6 \mathrm{H}, \mathrm{d},(J=6.6 \mathrm{~Hz})$ & $0.85, d(J=6.6 \mathrm{~Hz})$ \\
\hline $\mathrm{NH}$ & $6.66,1 \mathrm{H}, \mathrm{d},(J=8.9 \mathrm{~Hz})$ & 6.64, d $(J=9.0 \mathrm{~Hz})$, \\
\hline H-2' & $5.10,1 \mathrm{H}, \mathrm{m}$ & $5.11, \mathrm{~m}$ \\
\hline $\left.\mathrm{CH}_{2}-3^{\prime}\right)$, & $1.82,2 \mathrm{H}, \mathrm{m}$ & $1.82, \mathrm{~m}$ \\
\hline $\mathrm{CH}_{2}$ & $1.34,2 \mathrm{H}, \mathrm{m}$ & Não listado \\
\hline $\mathrm{CH}_{2}$ & $1.28,2 \mathrm{H}, \mathrm{m}$ & $1.30, \mathrm{~m}$ \\
\hline $\mathrm{CH}_{2}-18$ & $0.88,2 \mathrm{H}, \mathrm{t},(\mathrm{J}=6.8 \mathrm{~Hz})$ & $0,88, \mathrm{t}(\mathrm{J}=6.3 \mathrm{~Hz})$ \\
\hline $\mathrm{CH}_{2}-4^{\prime}$ ao $\mathrm{CH}_{2} 17^{\prime}$ & $1.25(\mathrm{~m})$ & $1.29, \mathrm{~m}$ \\
\hline $\mathrm{CH}_{3}-20$ & $0.88,3 \mathrm{H}, \mathrm{t},(\mathrm{J}=6.8 \mathrm{~Hz})$ & $0.88, \mathrm{t}(\mathrm{J}=6.3 \mathrm{~Hz})$ \\
\hline $\mathrm{CH}_{3}$ & $2.05,3 \mathrm{H}, \mathrm{s}$ & $2.06 \mathrm{~s}$ \\
\hline $\mathrm{CH}_{3}$ & $2.17,3 \mathrm{H}, \mathrm{s}$ & $2.19 \mathrm{~s}$ \\
\hline $\mathrm{CH}_{3}$ & $2.08,3 \mathrm{H}, \mathrm{s}$ & $2.09 \mathrm{~s}$ \\
\hline $\mathrm{CH}_{3}$ & $2.03,3 \mathrm{H}, \mathrm{s}$ & $2.03 \mathrm{~s}$ \\
\hline
\end{tabular}

O espectro de RMN tipo $\operatorname{COSY}{ }^{1} \mathrm{H}-{ }^{1} \mathrm{H}$ (Figura 6, p. 22, Volume 2), que correlaciona hidrogênios acoplando entre si, forneceu os seguintes resultados:

- hidrogênios metilênicos $\left(\mathrm{CH}_{2}-1\right)$ em $\delta 4.34$ e 4.01 apresentou correlações com hidrogênio $(\mathrm{H}-2)$ em $\delta 4.45$;

- hidrogênio em $\delta 4.45$ apresentou correlações com hidrogênio $(\mathrm{N}-\mathrm{H})$ em $\delta 6.66$ e com hidrogênio em $\delta 5.09(\mathrm{H}-3)$;

- hidrogênio em $\delta 5.09(\mathrm{H}-3)$ apresentou correlação com hidrogênio em $\delta$ 4,95 (H4), que por sua vez apresentou acoplamento com hidrogênio em $\delta 1.68(\mathrm{H}-5)$;

- hidrogênio em $\delta 1.68(\mathrm{H}-5)$ apresentou correlações com hidrogênios em $\delta 1.26$. 
Tais dados permitiram identificar a porção esfingosínica.
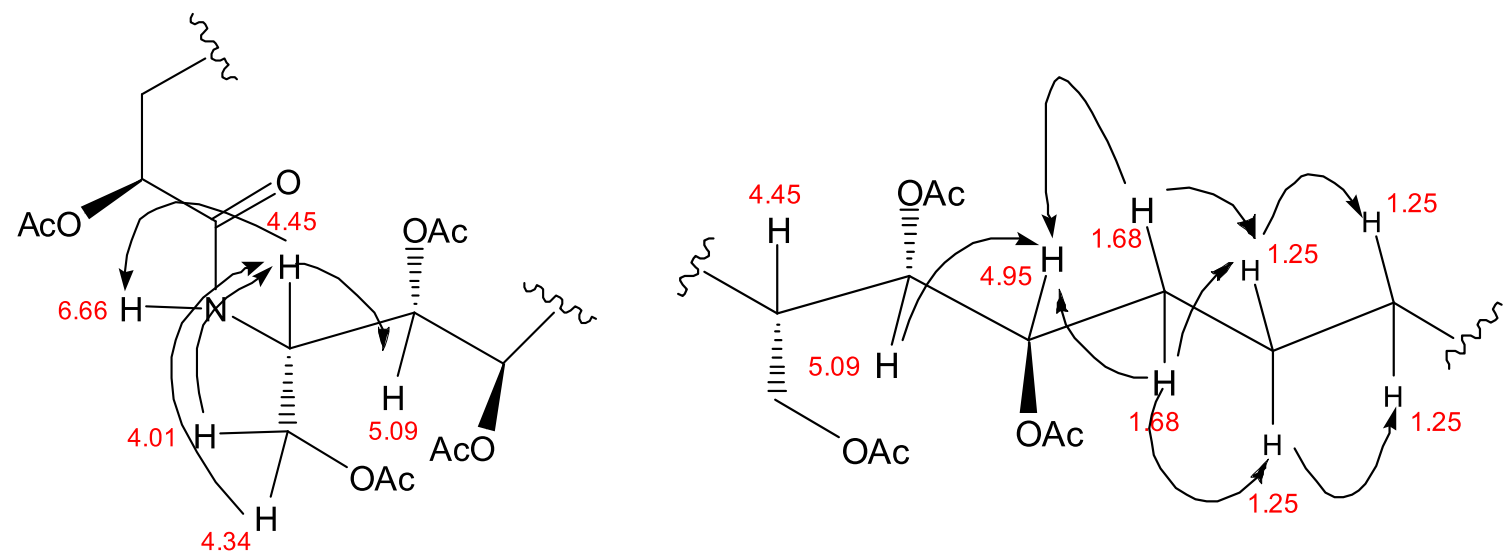

Figura 36. Correlações observadas no espectro de $\operatorname{RMN}$ tipo $\operatorname{COSY}-{ }^{1} \mathrm{H}-{ }^{1} \mathrm{H}$, da porção esfingosínica das ceramidas tetracetiladas 25-27.

Também foram observadas correlações adicionais, referentes à porção $\alpha$ hidróxi-ácido, tais como:

- hidrogênio em $\delta 5.10\left(\mathrm{H}-2^{\prime}\right)$ apresenta correlação com hidrogênios em $\delta 1.82$ $\left(\mathrm{CH}_{2}-3^{\prime}\right)$, que por sua vez correlacionam-se com hidrogênios em $\delta$ 1.20-1.40, referentes à cadeia alquílica.

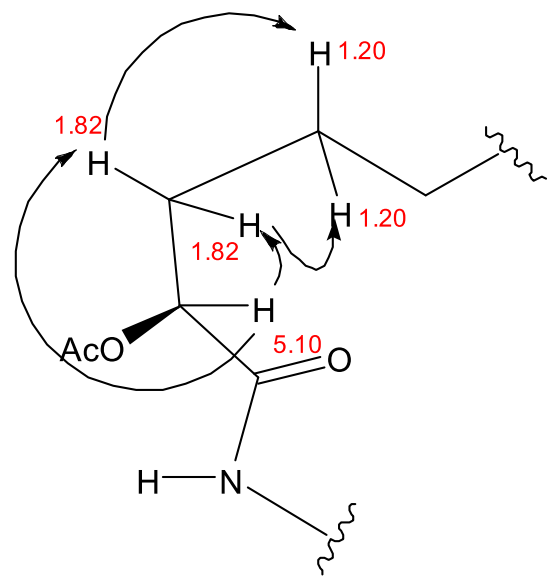

Figura 37. Correlações observadas no espectro de $\operatorname{RMN}$ tipo $\operatorname{COSY}-{ }^{1} \mathrm{H}-{ }^{1} \mathrm{H}$, da porção do ácido graxo a-hidroxilado das ceramidas tetracetiladas 25-27. 
O espectro do tipo $\mathrm{HMBC}{ }^{1} \mathrm{H}^{13} \mathrm{C}$ (Figura 8, p. 24, Volume 2), que correlaciona hidrogênios ligados a carbonos através de 2, 3 ou 4 ligações $\left({ }^{2} \mathrm{~J},{ }^{3} \mathrm{~J}\right.$, $\left.{ }^{4} \mathrm{~J}\right)$, apresentou os seguintes resultados:

- hidrogênio em $\delta 6.66(\mathrm{~N}-\mathrm{H})$ se correlaciona com carbono em $\delta 169.9\left(\mathrm{C}-1^{\prime}\right)$;

- hidrogênio em $\delta 4.45(\mathrm{H}-2)$ se correlaciona com carbono em $\delta 169.9\left(\mathrm{C}-1^{\prime}\right)$;

- hidrogênio em $\delta 5.10\left(\mathrm{H}-2^{\prime}\right)$ se correlaciona com carbono em $\delta 31.8\left(\mathrm{C}-3^{\prime}\right)$;

- hidrogênios em $\delta 1.82\left(\mathrm{H}^{\prime} 3^{\prime}\right)$ se correlacionam com carbonos em $\delta$ 24.9, referentes à cadeia alquílica;

- hidrogênio em $\delta 4.34(\mathrm{H}-1 \mathrm{a})$ se correlaciona com carbono em $\delta 47.9(\mathrm{C}-2)$;

- hidrogênio em $\delta 5.09$ (H-3) se correlaciona com os seguintes carbonos: C-1, em $\delta 62.4$, C-2, em $\delta 47.8$ e C-4, em $\delta 72.8$.

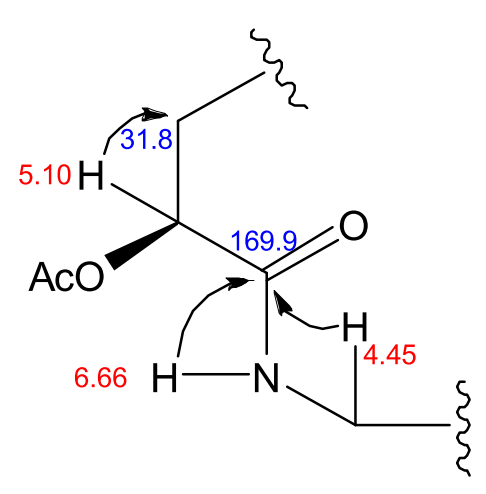

Figura 38. Correlações observadas no espectro de RMN tipo $\mathrm{HMBC}{ }^{1} \mathrm{H}^{-13} \mathrm{C}$ das ceramidas tetracetiladas 25-27.

A etapa seguinte consistiu na identificação da posição do grupo terminal isopropil, isto é, se este se encontrava na porção esfingosínica ou na porção do ácido graxo $\alpha$-hidroxilado. Tal identificação foi realizada por meio da metanólise do grupo amida da fração DR1-EP-5A, solúvel em piridina, gerando a fração solúvel em $\mathrm{CH}_{2} \mathrm{Cl}_{2}$, DR1-EP-5A-4-TD, que continha a fração esfingosínica (página 45, item: Parte Experimental). 


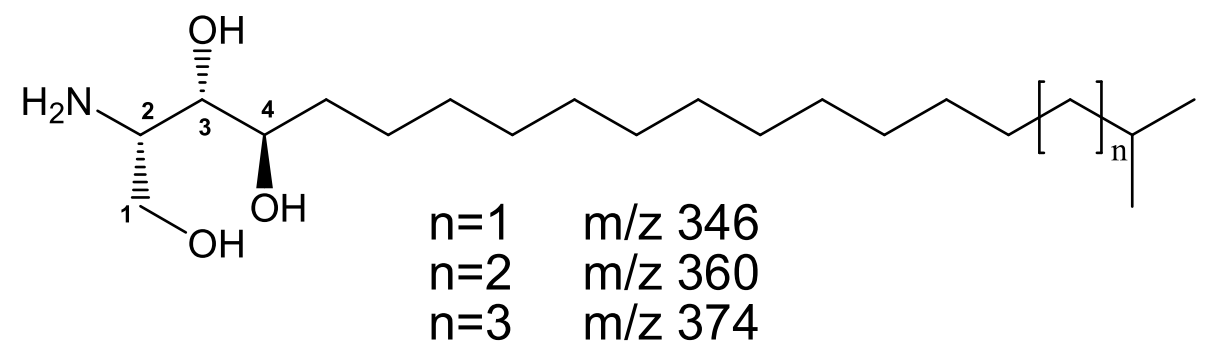

Figura 39. Porção esfingosínica das estruturas básicas de 22-24

Análises de RMN- ${ }^{1} \mathrm{H}$ (Figura 9, pp. 25-27, Volume 2) e LC-MS (Figuras 10A e 10B, p. 29, Volume 2) de DR1-EP-5A-4-TD indicaram a presença de três homólogos em m/z 346, 360 e 374. Um dubleto na região de $\delta 0.81(J=7,2 \mathrm{~Hz})$ indicou a presença de um grupo isopropil no final da cadeia alquilica da mistura. Desta forma, a estrutura planar dos compostos 22-24 foi estabelecida como sendo 2-hidroxi-N- (1,3,4-trihidroxi-18- metilnonadecan-2-il) icosanamida, 2-hidroxi-N(1,3,4 trihidroxi-19- metilicosan-2-il)icosanamida e 2-hydroxy- $N$-(1,3,4-trihydroxy20-methylhenicosan-2-il)icosanamida, respectivamente (figura 28).

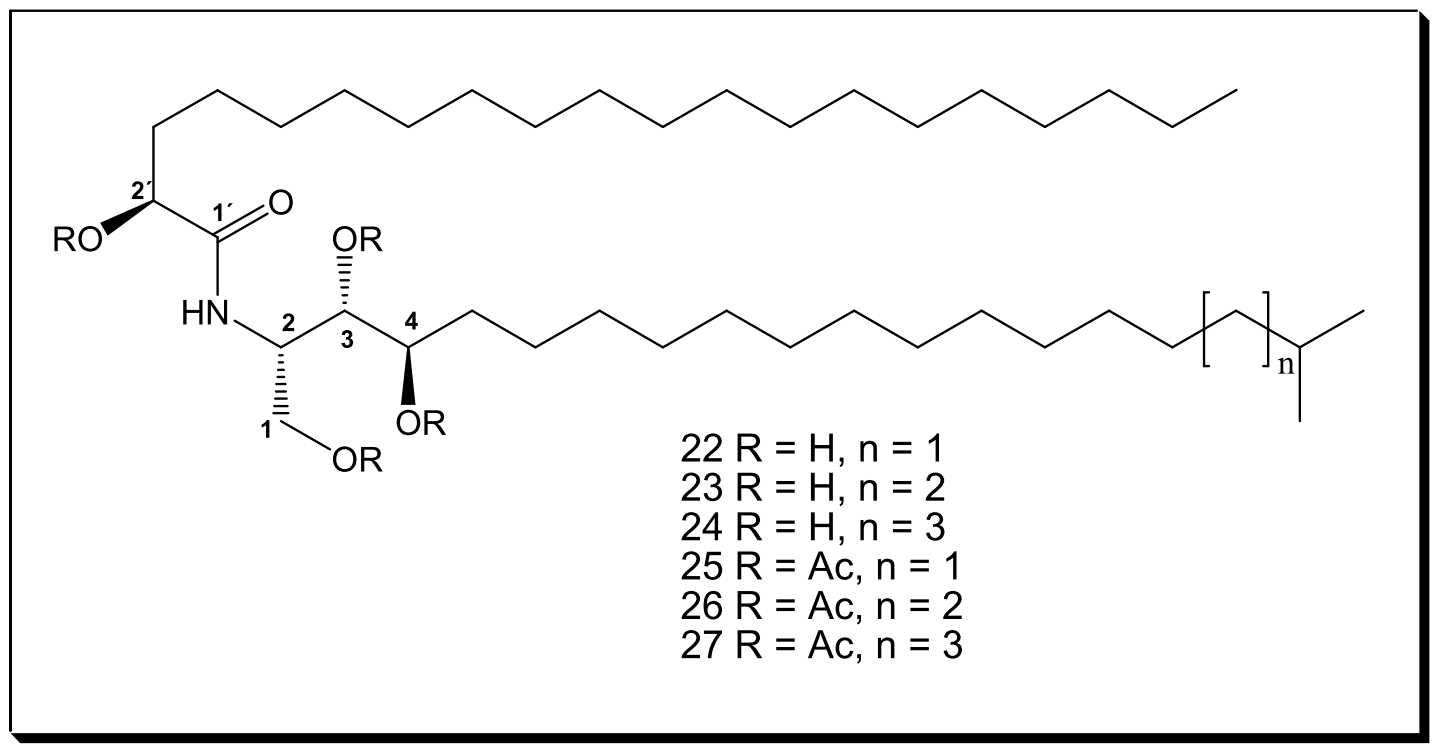

Figura 40. Estruturas das ceramidas isoladas e seus respectivos derivados acetilados. 
Através de análises de deslocamentos químicos e das constantes de acoplamento de $\mathrm{H}-1 \mathrm{a}(\delta 4.51$, dd, $J=4.5$ e $10.8 \mathrm{~Hz}), \mathrm{H}-1 \mathrm{~b}(\delta 4.42, \mathrm{dd}, J=4.9$ e 10.8 Hz), de H-2 ( $\delta 5.11$, dddd, aparentemente um sexteto, $J=4.6 \mathrm{~Hz})$, de $\mathrm{H}-3$ ( $\delta$ 4.35, dd, $J=4.6$ e $6.5 \mathrm{~Hz})$, de $\mathrm{H}-4(\delta 4.28, \mathrm{~m})$ e de $\mathrm{H}-2^{\prime}(\delta 4.62, \mathrm{dd}, J=3.7$ e 7.7 $\mathrm{Hz}$ ) de 22-24 realizadas em piridina- $d_{5}$ indicaram a estereoquímica relativa do tipo D-eritro na região de alta polaridade da porção esfingosínica. Através de comparações com dados da literatura das ceramidas naturais (Ibrahim et al, 2008; Krishna et al, 2004; Inagaki et al, 1998) e sintéticas (Sugiyama. et al, 1991), cujos compostos apresentam uma estereoquímica absoluta já conhecida, foi possível estabelecer a estereoquímica absoluta para C-2(S), C-3(S), C-4(R) e C-2'(R). A rotação específica da mistura 22-24 foi medida, obtendo-se o valor de $[\alpha]^{\mathrm{D}}{ }_{25}+9.6$ (c 0.54 , piridina) mostrando ser muito similar aos valores estabelecidos para os compostos análogos. Assim sendo, a estereoquímica absoluta dos compostos 2224 foi estabelecida.

Ceramidas saturadas e insaturadas foram isoladas de esponjas marinhas, apresentando variações tanto na porção esfingosínica quanto na porção do ácido graxo $\alpha$-hidroxilado. Entretanto, não há relatos do isolamento dos compostos 2224 na literatura (Marques et al, 2009).

Uma mistura de ceramidas saturadas de caráter bastante similar a $\mathbf{2 2 - 2 4}$ (28) foi recentemente isolada da esponja Negombata corticata e apresentou atividade anticonvulsivante (Ahmed et al, 2008.). As ceramidas $\mathbf{2 9}$ e $\mathbf{3 0}$, isoladas da gorgônia Pseudopterogorgia australiensis apresentaram atividade antibacteriana moderada $(1 \mathrm{mg} / \mathrm{mL})$ contra Bacillus pumilis, B. subtilis, Staphylococcus aureus, Escherichia coli, Proteus vulgaris e Pseudomonas aeruginosa (Krishna et al, 2004). 


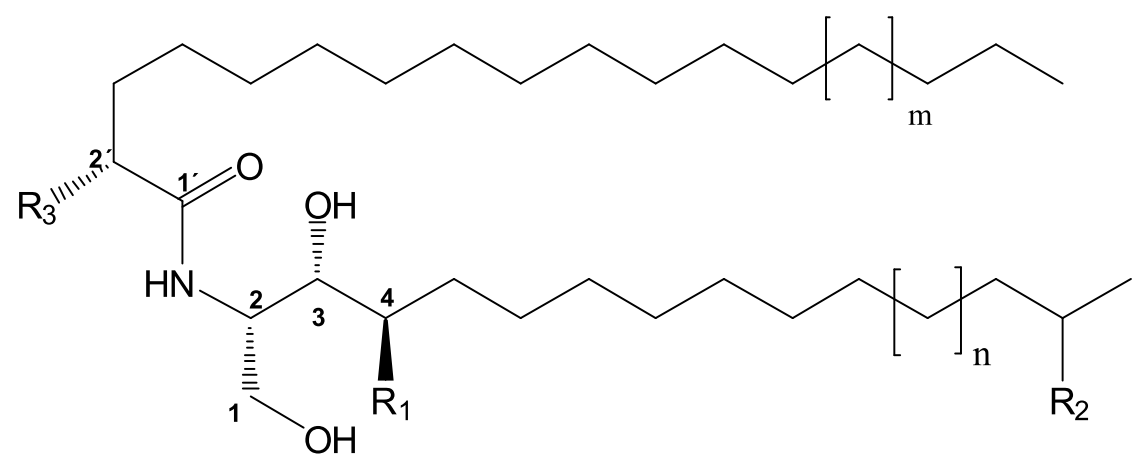

$$
\begin{aligned}
& 28 R_{1}=O H, R_{2}=M e, R_{3}=H ; m=1, n=10 \text { ou } m=3, n=8 \\
& 29 R_{1}=H, R_{2}=H, R_{3}=H ; m=7, n=7 \\
& 30 R_{1}=O H, R_{2}=H, R_{3}=O H ; m=3, n=6 \\
& 31 R_{1}=O H, R_{2}=M e, R_{3}=O H ; m=6, n=1 \\
& 32 R_{1}=O H, R_{2}=M e, R_{3}=O H ; m=17,18,19, n=7,8,9 \\
& 33 R_{1}=O H, R_{2}=M e, R_{3}=H ; m=7, n=4 \\
& 34 R_{1}=O H, R_{2}=M e, R_{3}=O H ; m=7, n=4 \\
& 35 R_{1}=O H, R_{2}=M e, R_{3}=H ; m=6, n=5
\end{aligned}
$$

Figura 41. Estruturas das ceramidas similares a mistura 22-24.

Outros membros desta classe (31 e 32) isolados da ascídia Cystodytes cf. dellechiajei inibiram a atividade enzimática da fosfolipase A2 Crotalus adamanteus com um ED $\mathrm{D}_{50}$ de $100 \mu \mathrm{g} / \mathrm{mL}$ (Loukaci et al, 2000).

Recentemente, três novas ceramidas saturadas, strepsiamidas A-C (33 35) foram isoladas da esponja Strepsichordaia lendenfeldi e apresentaram atividade citotóxica moderada contra L5178Y (linfoma de rato) e células cancerígenas HeLa (Ibrahim et al, 2008). E finalmente, uma mistura de 13 ceramidas isolada do caranguejo Erimacrus isenbeckii apresentou atividade de feromônio de atração sexual (Asai et al, 2000).

Pelo fato de os compostos 22-24 apresentarem solubilidade limitada nos demais solventes a não ser piridina, não foi possível a realização de ensaios biológicos com a mistura de ceramidas. 


\section{CONCLUSÃO}

Os resultados obtidos deste estudo indicam que, apesar da grande freqüência em que esponjas do gênero Dysidea vêm sendo estudadas, estas ainda podem apresentar substâncias estruturalmente únicas. $\mathrm{O}$ isolamento de três compostos inéditos contendo o esqueleto da furodisina e de uma mistura de três ceramidas ainda não relatadas na literatura indicou a importância do estudo de esponjas do gênero Dysidea.

Todavia, em função da solubilidade limitada apresentada pela mistura de ceramidas e a quantidade insuficiente obtida dos derivados do ácido pirodisinóico, não foi possível avaliar as atividades biológicas dos compostos isolados. 


\section{REFERÊNCIAS BIBLIOGRÁFICAS}

AHMED, S.A.; KHALIFA, S.I.; HAMANN, M.T. Antiepileptic ceramides from the Red Sea sponge Negombata corticata. Journal of Natural Products, v.71, n.4, p.513-515, 2008.

ASAI, N.; FUSETANI, N.; MATSUNAGA, S.; SASAKI, J. Sex pheromones of the hair crab Erimacrus isenbeckii. Part 1: isolation and structures of novel ceramides. Tetrahedron, v. 56, p. 9895-9899, 2000.

BERLINCK, R. G. S. Chromatographic Approach To Polar Compounds: Isolation Of The Hydrophylic Constituents Of The Marine Sponge Crambe Crambe.. Química Nova, v. 17, p. 167-171, 1994.

BERLINCK, R. G. S.; HAJDU, E.; ROCHA, R. M.; OLIVEIRA, J. H. H. L.; HERNANDEZ, I. L. C.; SELEGHIM, M. H. R.; GRANATO, A. C.; ALMEIDA, E. V. R.; NUNEZ, C. V.; MURICY, G.; PEIXINHO, S.; PESSOA, C.; MORAES, M. O.; CAVALCANTI, B. C.; NASCIMENTO, G. G. F.; THIEMANN, O.; SILVA, M.; SOUZA, A. O.; SILVA, C. L.; MINARINI, P. R. R. Challenges and rewards of research in marine natural products chemistry in Brazil. Journal of Natural Products, v. 67, n.3, p. 510-522, 2004.

CARROLL, A. R.; PIERENS, G. K.; FECHNER, G.; DE ALMEIDA LEONE, P.; NGO, A.; SIMPSON, M.; HYDE, E.; HOOPER, J. N. A.; BOSTROM, S. L.; MUSIL, D.; QUINN, R. J. Dysinosin A: A Novel Inhibitor of Factor VIla and Thrombin from a New Genus and Species of Australian Sponge of the Family Dysideidae. Journal of the American Chemical Society, v.124, n. 45, p. 13340-13341, 2002.

FAULKNER, D. J.; Marine Natural Products. Natural Product Reports, v.19, n.1, p. 1-48, 2002.

FLATT, P. M.; GAUTSCHI, J. T.; THACKER, R. W.; MUSAFIJA-GIRT, M.; CREWS, P.; GERWICK, W. Identification of the cellular site of polychlorinated peptide biosynthesis in the marine sponge Dysidea (Lamellodysidea) herbacea and symbiotic cyanobacterium Oscillatoria spongeliae by CARD-FISH analysis. Marine Biology, v. 147, p. 761-774, 2005.

FLOWERS, A. E.; GARSON, M. J.; WEBB, R. I.; DUMDEI, E. J.; CHARAN, R. D. Cellular origin of chlorinated diketopiperazines in the dictyoceratid sponge Dysidea herbacea (Keller). Cell Tissue Research, v. 292, p. 597-607, 1998.

GOETZ, G. H.; HARRIGAN, G. G; LIKOS, J. Furodysin Lactone and Pyrodysinoic Acid, New Sesquiterpenes from a Philippines Dysidea Species. Journal of Natural Products, v. 64, p. 1486-1488, 2001. 
HINDE, R.; PIRONET, F.; BOROWITZKA, M. A. Isolation of Oscillatoria spongeliae, the filamentous cyanobacterial symbiont of the marine sponge Dysidea herbacea. Marine Biology, v.119, n. 1, p. 99-104, 1994.

HIRSCH, S.; KASHMAN, Y. New glycosphingolipids from marine organisms. Tetrahedron, v.45, n.12, p.3897-3906, 1989.

HUANG, X-C.; LI, J.; LI, Z. Y.; GUO, Y. W. Sesquiterpenes from the Hainan Sponge Dysidea septosa. Journal of Natural Products, v.71, p. 1399-1403, 2008.

IBRAHIM, S. R. M.; MOHAMED, G. A.; ELKHAYAT, E. S.; GOUDA, Y, G.; $\mathrm{PROKSCH}, \mathrm{P}$. Strepsiamide A-C, new ceramides from the marine sponge Strepsichordaia lendenfeldi. Natural Product Communications, v.3, p. 205-209, 2008.

INAGAKI, M., ISOBE, R., KAWANO, Y., MIYAMOTO, T., KOMORI, T.; HIGUCHI, $\mathrm{R}$. Isolation and structure of three new ceramides from the starfish Acanthaster planci. European Journal of Organic Chemistry, v.1, p.129-131,1998.

KAZLAUSKAS, R.; LIDGARD, R. O.; WELLS, R. J.; VETTER, W. A novel hexachloro-metabolite from the sponge Dysidea herbacea. Tetrahedron Letters, v.36, p. 3183-3186, 1977.

KELLY-BORGES, K. Sponges out of their depth. Nature, v. 373, p. 284, 1995.

KRISHNA, N.; MURALIDHAR P.; MURALIKRISHNA KUMAR, M.; VENKATA RAO, D.; BHEEMASANKARA RAO, Ch. New sphingosines from a gorgonian, Pseudopterogorgia australiensis Ridley, of the Indian Ocean. Journal of Natural Products, v. 67, p. 1423-1425, 2004.

LEE, D.; SHIN, J.; YOON, K-M.; KIM, T- I.; LEE, S-H.; LEE, H-S.; OH, K-B. Inhibition of Candida albicans isocitrate lyase activity by sesterterpene sulfates from the tropical sponge Dysidea sp. Bioorganic \& Medicinal Chemistry Letters, v.18, p. 5377-5380, 2008.

LOUKACI, A.; BULTEL-PONCÉ, V.; LONGEON, A.; GUYOT, M. New lipids from the tunicate Cystodytes cf. dellechiajei as PLA2 inhibitors. Journal of Natural Products, v. 63, n.6, p. 799-802, 2000.

MACMILLAN, J. B.; MOLINSKI, T. F. Herbacic Acid, a simple prototype of 5,5,5trichloroleucine metabolites from the sponge Dysidea herbacea. Journal of Natural Products, v. 63, p. 155-157, 2000.

MARQUES, S. O.; VELOSO, K.; FERREIRA, A. G.; HAJDU, E.; PEIXINHO, S.; BERLINCK, R. G. S. Saturated ceramides from the sponge Dysidea robusta. Natural Product Communication, v. 7, n. 4, p. 917 - 920, 2009. 
MATSUNAGA, S.; FUSETANI, N. Nonribosomal Peptides from Marine Sponges. Current Organic Chemistry, v. 7, n. 10, p. 945-966, 2003.

MOLINSKI, T.F.; IRELAND, C. M. Dysidazirine, a cytotoxic azacyclopropene from the marine sponge Dysidea fragilis. Journal of Organic Chemistry, v.53, n.9, p.2103-2105, 1988.

MURICY, G.; HAJDU, E. Porifera Brasilis: Guia de identificação das esponjas mais comuns do Sudeste do Brasil. Museu Nacional, série Livros, v.17, Rio de Janeiro, 2006.

PIGGOTT, A. M.; KARUSO, P. 9-Hydroxyfurodysin-O-ethyl Lactone: A New Sesquiterpene Isolated from the Tropical Marine Sponge Dysidea arenaria. Molecules, v.10, p. 1292-1297, 2005.

QIU, Y.; WANG, X. M. A New Sesquiterpenoid Hydroquinone from the Marine Sponge Dysidea arenaria. Molecules, v.13, p. 1275-1281, 2008.

RADHIKA, P.; LAKSHMANA RAO, V.; LAATSCH, H. Chemical constituents of a marine soft coral of the genus Lobophytum. Chemical and Pharmaceutical Bulletin, v. 52, p. 1345-1348, 2004.

RAVI, B.N.; PERZANOWSKI, H. P.;ROSS, R. A.; ERDMAN, T. R.; SCHEUER, P. J.; FINER, J.; CLARDY, J. Recent Research in Marine Natural Products: The Puupehenones. Pure and Applied Chemistry, v.51, p. 1893-1900, 1979.

RUPERT, E.E.; BARNES, R.D. Zoologia dos Invertebrados. 6. ed. São Paulo: Editora Roca, 1996. p. 72-93.

SAKAI, R.; KAMIYA, H.; MURATA, M.; SHIMAMOTO, K. Dysiherbaine: a new neurotoxic amino acid from the Micronesian marine sponge Dysidea herbacea. Journal of the American Chemical Society, v.119, p. 4112-4116, 1997.

SAKAI, R.; OIWA, C.; TAKAISHI, K.; KAMIYA, H.; TAGAWA, M. Dysibetaine: a new $\alpha, \alpha$-disubstituted $\alpha$-amino acid derivative from the marine sponge Dysidea herbacea. Tetrahedron Letters, v.40, n. 38, p. 6941-6944, 1999.

SAKAI, R.; YOSHIDA, K.; KIMURA, A.; KOIKE, K.; JIMBO, M.; KOIKE, K.; KOBIYAMA, A.; KAMIYA, H. Cellular Origin of Dysiherbaine, an Excitatory Amino Acid Derived from a Marine Sponge. ChemBioChem: A European Journal of Chemical Biology, v.9, n. 4, p. 543-551, 2008.

SELEGHIM, M. H. R.; LIRA, S. P.; KOSSUGA, M. H.; BATISTA, T.; BERLINCK, R. G. S.; HAJDU, E.; MURICY, G.; ROCHA, R. M. DA; NASCIMENTO, G. G. F. DO; SILVA, M.; PIMENTA, E. F.; THIEMANN, O. H.; OLIVA, G.; CAVALCANTI, B. C.; PESSOA, C.; MORAES, M. O. DE; GALETTI, F. C. S.; SILVA, C. L.; SOUZA, A. O. DE; PEIXINHO, S. Antibiotic, cytotoxic and enzyme inhibitory activity of crude extracts from Brazilian marine invertebrates. Revista Brasileira de Farmacognosia, v. 17, n.3, p. 287-318, 2007. 
SKEPPER, C. K.; MOLINSKI, T. F. Long-Chain 2H-Azirines with Heterogeneous Terminal Halogenation from the Marine Sponge Dysidea fragilis. Journal of Organic Chemistry, v. 73, p. 2592-2597, 2008.

SUGIYAMA, S.; HONDA, M.; HIGUCHI, R.; KOMORI, T. Biologically-active glycosides from Asteroidae. 26. Stereochemistry of the 4 diastereomers of ceramide and ceramide lactoside. Liebigs Annalen der Chemie, p. 349-356, 1991.

UEDA, K.; KADEKARU, T.; SIWU, E. R. O.; KITA, M.; UEMURA, D. Haterumadysins A-D, Sesquiterpenes from the Okinawan Marine Sponge Dysidea chlorea. Journal of Natural Products, v 69, p.1077-1079, 2006.

UEDA, K.; OGI, T.; SATO, A.; SIWU, E. R. O.; KITA, M.; UEMURA, D. Cytotoxic Haterumadienone Congeners from the Okinawan Sponge Dysidea $s p$. Heterocycles, v. 72, p. 655-663, 2007.

USHER, K. M. The ecology and phylogeny of cyanobacterial symbionts in sponges. Marine Ecology, v.29, n. 2, p. 178-192, 2008.

UTKINA, N. K.; DENISENKO, V. A. Nem Polybrominated Diphenyl Ether from the Marine Sponge Dysidea herbacea. Chemistry of Natural Compounds, v.42, n.5, p. 606-607, 2006.

VILANOVA, E.; MURICY, G. Taxonomy and distribution of the sponge genus Dysidea Jonhston, 1842 (Demospongiae, Dendroceratida) in the extractive reserve of Arraial do Cabo, SE Brazil (SW Atlantic). Boletim do Museu Nacional, série Zoologia, v.453, p.1-16, 2001.

WEINHEIMER, A. J.; SPRAGGINS, R. L. The occurrence of two new prostaglandin derivatives (15-epi-PGA ${ }_{2}$ and its acetate, methyl ester) in the Gorgonian Plexaura homomalla. Chemistry of Coelenterates. XV. Tetrahedron Letters, v. 10, n. 59, p. 5185-5188, 1969.

WILLIAMS, D. E.; MARQUES, S. O.; HAJDU, E.; PEIXINHO, S.; ANDERSEN, R. J.; BERLINCK, R. G. S. Pyrodisinoic Acid Derivatives from the marine sponge Dysidea robusta. Journal of Natural Products, v. 72, p. $1691-1694,2009$.

ZHANG, H.; SKILDUM, A.; STROMQUIST, E.; ROSE-HELLEKANT, T.; CHANG, L.C. Bioactive Polybrominated Diphenyl Ethers from the Marine Sponge Dysidea sp.. Journal of Natural Products, v.71, p. 262-264, 2008. 
